Portland State University

PDXScholar

7-11-1996

\title{
The Socio-cultural Content Analysis of English as a Foreign Language Textbooks Used in Junior High School in Taiwan, Republic of China
}

Vivian Yann-Ling Lu

Portland State University

Follow this and additional works at: https://pdxscholar.library.pdx.edu/open_access_etds

Part of the Bilingual, Multilingual, and Multicultural Education Commons Let us know how access to this document benefits you.

\section{Recommended Citation}

Lu, Vivian Yann-Ling, "The Socio-cultural Content Analysis of English as a Foreign Language Textbooks Used in Junior High School in Taiwan, Republic of China" (1996). Dissertations and Theses. Paper 5171. https://doi.org/10.15760/etd.7047

This Thesis is brought to you for free and open access. It has been accepted for inclusion in Dissertations and Theses by an authorized administrator of PDXScholar. Please contact us if we can make this document more accessible: pdxscholar@pdx.edu. 


\section{THESIS APPROVAL}

The abstract and thesis of Vivian Yann-Ling Lu for the Master of Arts in TESOL were presented July 11,1996 , and accepted by the thesis committee and the department.

COMMITTEE APPROVALS:

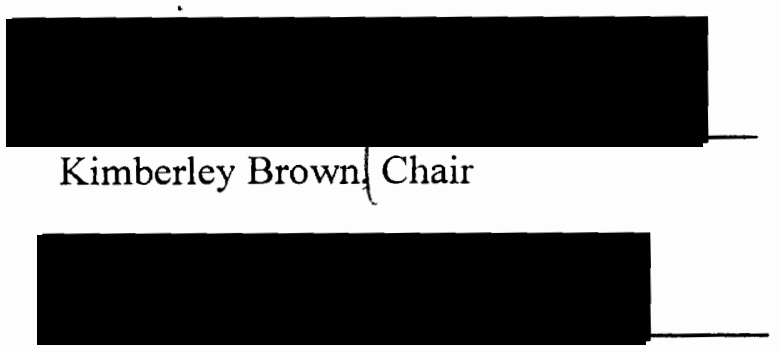

Beatrice T. Oshika

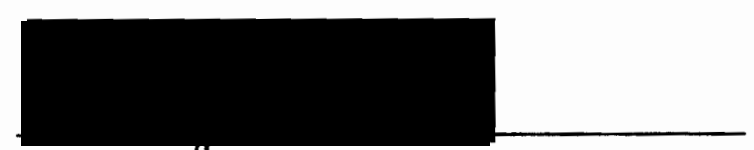

Ma-Ji Rhede

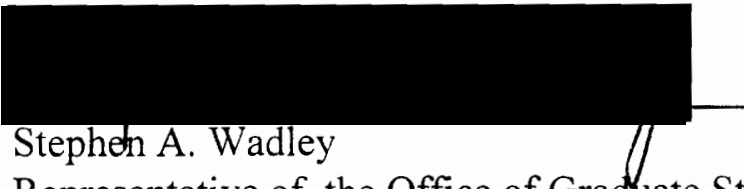

Representative of the Office of Graduate Studies

DEPARTMENT APPROVAL:

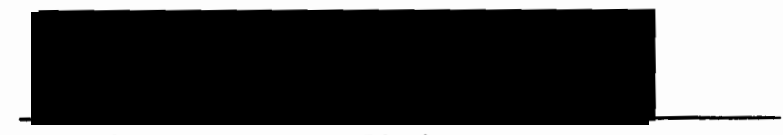

Beatrice T. Oshika, Chair

Department of Applied Linguistics

ACCEPTED FOR PORTLAND STATE UNIVERSITY BY THE LIBRARY

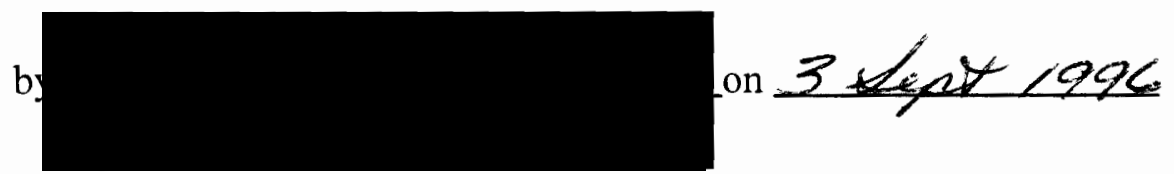




\begin{abstract}
An abstract of the thesis of Vivian Yann-Ling Lu for the Master of Arts in TESOL presented July 11, 1996.
\end{abstract}

Title: The Socio-Cultural Content Analysis of English as a Foreign Language Textbooks Used in Junior High School in Taiwan, Republic of China.

The English textbooks evaluated are used to prepare students for the competitive high school entrance examinations in Taiwan, thus students spend a great deal of time studying them. Though the textbooks were stated to be designed for language and cultural learning purposes, it seems no study exists that examines to what degree there is clear articulation between the government's stated culture learning goal and actual textbook content. Therefore, this study examines to what degree the textbooks allow students to reach said goal, that is, "to increase culture awareness of the societies and cultures of foreign countries and our own" (Junior High English Language Curriculum 1985, p.1). This study intends to answer five major questions: (1) what is the scope of the cultures presented?; (2) what sub-cultures represent Chinese and foreign cultures?; (3) what is the nature of inter and intracultural interactions between characters?; (4) what level(s) of culture do the textbooks deal with?; (5) how is the socio-cultural information presented?

Hernandez's dissertation (1986) was followed in developing this study: the 
coding system was developed to correspond to the five questions above, and content analysis was the study method used. Data was gathered from two textbooks.

Research revealed that the textbooks did not reflect the stated cultural study goal. The textbooks provided a narrow spectrum of socio-cultural elements, presenting the American culture as the only representative of foreign cultures. Both American and Chinese socio-cultural elements were portrayed on the surface level. Little interaction existed between Chinese and American cultures, with relationships confined to primarily acquaintances, and the issues discussed limited to daily life and trivial issues. The readings emphasized surface level culture with few attempts at linking more overt behavioral and cultural features. Most of the readings discussed information from a historical view, and the post-reading questions presented in the textbooks focused on a factual nature 
THE SOCIO-CULTURAL CONTENT ANALYSIS OF ENGLISH AS A FOREIGN

LANGUAGE TEXTBOOKS USED IN JUNIOR HIGH SCHOOL IN TAIWAN, REPUBLIC OF CHINA

by

VIVIAN YANN-LING LU

A thesis submitted in partial fulfillment of requirements for the degree of

MASTER OF ARTS

in

TESOL

Portland State University

1996 


\section{TO ALL OF YOU}




\section{ACKNOWLEDGMENT}

Thank you Wei, my husband,

You carried the yoke with me through the every day life all these years.

Thank you Veronica, my daughter,

Your trust and smiles kept mom moving through the dark nights

Thank you Dad and Mom,

Your belief, pride and love persuaded me to finish this work.

Thank you Dr. Brown., my advisor

Your guidance, trust, and heart not only helped me to accomplish my thesis but also taught me the meaning of education. Thank you Kim.

Thank you thesis team members:

My sisters- Huei-Ling, Hsei-Ling, my brother Min-Hso, my friends- Terry, Norieo, Jay, Julie, Linda, Ahmad, Akiko, Michio, Anne, and others. Thank you for listening all these years.

Thank you thesis writing process,

I have learned not only ways of conducting research but also learning to trust myself.

Thank you Vivian,

Thank you for trusting yourself. 
ACKNOWLEDGMENTS . . . . . . . . . . . . . . . . vi

LIST OF TABLES . . . . . . . . . . . . . . . . . . .

LIST OF CHARTS $\ldots \ldots \ldots \ldots \ldots \ldots \ldots \ldots \ldots \ldots \ldots \ldots \ldots \ldots \ldots$

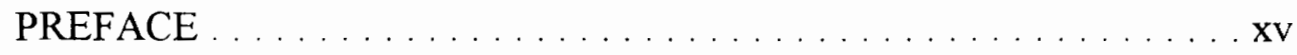

\section{CHAPTER}

I INTRODUCTION . . . . . . . . . . . . . . . . 1

Research Questions . . . . . . . . . . . . . . . 1

Outline of the Study . . . . . . . . . . . . . . . . . 5

Definitions of Terms . . . . . . . . . . . . . . 6

II REVIEW OF THE LITERATURE . . . . . . . . . . 7

Introduction . . . . . . . . . . . . . . . . . . 7

Education and English in Taiwan . . . . . . . . . . 8

Impact of Reading and Reading Content on the Reader. . . . 13

Problems of the Socio-cultural Content of Textbooks . . . . . 17

Hernandez' Study . . . . . . . . . . . . . . . . . . . . 22

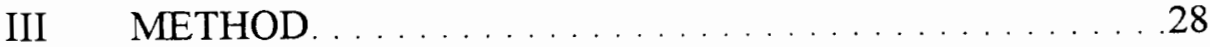

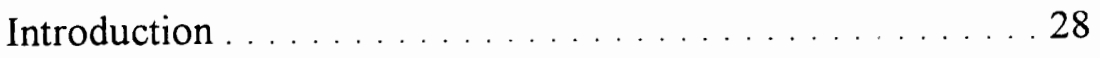

Object of the Study . . . . . . . . . . . . . . . . . . 29 
Coding System

Modification of Hernandez' Coding System

Coding Procedures

Statistical Procedures 59

Limitation of the System 65

Summary 65

IV THE ANALYSIS OF THE DATA 67

Introduction . 67

Characters' National Origins, Social Backgrounds, Conversational Topics, Problems, Interests, and Activities 68

Selected Sub-cultures as Representatives of Chinese and American Culture 78

Nature of the Interaction between Inter-cultural and Intra-cultural Groups 86

Explicit Cultural Information Presented and Level(s) of Culture the Texts Dealt with . . . . . . . . . . . . . . . . . . . . 92

Manner of Presentation of Socio-cultural Information . . . . . . 96

V CONCLUSION . . . . . . . . . . . . . . . . . . . 99

Introduction . . . . . . . . . . . . . . . . . . . . . . . . . . .999

Discussion . . . . . . . . . . . . . . . . . . . . . . . .99

Characters' National Origins, Social Backgrounds, Conversational Topics, Problems, Interests, and Activities 
Selected Sub-cultures as Representatives of Chinese and American

Culture

Nature of the Interaction between Inter-cultural and Intra-cultural

Groups

Explicit Cultural Information Presented and Level(s) of Culture the

Texts Dealt with ...................... 118

Manner of Presentation of Socio-cultural Information . . . . . . . 121

Other Issues . . . . . . . . . . . . . . . . . . . . . . . . . . 122

Conclusion . ............................ 123

Implication . . . . . . . . . . . . . . . 126

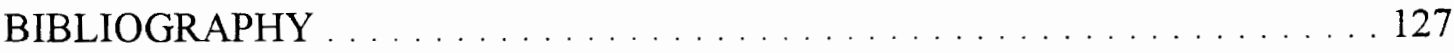

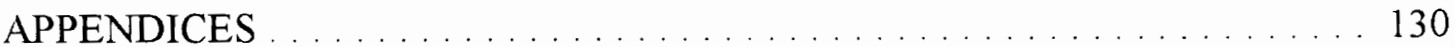

A CODING MATERIALS . . . . . . . . . . . . . . . 130

B SAMPLE CODING TABULATION SHEETS . . . . . . . . . 177 


\section{LIST OF TABLES}

TABLE

PAGE

1 Distribution of Characters by Textbook

2 Distribution of All Characters by National Origin . . . . . . . . 70

3 Distribution of All Characters by Gender . . . . . . . . . . . . 71

$4 \quad$ Distribution of All Characters by Occupation .......... 72

5 Distribution of All Characters by Age ...............73

6 Distribution of All Characters by Educational Level . . . . . . . .73

7 Distribution of All Characters by Role Type . . . . . . . . . . .74

8 Distribution of All Characters by Conversational Topic . . . . . 75

9 Distribution of All Characters by Problem ............76

10 Distribution of All Characters by Interests . . . . . . . . .77

11 Distribution of All Characters by Activities . . . . . . . . . . . 78

12 Distribution of Chinese \& American Characters by Gender . . . . 79

13 Distribution of Chinese \& American Characters by Occupation . .80

14 Distribution of Chinese \& American Characters by Age . . . . . 8 81

15 Distribution of Chinese \& American Characters by Educational Level . . . . . . . . . . . . . . . . . . . . . . . 82

16 Distribution of Chinese \& American Characters by Conversational Topic

17 Distribution of Chinese \& American Characters by Problem 
18 Distribution of Chinese \& American Characters by Interests . . . . 85

19 Distribution of Chinese \& American Characters by Activities . . . . 86

20 Distribution of All Characters by Inter-cultural \& Intra-cultural

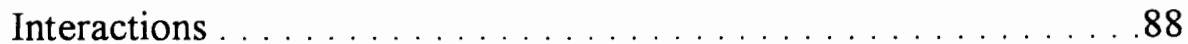

21 Types of Relationships Presented in Chinese-Chinese, AmericanAmerican, \& Chinese-Chinese . . . . . . . . . . . . . . . . . . . 889

22 Conversational Topics by Inter-cultural \& Intra-cultural Interactions .90

23 Geographical Location- Country . . . . . . . . . . . . . . . . . . 991

24 Geographical Location- Area . . . . . . . . . . . . . . . . . . .91

25 Geographical Location- Setting . . . . . . . . . . . . . . . . 92

26 Topical Area of Readings . . . . . . . . . . . . . . . . . . . . . 94

27 Reading Combining Character Description with Cultural Aspects or

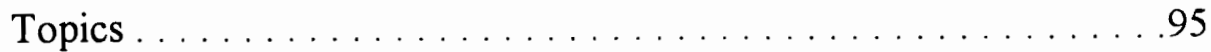

28 Cultural Area Emphasized in Reading . . . . . . . . . . . . . . . 95

29 Time Perspective for Cultural Specific Topics . . . . . . . . . . . . . 97

30 Time Perspective for Character Description . . . . . . . . . . . 97

$31 \quad$ Types of Exercise $\ldots \ldots \ldots \ldots \ldots \ldots$. . . . . . . . . . . . . . .

32 Stance of Questions . . . . . . . . . . . . . . . 98 


\section{LIST OF CHARTS}

1 Sample Blank Coding Tabulation Sheet of Area I. "National

Origin and Social Background (Reading)"

2 Sample Blank Coding Tabulation Sheet of Area IV. "Explicit

Information and Historical Dimension" . . . . . . . . . 35

3 Sample Coded Coding Tabulation Sheet of Area I. "National

Origin and Social Background (Reading)" . . . . . . . . . 38

4 Sample Coded Coding Tabulation Sheet of Area V " Manner of

Presentation . . . . . . . . . . . . . . . . 42

5 Sample Coded Coding Tabulation Sheet of Area IV. "Explicit

Information and Historical Dimension" (Original Coding Sheet). . 48

6 Sample Coded Coding Tabulation Sheet of Area IV. "Explicit

Information and Historical Dimension" (Character Description

Coding Sheet). 


\section{PREFACE}

What inspired me to examine the degree in which the English textbooks used in junior high schools in Taiwan allow students to reach the educational goal in English learning through the portrayal of cultural information was an experience of teaching English there. That is:

to reflect upon oneself and one's own culture from the archimedean standpoint of another language and culture, and the acquisition of new insight into self and native surrounds which are fundamental to the notion of education.

(M. Byram, 1988: 15)

When I taught my young learners, I sometimes invited American friends of mine to the class. From the experience of their first encounter, I realized that how much my learners and I, an English teacher who is supposed to be one of the most influential "foreign cultural bearers," in a foreign language classroom were confined in our native habitat and culture.

The Story Behind the Study

It was a late afternoon class in the summer of 1987. I was finishing up telling my American friend about my students' general backgrounds on the way to the class. My class was as noisy as usual during the 10 minute break. "American!" one student's "announcement" smashed the tumult into pieces of trembling silence as soon as the shadows of my friend and I crept into the room. That quick "announcement" calmed down the class a lot faster than any of my routine announcements.

When I introduced my friend, I saw my words were like empty bottles. They were struck back and forth by the waves of silence billowing among the young faces 
framed by curious wide open eyes and mouths. Slowly, these eyes and mouths started whispering, smiling and laughing. The waves of silence then changed and became excited and started to dance toward the back of a corner of the classroom. A little hand was lifted up by several other little hands and struggled out of the surface of the waves of laughter and whisper.

One student was squeezed out from his seat by his classmates around him and he began to speak: "Um...I...,". His blushed cheeks searched for the words from his fingers which were scribbled around on his desk. "No, I mean, they want to know do you kiss your boyfriend on street? We saw Americans always kiss each other on street in movies." More hands were raised after our visitor answered that question. The other questions were things like: "Were you kicked out by your cruel Mom and Dad when you were 18 years old?" One of my students said that when he refused to eat his dinner, his mom always told him that he was lucky to be born here, because if he had been born in the U.S., he would have been kicked out by his cruel parents when he was still very young. And those who do not eat dinner will be kicked out even earlier! The questions gained lots of little nodding heads doting in the waves of laughter.

One question after the other, we ran out of time. That particular culture journey brought me and my students a very new experience, and left me with "souvenirs" that have stayed with me all these years, i.e., all those memories of their questions and mine about foreign culture. I have been thinking, what made my students assume that my blonde haired friend was an American but not an Australian or English woman before I even introduced her? What made the mother think 
American parents were cruel? In fact, although I did not like the way the mom educated her son, a voice coming from a corner of my Chinese heart tended to agreed with her--- yeah, American parents seem cruel. In fact, the question might be, why do the mom, the students and me, and perhaps most Chinese people think this way? Is it because we have been surrounded by too much media that stereotyped the image of American culture? Is it because we can not step into a stranger's shoe to look at their world? As an English teacher, I think it is my job to search for a more realistic foreign cultural message for the students. As an English teacher, I also think that we should be able to find this information in the English textbooks as well. 


\section{CHAPTER I}

\section{INTRODUCTION}

The purpose of this study is to identify what aspects of culture are taught through the junior high English language textbooks used in Taiwan. The English textbooks evaluated are used to prepare students for the competitive high school entrance examinations, thus students spend a great deal of time studying them. Hernandez' dissertation (1986) was followed in developing this study. Based on his design, the coding system was developed to correspond to the research questions discussed in the following. Content analysis was the methodology used. Chapter II will discuss it in detail. The study also looks at the degree to which textbooks allow students to reach the stated goal of cultural study in the language classroom, that is, "to increase culture awareness of societies and cultures of foreign countries and our own" (Junior High English Language Curriculum 1985, p.1) through the portrayal of cultural information and aspects. Ideologically, this study looks at the degree to which the textbooks allow students to reach the educational goal in English learning of developing "the awareness of one's own culturally-induced behavior and the culturally-induced behavior of others" (Tomalin 1993, p.5). This study intends to answer five major questions:

\section{Research Questions}

I. What is the scope of the cultures and sub-cultures presented, and to what degree 
does the information presented enable students to better understand the individual cultures appearing in textbooks?

---What groups of people appear in the textbooks' dialogs, and readings in terms of their national origins and social background?

---What appear to be the topics, problems, and interests the characters express through their conversations and what are the activities they carry on in the textbooks' dialogs and readings?

II. What sub-cultures are selected as representative of Chinese culture and American culture to achieve the goal of cross-culture awareness and understanding stated by the Ministry of Education of Taiwan?

---What groups of people that represent Chinese culture appear in the dialogs and readings in terms of their social backgrounds?

---What appear to be the topics, problems, and interests the Chinese characters express through their conversations, and what are the activities they are involved in that represent Chinese culture?

---In terms of the characters' social backgrounds, what groups of people that represent American culture appear in the dialogs and readings?

---What appear to be the topics, problems, and interests the American characters express through their conversations, and what are the activities they are involved in that represent American culture?

III. What is the nature of the interactions between the characters with respect to their 
cultural, gender, inter-personal relationships, and conversational topics the characters discuss, as well as the geographical settings in which the interactions occur in the textbooks?

---Do most interactions occur between Chinese-Chinese groups? ChineseAmerican groups? Or American-American groups?

---What types of interpersonal relationships are presented between AmericanChinese characters? Chinese-Chinese characters? American-American characters?

---What types of conversational topics are discussed between ChineseAmerican characters? Chinese-Chinese characters? American-American characters? ---In what types of geographical settings do the interactions occur? IV. What levels of culture do the junior high English textbooks deal with? ---What topical area do the readings deal with? ---Do the readings deal with surface culture only? Deep culture only? Or attempt to link both surface culture and deep culture? $\mathrm{V}$. What is the manner of presentation of the socio-cultural information?

---Do the readings portray culture from an historical view?

---Do the questions related to the readings emphasize mnemonic processes or heuristic understanding?

As Costo (1970) suggests, there is a difference between a book for general readers and one accepted for classroom use. General readers have choices. Students, however, do not. They are forced to study approved textbooks. In Taiwan, students 
are not only compelled to study this set of textbooks at school, but also to study them after school in order to pass the competitive entrance examinations. Therefore, it is significant to evaluate whether the textbooks provide objective information.

Examining the impact of foreign language textbooks on students is also important. When students walk into the language classroom they are not linguistic or cultural apprentices, but already have some ideas and preconceptions about the foreign culture. The instructor and textbooks "may serve to correct [students'] misconceptions, to increase their cultural understanding or to confirm them in their prejudices" (Joiner 1974, p. 242). Therefore, it is important to examine whether the textbooks portray a wide spectrum of cultural information to students that confirm or correct their preconceptions.

The other reason to examine the cultural content presented in foreign language textbooks is that foreign language textbooks have often been found to fail in reflecting the goal of cultural study through foreign language education. This issue is of particular importance in a situation like Taiwan's, where linguistic content dominates foreign language textbooks. As Robinson (1978) indicates, although the study of a foreign language has been long claimed by foreign language educators around the world as the key to understanding people from another culture, this claim has rarely been reflected in specific instructional and evaluation practices of the foreign language classroom. She raises the examples of the syllabi of French and Italian for grades 11-12 in Australia. These syllabi claim to afford insights into 
another culture, but an examination of actual language course, methods, and materials shows that they do very little to fulfill the aim of fulfilling these insights (pp. 135138). Therefore, it is essential to identify whether the Taiwan Ministry of Education's stated goal of cultural study is reflected in the English textbooks.

\section{Outline of the Study}

Chapter II, the review of literature, provides a macro-level picture of the education background of Taiwan, English language status, and English education. It also investigates the relationship between reading and learners, as well as the problems of socio-cultural content that have been commonly found in language textbooks. Because Hernandez' (1986) dissertation was the study I followed closely to develop my thesis, this chapter profiles his study in detail, and also presents essential attributes of content analysis.

Chapter III discusses the design of the research and how Hernandez' study was modified to meet the needs of this study. It outlines the object of the study, the coding system, coding procedures, statistical procedures, and the limitations of the system.

Chapter IV presents the results from the analysis of the data collected. This Chapter is divided into five sections following the format of the research questions. Chapter V summarizes and discusses the findings presented in Chapter IV. It also includes a general discussion about the cultural information in a randomly chosen lesson, lesson 2 in textbook III. Following is a glossary of the terms used in this 
study :

\section{Definition of Terms}

Surface Culture: Observable elements of people's culture such as dress styles, customs, foods, physical aspects, house types, shopping habits, holidays, birthday, instruments, and leisure activities, etc.

Deep Culture: Values, assumptions, motivations, and beliefs that underlie surface culture elements.

Chinese people: Residents of Taiwan, Republic of China. "Chinese people" and "local people" will be used alternatively in the method section.

Praxis: This term has been defined in Hernandez' study (1986) as "any meaningful human activity, any act which is not mere random, undirected motion" (P. 53).

Tributary Cultures: According to Byrd (1993), they are the cultures of "ethnic groups [who] are tributary groups within a larger culture and are distinguishable from the power dominant group on the basis of tradition, values, ways of thinking, world perspective and/or language" (p. 13). 


\section{CHAPTER II}

\section{LITERATURE REVIEW}

\section{Introduction}

Chapter II explores the elements involved in the following areas in order to outline the nature of the study. This chapter starts with introducing a macro-level picture of the education background of Taiwan, English language status, and English education. This area provides the educational background information from the perspectives of an important Chinese education ideology, Confucianism, and the national school entrance examination. This area also discusses English language status and education in Taiwan from the perspectives of individual interest, school curriculum, business, private English language schools, and English learning facilities.

Because the output of a student's cultural learning from the English textbook is the eventual concern of the study, the next area explores the relationships between readings and learners, as well as the problems of socio-cultural content of language textbooks. The issue of the relationships between the readings and learners is discussed from the perspectives of the influence of reading and reading content on reader's opinions and attitudes in general, and the impact of the socio-cultural content of foreign language textbooks on the foreign language student in specific. The problems of socio-cultural content which have been often found in foreign language textbooks discussed in this study are racism, sexism, emphasis on surface culture, and 
a failure to reflect the socio-cultural goal of cultural study.

The final area profiles Hernandez' doctoral dissertation (1986). I have heavily adopted a large portion of research questions he addressed and the methods he used. Therefore, it is important to give a general picture of his dissertation.

\section{Education and English in Taiwan}

This section includes the influence of Confucius' aim of education on old Chinese, the examination system, and modern Chinese, and the link among the examination system.

\section{The Influence of Confucius' Aim of Education on the Chinese}

Throughout China's long history, education has been one of the highest cultural values. A major reason for this has been the influence of Confucianism as a philosophy of human nature and as a social ideology.

\section{(The Encyclopedia of Education 1971, p. 96)}

Confucius has obviously influenced the Chinese in many ways. His philosophy of education was the cultivation of moral character through education, and the policy he instigated regarding education helped determine the shape of present day education in Taiwan. In the past, his education philosophy affected not only individuals but also kings, and later the system of imperial recruitment. He made individuals believe in the values of education. He persuaded kings to use educated people to help them rule their country; later he influenced the evaluation system of imperial recruitment. On the pragmatic level, the policy he made for education was equal educational opportunity. 
This broke with Chinese tradition and offered new hope to the poor, that they could advance their life by receiving an education. According to the Encyclopedia of Education (1971):

Confucius also held that education should be available to all, irrespective of social class. This ideal of social equity was promoted early in China in order to find the most able and virtuous rulers, and it provided the rationale behind the later system of examinations aimed at recruiting officials on the basis of individual merit.

Educated people are still considered to be prestigious. Children have grown up with the belief of education reflected in a popular Chinese idiom: "only the learned rank high, all other trades are low." Most parents with different levels of socialeconomic backgrounds view education as a way for their children to maintain the same as or attain a higher status than themselves, or see education as an opportunity for their children to change their future. In turn, students see school entrance examinations as turning points in their lives. When they pass the exams they feel they glorify their forebears because of their great achievements. The current examination system at the college level affects decisions about education all the way down to the kindergarten level. Some understanding of this process is in order.

The College Entrance Examination in Taiwan

The American Association of Collegiate Registrars and Admissions Office (AACRAO) (1977) reports that in the summary of a 1974 joint entrance examination for universities and four-year colleges in Taiwan, only 26.83 percent of the students who took the entrance examination passed. In Taiwan, students try very hard to pass 
the highly competitive entrance examination to get into universities. From the time they begin kindergarten, students work very hard in order to pass a battery of examinations that will allow them to enter so called "star" elementary schools, junior high schools, and senior high schools respectively. Education still holds the promise of advancement, so the hard work is necessary. Therefore, students have to spend a great deal of time working with textbooks in order to pass all the examinations.

\section{English Language Status and Education in Taiwan}

English is not an official language in Taiwan. However, it is very important to people in Taiwan because "it links Taiwan to the world of business and enables it to stay in touch with the most recent advances from such diverse fields as medicine and education" ("Teaching English in Taiwan," 1994)1. It is considered prestigious to be able to speak English fluently. In general, the attitude of people in Taiwan toward English is positive.

Regardless of an individual's interest or desire, the pressure to learn English is immense. In school, English is a critical factor for those who wish to be promoted to the next level because it is a required subtest. The importance of English to the school curriculum can be seen in the Curriculum Policy of Junior High School (1983), Senior High School (1983), and University of R. O.C. (1985), policy documents

' This paper was received from my advisor who was a blind reader for the TESOL Quarterly board. There is no further information available on this manuscript. 
published by the Ministry of Education of Taiwan, R. O.C. English language is a required subject and emphasized by these curriculums. The following Chapter will discuss this issue in detail. Schools in Taiwan do not currently teach English as a foreign language until junior high school. (However, I have also recently heard that the Ministry of Education of Taiwan is planing to set up English language as an elective course for the primary school curriculum).

In Taiwan, junior high and high school are each three years in length.

Currently, English is a required subject for the first two years of both; therefore, the total hours it is studied are greater than other subjects. For instance, in the first term of the first grade of the junior high school curriculum, English is one of the fifteen subjects students need to take and is studied a maximum of 3 hours per week. The total hours for all subjects is a maximum of 34 hours. Even though English is one subject out of fifteen, or 6\%, the total hours spent on English is three out of thirty four, or $9 \%$. Therefore, the portion of English hours is emphasized.

This emphasis is even stronger in the high school curriculum. English classes make up only $5 \%$ of all the subjects; however, the portion of the total hours studied is 12\%. According to AACRAO (1977), at the college and university level, the portion of English courses taken is only 16\% of all the subjects; however, the portion of the total hours studied is 26\%. It can be seen that English is emphasized in all levels of education in the education system of Taiwan by the Ministry of Education of Taiwan, R.O.C. As a consequence, students need to spend a lot more time studying English 
than other subjects. In addition, since English is a required subject on all entrance examinations, students have to spend more time on English in both regular schools and cram schools, which they go to after regular schools.

The paper "Teaching English in Taiwan" discusses the issue of English language status in Taiwan. In business, English fluency is a determining factor for one's success because Taiwan's economy relies so much on international business. For the public in general, learning conversational English is demanded because of the increasing number of people from Taiwan traveling overseas. The stress on learning English is reflected by English cram schools sprouting like mushrooms around the country.

The importance of English language can also be seen from the proportion of English language schools and English language learning facilities. According to statistics from the Taiwan Provincial Department of Education, by the end of August 1993 , there were 2,478 cram schools nationwide. Out of a total of $2,478,455(18 \%)$ of the cram schools were specifically focused on preparation for college exams. Out of a total of $2,478,602(24 \%)$ of cram schools were geared toward teaching foreign languages. And 580 out of a total of $602(96 \%)$ of foreign language schools, were focused on teaching English. The importance and pressure of learning is also reflected in the growing number of so called "bilingual kindergartens," although bilingual education is not yet official. In the bilingual kindergartens, children study in Chinese and English. Compared with normal kindergartens, the tuition is usually 
fairly high. However, most parents consider this as a worth investment in order to establish a good English language foundation for their children. Moreover, ICRT, an English radio station, and several magazines for learning English through radio stations have become very popular.

The Impact of Reading and Reading Content on the Reader

Based on Sartre's philosophical theory, De Meo (1980) argues that "a book is not merely the sum of its material parts; it carries within it the stamp of praxis: that of the author and of the publisher, and perhaps even that of a prior owner who has marked it" (p.6). De Meo explained that praxis is "man's fundamental mode of beingin-the-world" (p.3). It implies any meaningful human activity. Using a book as an example, a book is a "thing " to the extent it is composed of paper, ink, binding, etc. However, a book is not merely the sum of its material parts; a book combines the inertia of matter and the transformational capacity of human action. A book implies the praxis of the author and it solicits the praxis of the reader (p. 53). A book therefore has a dynamic interaction rather than a linear relationship with the reader.

In Quillen's (1950) discussion of the contribution of textbooks to world understanding, he points out that most literate adults' opinions and attitudes have been influenced by the textbooks and teaching materials they studied in school. Wirtenberg (pp. 13-19, 1980) suggests that children form their ideas and behavior through their school experience. About seventy five percent of the classroom work and ninety 
percent of the homework focus on texts. Therefore, texts may have a significant influence on children's lives.

In addition to the theoretical issues, there are some experimental studies that have been done in this area. Haugh (1952) tested the relative effectiveness of reading versus listening to the radio in eleventh graders. He wanted to see which way would impart information and shift reader attitudes toward minority groups more effectively. He found that the treatments of reading a script and added materials was significantly more effective than the treatments of reading a radio script, and the treatment of listening to a radio only. The subjects of the group reading the script and added materials also retained the information better.

Fisher (1968) in another experimental study, evaluated the influence of reading versus discussion on fifth graders' attitudes toward Native Americans. His findings indicated that the reading only and reading plus discussion groups were significantly more effective than the no-reading group. Fisher concludes that there is clear evidence that reading can change the attitudes of children. Therefore, the perspective of the textbooks written for young learners might influence children's attitudes, and from the theoretical arguments and experimental studies, by logical extension, it can be argued that textbooks can have significant influence on children's attitudes. 
The Influence of Socio-cultural Content of Foreign Language Textbooks on Learners

In a discussion on the cultural content of foreign language textbooks, Carroll (1978) raises a question about whether readers' behaviors will be influenced by the way the characters are treated in textbooks. In order to make the communicative context of dialogues effective, she suggests that readers' identification with the characters be significant. As a consequence, readers will not only learn linguistic aspects but also take in cultural patterns and attitudes unconsciously. The issue of readers' identification with characters related to cultural study is further examined in De Meo's (1980) dissertation.

When learning culture in the foreign language classroom, De Meo (1980, pp 69-71) argues that the learners' concrete situation is necessarily "outside" that of the target culture. Consequently, the students can adopt an "insider's" view only on an intellectual level. In the realm of culture, the textbook becomes the primary locus of the student's experience. However, the textbook itself is also "outside" of that target culture just as are the students; "the issue becomes whether or not the textbook allows the students to take an insider's view through the conceptual and through the imaginary" (pp. 68-69).

Through the conceptual and imaginary, the textbooks present two types of characters: target culture characters and characters who are students of the target culture. De Meo suggests that the latter type of characters are symbolic representations of the students using the textbooks, characters with whom the 
students are expected to identify. On the other hand, the target culture characters are perceived by the students as representatives of the target culture. Therefore, the target culture characters are necessarily more fully defined than the other to provide insights into significant aspects of that target culture

To provide for a symbolic insiders' view of that target culture through the imaginary, De Meo suggests, would require that the textbook present the symbolic native culture character interacting with the target culture characters in situations that reveal significant aspects of that target culture. The existence of post-reading questions which guide the students to a heuristic understanding of those significant aspects of that target culture would further reinforce the "insider's" perspective (1980, pp 69-71). De Meo suggests the assumed role of language textbooks is to create a realistic fiction of the foreign culture, both through readings involving a cast of imaginary characters and through readings of an expository nature (p. 249).

The role foreign language textbooks play in foreign language education amplifies the influence of socio-cultural content of foreign language textbooks to students. Foreign language textbooks play a role in correcting or confirming student's prejudices of the culture they learn from the foreign language classroom. As Joiner points out, since the students who are coming to the language classroom already have some preconception about the language and the culture they are going to learn, the textbooks "may serve to correct [student's] misconceptions, to increase his cultural understanding or to confirm him in his prejudices" $(1974$, p. 242). The 
functions of correction and confirmation may work even more significantly for most

Chinese students because they trust the authority of books. According to Scarcely, "for many Chinese students and teachers, books contain knowledge, wisdom and truth" (1990, p. 188).

While scholars suggest the significant impact of the socio-content of textbooks on learner's behavior, several common problems have been often found in presenting the socio-cultural content of textbooks.

\section{Problems of the Socio-cultural Content of Textbooks}

According to Aries (1982), textbooks have often been found to portray inaccurate descriptions and characterizations, neglect topics, mistreat others or distort foreign cultures (p. 4). These problems are usually found in the forms of racism, sexism, emphasis on surface culture, and failure to reflect socio-culture goals in language learning.

\section{Goal is not Reflected}

The focus of second language teaching has moved from the structures of language to a new focus on communicative language teaching. The goal is to enable students to use English for the purpose of communication. Muriel Seville-Troike (1982) defines communicative competence as:

knowing not only the language code, but also what to say to whom, and how to say it appropriately in any given situation. It deals with the social and cultural knowledge speakers are presumed to have to enable them to see and interpret linguistic forms. (p. 22) 
In a discussion of the role of cultural learning in foreign language education, Robinson (1978) indicates that although the study of a foreign language has been long claimed by foreign language educators around the world as the key to understanding people from another culture, unfortunately, this claim has rarely been reflected in specific instructional and evaluation practices of the foreign language classroom.

Byram (1988) also raises this issue in his concern over the educational purpose of foreign language learning. In spite of the philosophy of major theorists of communicative language teaching, the "real danger" as he sees it, is that foreign language teaching is losing sight of important dimensions of the potential contribution of language learning to the learners' education:

Foreign language learning is educational. It offers the opportunity for emancipation from the confines of learners' native habitat and culture, with the development of new perceptions and insights into foreign and native cultures alike. (p.15)

He also uses examples of England and the United States, where the goal of foreign language study as stated by the President's Commission in a national policy of foreign language is apparently not yet reflected.

\section{Emphasis on Surface Culture}

Tinsley and David (1994) argue that textbooks which concentrate on the aspect of surface culture and cross-culture contrast in a isolated situation, yet do not even take an intellectual grasp of the underlying cultural assumptions and values, will 
not bring the student to a true understanding of the target culture. Indeed, this could even "confirm and [fixate] existing stereotypes and produce or even [implant] new ones when the [target culture's] behavior is evaluated on the basis of the students' own cultural assumptions and related values" (p. 125).

Hernandez (1986) also found that the textbooks offer little explicit information about specific topics of U.S. culture and society. The readings of the textbooks center on surface level culture and have very few links to the more overt behavioral and cultural future with their underlying values, assumptions and motivations. The dialogs also emphasize superficial behavior and trivial conversational topics (p.213).

\section{$\underline{\text { Racism }}$}

Rothenberg defines racism as "any attitude, action, or institutional structure which subordinates a person or group because of his or their color" ( 1978, p. 20). Hernandez found that the EFL textbooks used in Costa Rica accentuate White Americans and fail to recoganize the existence of other minority members like American Indians, Eskimos, Asians and Aleuts. In addition, Whites predominantly related with Whites, and when they interacted with minorities, it was usually limited to Blacks. There were only token references to other minorities (pp. 202-11).

Costo and Henry (1970) report an evaluation by thirty two American Indian scholars, native historians, and Indian students, of more than three hundred books for primary grades through high school. They conclude that not one of the books they 
examined could be approved as a dependable source of knowledge about the history and culture of the Indian people in American. Most of the books were, one way or the other, derogatory to Native Americans, extremely superficial, and oversimplified and generalized when describing American Indian culture and history. Most contained misinformation, distortions or omissions of important history. Stutzman (1993) made a similar report from a study of several social studies texts for grades 312. He concludes that both primary and secondary textbooks tend to reinforce the stereotypes of American Indians, whom have already been perpetuated as savages through movies, coloring books and toys. He demonstrates that Indian-related materials from texts, coloring books, and advertisements show widespread offensive stereotypes and erroneous information.

Regarding the presentation of African-Americans in the U.S., Latimer (1972) reports on a study of more than 300 children's books written about or including African-Americans conducted for the Wisconsin Department of Public Instruction. He concludes that African-American people were unfavorably treated through textbook characterization. Most of children's books present White as the norm in American society, and most biographies of great personalities have been written about men and women of White ancestry to the exclusion of equally great Americans with black or brown or yellow skin. When African American characters have entered into children's literature in the past, their roles have been restricted to stereotyped and negative images, proving further confirmation of the idea that African-Americans 
were somehow inferior to Whites. At best, these books lack authenticity; at worst they tend to reinforce some of the racist attitudes they apparently attempt to dispel (pp. 1-3)

The results of the study have been classified into five common flaws in the portrayal of African-Americans: (1) romanticism: a tendency to glorify situations and to ignore and camouflage realities; (2) avoidance: a denial of the harsh and oppressive conditions under which African-Americans have functioned; (3) bootstrap: suggests that only if African-Americans are properly motivated and helped themselves, they will succeed; (4) oasis: Black people presented as "token integration"; (5) ostrich-inthe-sand: an attempt to demonstrate acts of prejudice and discrimination but from a distorted, unreal, and oversimplified point of view.

Inaccurate images of American-Asians have also been perpetuated through textbooks. The Asia Society (1976) conducted a survey of 306 social studies texts in use in the United States in 1974-75. They were reviewed by over 100 scholars and teachers to determine how Asia is depicted in American school textbooks. According to the study, Asia has been presented as "exotic [yet] also fails to reflect the full humanity of its people by making them seem alien and 'other than us" (p. 19). In addition, "textbooks often treat Asian cultures negatively, regarding them as hindrances to progress or as primitive trappings that will become outmoded when change has taken place" (p. 22). Moreover, Asian data are usually colored with a 
Western point of view rather than how Asians see themselves. ${ }^{2}$

One other study about the presentation of American Asians shows similar results. Yee (1973) examined 300 American social studies textbooks for elementary and secondary schools, and showed that Asian studies and the involvement of Asians in American history are barely mentioned or neglected completely. Even worse, when little information is given, it reinforces stereotypes. About $75 \%$ of the 300 textbooks made no mention of Chinese at all, and the remaining texts gave a token representation with a picture of an Asian, often in an interracial group of Americans or few lines mentioning the existence of urban Chinatown (p. 107) This study also found a significant lack of comprehensive and accurate representation of three other cultural groups--American Indians, Blacks and Chicanos. Hernandez's (1986) study closely examined the function of English textbooks on development of student attitudes. The following section gives an outline of his study:

\section{Hernandez' Study}

Hernandez (1986) examined the selection and manner of presentation of socio-cultural elements in English as a Foreign Language textbooks used in Costa Rican Public secondary schools. His study investigated the following research

${ }^{2}$ out of 261 books for which these evaluations were received, 63 were designated either as "excellent, should be highly recommended" or "can be used, but has some problems." Reports from readers indicated that 118 books should not be used without revision and an additional 80 were declared to be so inadequate that they should be replaced by new texts (p. 29). 
questions:

(1) What is the correspondence of the U.S. socio-cultural portrayal with U.S. census data?; (2) What are the accomplishments of such portrayal in relation to the goals of cross-cultural awareness and understanding?; (3) What are the implications of the socio-cultural portrayal of U.S. culture and society in relation to national cultural development, education, and indigenous development in Costa Rica?; (4) What is the feasibility of a conceptual framework, and systematic, objective, and quantitative methodology for the description and analysis of socio-cultural content in foreign language textbooks? (p.201)

\section{Theoretical Orientation}

Hernandez developed the theoretical issue that textbooks could have a lot of potential impact on the opinions and attitudes of the readers. Therefore, he suggested, English textbooks would become harmful if the essential features of the target culture and the method of presentation were carried out improperly-promoting a distorted or highly selected view of the target culture. Hernandez also looked at what he called "dynamic triangular interaction" (1986) among reader, textbook and writer. He found that a systematic socio-cultural content analysis model could best measure this interaction.

\section{Coding System}

Hernandez developed his coding system by combining content analysis methodology, facet design, and a model for the description of socio-cultural content 
in textbooks. The system evaluated his texts in four areas: (1) representatives and demographic characteristics of characters; (2) conversational topics, problems and concerns, interests, context and activities of characters; (3) interpersonal relations; and (4) explicit information, historical dimension, and manner of presentation . Each area contained a set of variables, and each variable consisted of several categories. The characters, dialogues, readings and questions were the units used to record the data, and each were judged and classified within the context of their instructional units. The coding was recorded on tabulation sheets developed by the researcher. Two coders each independently coded each character, reading, dialogue and question in the sample units.

\section{Content Analysis}

Content analysis is a research technique conducted widely to understand the messages embedded in texts or to evaluate a text by applying a set of criteria. According to Frey (1992), content analysis was used as early as the eighteenth century. Swedish scholars used it to count the number of religious symbols contained in a collection of hymns in order to examine whether the hymns were preaching against the church. Today, researchers use content analysis to find out such things as how much violence children are exposed to through cartoons or what kind of message is presented in presidential speeches.

As Botan, Frey, Friedman, and Kreps (1992) points out, "Content Analysis was developed and is used primarily to study the messages embedded in mass- 
mediated and public text" (p. 194). It is a research instrument conducted to understand the characteristics embedded in texts according to set of criteria, an "objective, systematic, and quantitative approach to analyzing texts" (p. 525) Berelson (1950) argues that because of its objectivity, different persons can apply the same precisely defined categories and get the same results (p. 125)

\section{Choice of this Methodology}

I chose this methodology primarily because this was the coding instrument Hernandez used and his study is the model for my own. As I read more information in this area, I found that content analysis has been widely used for analyzing messages embedded in mass-media and public texts, and it is generally considered effective and useful for analyzing communication in a systematic, objective, and quantitative manner for the purpose of measuring variables (Kerlinger 1973; Stempel 1989).

\section{Hernandez' Coding System}

Because the design of this study was developed from Hernandez' coding system, I would like to provide a picture of his coding system, and the reason I chose this system.

\section{Choice of this System}

Hernandez's dissertation has contributed to my study in many ways. Intellectually, his research questions triggered my curiosity about the way English textbooks used in Taiwan were written to transmit cultural messages to the learners. Therefore, I would like to see to what degree the Taiwanese textbooks were written 
in response to government proposed goals to enable students to learn about Chinese and non-Chinese cultures in the English language classroom. Primarily though, his systematic and objective coding system has offered me a valid and reliable instrument to analyze the cultural content in English textbooks. It seems no study exists that examines this issue, yet it is of crucial importance.

\section{Coding System}

The system had four areas. Each area included a set of variables, and each variable consisted of several categories. The characters, dialogues, readings and questions were the units used to record the data. The instructional units were the context within which the recording units were judged and classified. The coding was recorded on tabulation sheets developed by the researcher. Two coders each, independently, coded each character, reading and dialogue in the sample units.

Hernandez found that the English language text series, Modern American English (1978), had a narrow view of cross-ethnic interactions. The limited scope of concerns that the Americans appeared to have was closely related to the limited scope of activities in which they were portrayed. He found that some ethnic groups were presented in rather stereotypical terms and basically had little to contribute to the goals of cross-cultural awareness and understanding for Costa Rican learners of English. Little explicit information was offered about specific topics of U.S. culture and society, and social, political, or intellectual history were noticeably absent. 


\section{Findings}

Hernandez found that the English language text series, Modern American English (1978), presented White American by a high percentage in the character population and omitted the minorities. The textbooks also presented an inaccurate image of Americans in the textbooks, in comparison with the demographic characteristics of the Americans in U.S. census data. Americans were highly educated but had a narrow view of cross-ethnic interactions. The limited scope of concerns that the Americans appeared to have was closely related to the limited scope of activities in which they were portrayed. He found that some ethnic groups were presented in rather stereotypical terms. The Modern American English text offered little explicit information about specific topics of U.S. culture and society, and social, political, or intellectual history were noticeably absent. The dominant approach is to present a culture without looking at the historical dimension. Most readings describe daily life but do not offer larger cultural context, giving students no opportunity for synthetic understanding. Post reading questions entirely emphasize mnemonic process rather than heuristic understanding. Therefore, students were often forced to take an outsider's view through factual recall questions. He concluded that the textbooks had little to contribute to the goals of cross-cultural awareness and understanding for Costa Rican learners of English. 


\section{CHAPTER III}

\section{METHODS}

\section{Introduction}

Content and statistical analysis played key roles in this study. In this chapter, I outline how I designed my research and tailored Hernandez' methodology to meet my needs. This chapter presents the design of this study, including the description of the objects, the coding instrument used for data analysis, the coding system developed through Hernandez's study, the modifications made to adjust to the needs of this study, the coding procedure taken to collect the data, the statistical procedure used in analyzing the data collected, and the research questions of the study. I intend to describe how these measures have been taken in the order of the research questions.

The coding system of this study was designed to look at the selection and the manner of socio-cultural elements presented in the English textbook series used by junior high school students in Taiwan. From the collected data, the researcher analyzed and evaluated whether the way the socio-cultural elements were presented reflected the proposed goal of cross-cultural understanding stated by the Ministry of Education of Taiwan. The coding system was divided into five areas: (I) national origin and social backgrounds of characters in readings and dialogs; (II) conversational topics, problem-concerns, interests and activities of characters in readings and dialogs; (III) interpersonal relations of inter-locators and the settings of 
following interaction in readings and dialogs; (IV) explicit cultural information and historical dimension of readings; and (V) manner of presentation of post-reading questions. These areas follow for the most part from Hernandez (1986). The purpose, the function, and the ways the five areas were designed as well as the coders' coding processes will be explained in more detail in the section on the coding system.

\section{Object of the Study}

\section{Choice of Texts}

The texts chosen to be evaluated were part of the English textbook series used by junior high school students in Taiwan. As mentioned earlier, my choice of these teaching materials was primarily based on the important role they piay in the education system in Taiwan. This set of textbooks is used to prepare students for the competitive high school entrance examinations in Taiwan. In addition, since English language is a required subject, and is emphasized in the junior high school curriculum, students spend a great deal of time studying this set of textbooks. In addition to spending time in school, most students also spend a great amount of time working with these materials after school in order to pass the competitive high school examination.

Personal preference has played a role in my selection of these texts. What I was taught during junior high school has had an impact on my thinking and behavior as an adult. Culture is a garden bed for the seeds of ideas, beliefs and values. 
Because English textbooks are one of the important cultural messages "seeders" for the students who learn English in Taiwan, I would like to see what kind of cultural messages this set of textbooks presents.

\section{Characteristics of the Texts}

The textbook series chosen for this study is the new edition (1993) of a sixlevel English textbook series used by junior high school students in Taiwan. The first edition was published by the National Institute of Translation and Compilation (NITC) in 1988. This series includes six textbooks. The first four levels of textbooks were designed for the first and second year of junior high school students. The last two levels of textbooks were designed for third year students, who were students in their last year of junior high. Each textbook has a total of twelve lessons, with every fourth lesson a review of the preceding three. With the exception of lesson four, which had no dialog section, each lesson was divided into three major sections and several optional sections. The major sections include: reading, postreading questions, and dialogs. The optional sections include: sentence patterns, oral practice, verb forms, applications, sentence makings, questions and answers, and listening practice. For example, lesson 1 of textbook volume 5 included the sections of reading, post-reading questions, dialogs, sentence patterns and oral practice. Lesson 2 of the same textbook includes reading, post-reading questions, dialogs, sentence patterns, verb forms, oral practice and application. 


\section{Texts Samples}

As Botan et al. (1992) have pointed out, the best procedure for selecting texts "is to conduct a census of all the relevant texts" (pp. 162-65). In my case, I chose volumes 5 and 6 to be evaluated because these two volumes were designed to teach cultural information. According to the curriculum goal and the introduction to textbook volumes 5 and 6 by the Ministry of Education of Taiwan, these were texts where "the topics and stories about Chinese culture and foreign culture start to appear" (text $5 \& 6,1993$ ). Therefore, I chose these two volumes in the study's interest. Although the first four volumes are not intended to teach cultural messages explicitly, lesson two was randomly chosen from volume 3 to be evaluated because I was curious to see whether there are still cultural messages transmitted even when they are not intended.

In addition, since the textbook characters were developed throughout different textbooks, units, and sections, I decided to analyze all the characters that appeared in every unit of the sample textbooks as weil.

\section{Coding System}

The coding system of this study was developed through the design of Hernandez's coding system. As mentioned earlier, the system was divided into five areas to correspond to the five research questions, and each area was designed to answer one or two research questions. This section will give a brief review of the 
purpose and the design of both the coding materials and the five major coding areas. This section will also give examples of the coders' coding process of the first two areas to help readers to get a sense of how the coding process went.

\section{Purposes and Designs of Coding Materials}

Five coding materials were designed for this coding system and they were received by the coders in the first coding meeting: (1) coding materials notes; (2) general coding instructions; (3) specific coding instructions of each area; (4) distributions of variables, and the definitions of their categories (see samples in the following discussions and see Appendix A for complete information for above materials); and (5) coding tabulation sheets (see Chart 1 or 2 following, and see Appendix B for complete information). The purpose of the coding materials notes was to facilitate the coding process in three ways. First, the notes provide an overview of the coding materials. Second, the notes informed the coders of the instructional units they should code. For example, they were to code the readings of lessons 1 to 12 in textbook I, and lessons 1-3, 5-7, and 9-11 in textbook II. Third, the notes provided the material identification codes. For example, lesson one's identification code was "01," and page one's identification code was "001" (see the section of "materials" in Appendix A). These identification codes were the identification variables that coders needed to identify texts and to mark them in the section of "identification" on the coding tabulation sheets for each area (see Chart 1 sample or Appendix B for complete information). The notes of coding materials were 
explained in detail by the researcher in the coders' first meeting.

\section{Chart I}

Area I. National Origin and Social Backgrounds (Reading)

\begin{tabular}{|c|c|c|c|c|c|c|c|c|c|c|c|}
\hline Variables ....> & \multicolumn{5}{|c|}{ IDENTIFICATION } & \multirow{2}{*}{$\begin{array}{c}\text { National } \\
\text { Origin }\end{array}$} & \multicolumn{5}{|c|}{ Social Backgrounds } \\
\hline Character Name & $\begin{array}{l}\text { Character } \\
\text { Number }\end{array}$ & $\begin{array}{c}\text { Textbo } \\
\text { ok } \\
\text { Numbe } \\
r\end{array}$ & $\begin{array}{c}\text { Unit } \\
\text { Numb } \\
\text { er }\end{array}$ & $\begin{array}{l}\text { Page } \\
\text { Number }\end{array}$ & \begin{tabular}{|l} 
Coder \\
Initial
\end{tabular} & & Gender & $\begin{array}{l}\text { Occup } \\
\text { ation }\end{array}$ & Age & $\begin{array}{l}\text { Educa- } \\
\text { tional } \\
\text { Level }\end{array}$ & $\begin{array}{l}\text { Role } \\
\text { Type }\end{array}$ \\
\hline & & & & & & & & & & & \\
\hline & & & & & & 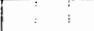 & & : & & & \\
\hline & & & & ; & & 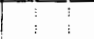 & 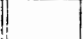 & 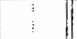 & & & \\
\hline
\end{tabular}

The purpose of general coding instructions was to help coders understand the coding instructions which apply to several or all areas (see "general instructions" in Appendix A). For example, general instructions gave the definitions of characters and the list of the five major areas coders should gather information about. Specific coding instructions told coders the process of identifying the material identification codes in the identification section on the coding tabulation sheets of each area. The specific instructions were also designed to help coders understand the instructions for the specific situations occurred in each area. For example, instruction $\# 7$ in area I gave a specific instruction of gathering characters' information:

If you do not have sufficient information to code a given variable for a character, leave the space blank for a while until you gather more information by going through the units in the textbooks. Sometimes you may need to go through the entire book before you gather all the information about a character.

(specific instructions for area I in Appendix A) 
The main purpose of the distribution of variables and the definitions of their categories was to provide a list of categories with definitions under each variable so that coders could identify the variable for characters, dialogs, readings, or postreading questions. For example, there were 6 categories under the variable of age, their definitions were meant to allow coders to identify character's age from the categories of infant/children to people who were deceased (see following sample and see Appendix for complete information).

1 Infants and children: (0-12)

Characters who are portrayed as infants or whose age is explicitly stated and falls within the range of 1 to 12 . Also those characters who are presented as elementary school students.

2 Teenagers: (13-18)

Individuals who are explicitly identified as teenagers, and or who are presented as high school students. Individuals whose age is directly given and falls within the range of 13-18.

3 Young adults/adults: (19-59)

Individuals presented as college students, employees of industries, factories, institutions, businesses. Individuals whose age is explicitly given and falls within the range of $19-59$.

$4 \quad$ Elderly: (60 and over) Individuals who are presented as retired, or of retirement age. Characters who are explicitly described as being 60 years or older, and/or as elderly individuals.

9 Unspecified:

Individuals who by the above definitions can not be classified in the above categories due to the lack of information.

0 Others:

When age variable is not apply to the individuals. For instance, for the characters described had passed away. 
Note: If no specific age is given, use the age of one of the peers for whom an specific age is given. If no peer's age is given, guess the age (in intervals of five) of the character on the basis of the given information on the character (i.e. occupation, education, friends, settings, activities).

In the Manuel of distribution of variables and the definition of categories, there were two groups of variables; identification variables and specific variables; developed to evaluate the information of each of the five areas (see Chart 1). The set of "identification variables" was used on the coding tabulation sheets to identify the text which was coded (see the section of "identification" in Chart 1). The first or/and the second identification variable varied depending on the recording units of each area. For example, in area I, because its recording unit was character, its identification variables included character number, textbook number, unit number (lesson number), page number and coder's initial. In area IV, because its recording unit was reading, its identification variables were reading number, textbooks number, unit number, page number and the coder's initial (see Chart 2).

\section{Chart 2}

Area IV. Explicit Information and Historical Dimension (Original Coding Sheet)

\begin{tabular}{|c|c|c|c|c|c|c|c|c|c|c|c|}
\hline \multirow{2}{*}{\multicolumn{3}{|c|}{$\begin{array}{c}\text { Variables } \rightarrow \\
\text { Characters' Names }\end{array}$}} & \multicolumn{5}{|c|}{ IDENTIFICATION } & \multicolumn{3}{|c|}{ Explicit Information } & $\begin{array}{c}\text { Historical } \\
\text { Dimenision }\end{array}$ \\
\hline & & & \multirow{2}{*}{\begin{tabular}{|l|} 
Total \\
Readin \\
$\mathbf{g}$ \\
Number
\end{tabular}} & \multirow{2}{*}{$\begin{array}{l}\text { Text i } \\
\text { book } \\
\text { No. }\end{array}$} & \multirow{2}{*}{ Uait } & \multirow{2}{*}{$\begin{array}{l}\text { Page } \\
\text { Number }\end{array}$} & \multirow{2}{*}{$\begin{array}{l}\text { Coder } \\
\text { Initial }\end{array}$} & Topical & \multicolumn{2}{|c|}{$\begin{array}{l}\text { Specifi } \\
\text { Em c Topic }\end{array}$} & \multirow{2}{*}{ Time Scope } \\
\hline$\# 1$ & *2 & \#3 & & & & & & Arca & & & \\
\hline & & & & & 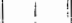 & & & & & & 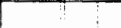 \\
\hline & & & & & & & & $i$ & & & i \\
\hline & & & & & & & & & & & $\|$ \\
\hline
\end{tabular}


The set of specific variables was designed to evaluate the information in each area. Therefore, varying depending on the purpose of each area. For example, area I was designed to look at the national origins and social backgrounds of characters; therefore, the variables of country, gender, occupation, age, and educational level were developed to gather the information for this area. On the other hand, area IV was designed to look at explicit information, the emphasis (surface or deep culture), and the historical dimension of readings, the variables of topical area, emphasis, and time thus were developed to gather this information. In the booklet, one list of categories was developed under each variable with definitions and each category was assigned a number for coding. They were used in coding tabulation sheets to gather the coding information. The definitions of these categories were designed to provide coding information through the booklet of the "distribution of the variables, and the definitions of their categories."

The following section will discuss the purposes and the designs of five major areas by linking them with research questions. This section will also illustrate the coders' coding process by giving coding examples for Area I and II. This area will also discuss two of the main problems I encountered during the coding procedure.

\section{Purpose and Design of Five Major Areas}

\section{Area I}

Area I, national origin and social backgrounds of characters in readings and 
dialogs, focused on reading and dialogue sections. It was designed to respond to research question I and II respectively. Question I dealt with the scope of cultures and sub-cultures addressed in the textbooks: "What was the scope of cultures and sub-cultures presented to better understand foreign cultures from a variety of perspectives?" Area I expands that question to ask: "What groups of people appear in the textbooks' dialogs and readings in terms of their national origins and social backgrounds?"

Area I was also designed to respond to question II. Question II deals with the representatives of individual cultural groups presented in the textbooks; "What subcultures are selected as representatives of Chinese and foreign cultures to achieve the goal of cross-cultural awareness and understanding stated by the Ministry of Education of Taiwan?" Area I expands that question to ask: "What groups of people appear in the textbooks' dialogs and readings in terms of their social backgrounds?"

Area I was designed to look at the characters in reading and dialog sections. The set of "identification variables" in this area were: character number, textbook number, unit number, page number, and coder's initial. As mentioned, in order to look at the national origins and the social backgrounds of the characters, a set of specific variables was developed to evaluate this information. These variables included: character's national origin, occupation, age, and educational level (see Chart 3). 


\section{Chart 3}

Area I. National Origin and Social Background (Reading and Dialog)

\begin{tabular}{|c|c|c|c|c|c|c|c|c|c|c|c|c|c|}
\hline Variables ---> & & IDEN & TIFICA & TION & & & ationa & \multicolumn{6}{|c|}{ Social Backgrounds } \\
\hline Character Name & $\begin{array}{l}\text { Character } \\
\text { Number }\end{array}$ & $\begin{array}{c}\text { Textbo } \\
\text { ok } \\
\text { Numbe } \\
\end{array}$ & $\begin{array}{c}\text { Unit } \\
\text { Numb } \\
\text { er }\end{array}$ & $\begin{array}{c}\text { Page } \\
\text { Number }\end{array}$ & $\begin{array}{l}\text { Coder } \\
\text { Initial }\end{array}$ & & ountry & & Gender & $\begin{array}{l}\text { Occup } \\
\text { ation }\end{array}$ & Age & $\begin{array}{l}\text { Educa- } \\
\text { tional it } \\
\text { Level }\end{array}$ & $\begin{array}{l}\text { Role } \\
\text { Type }\end{array}$ \\
\hline READING & & 1 & 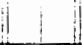 & $\|$ & & & & & & $i$ & & & \\
\hline No character & & 1 & 0 & $0: 0 \quad 1$ & $\mathrm{v}$ & 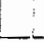 & 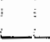 & & 1 & & & & \\
\hline Joe & $0: 0: 1$ & 1 & $0 ! 2:$ & $0: 104$ & $\mathrm{v}$ & & 3 & & 1 & $5: 0$ & 2 & 2 & 1 \\
\hline Mark & $0: 0: 2$ & 1 & $0: 2$ & $\begin{array}{l:ll}0 & 1 & 0 \\
\end{array}$ & $\mathrm{v}$ & 1: & $8:$ & 0 & 1 & 50 & 2 & 2 & 1 \\
\hline
\end{tabular}

Before I start to explain this specific example, let me explain the general procedure and some coding instructions that coders had to understand before coding this area. When coders code this area, they have to already understand the general coding instructions and coding instructions for Area I. For example, coders have to already understood the definition of characters. Characters are defined, in readings or dialogs, as those who actually appear in the illustrations and possess at least one of the following characteristics: (1) identified by name, (2) involved in dialogs, or (3) whose information is provided in the reading (see Appendix A, General Instructions). The coders also have to know that if they do not have sufficient information to code a given variable for a character; they have to leave that check space on the coding tabulation sheet blank for a while until they gather more information by going through the lessons in the textbooks. These instructions are provided in the "General coding instructions." 


\section{Example of Coding Process}

Now, let me explain the coding process by giving Joe's example. He was one of the characters who appeared in readings and dialogs of several lessons in Textbook I. Please refer to Chart 3, if necessary, when I exemplify Joe's case. The coding process began with the information of the identification section. First of all, because Joe was the first character coded, he was given the character identification code "001," and because Joe appeared in Textbook 1, lesson two, and page ten, the textbook number was given " 1 ," the unit number was coded as " 02 " and the page number was coded as "010." Finally coders entered the initials of their first names, in the sample was "v."

In the specific variable section, the coder had to first identify category "country" under the variable "national origin." Because Joe's nationality was not expressed directly in the reading content, his nationality was determined from the envelope address Joe wrote to his pen pal, Mark. After identifying Joe's nationality, Taiwan, the coder looked for the number of the country, Taiwan, in the Manuel of "distribution of variables and the definitions of their categories," and he coded Joe's nationality with Taiwan's identification number, "038." With the same process, the coder looked at the categories of gender, occupation, age, and education under the variable social background. First, the coder identified Joe's gender by his appearance in the illustration and gender pro-noun he was called in the reading. Thus, he was coded with the male identification code " 1 ." Next, the coder identified Joe's 
occupation as student because in a later lesson (lesson 4 ) the coder found that his occupation was explicitly expressed. Therefore, he was give a code number " 50 ," the identification code for student. Joe's age was not explicitly expressed in the reading. He was identified as teenager based on several context clues: his appearance in the illustration, he was called "boy" in the reading, and the activities he involved with his pen pal. Joe's educational level was identified from his occupation, his age, and his peers' educational levels.

Area II

Area II, conversation topics, problem-concerns, interests and activities of characters, focused on dialog sections of the textbooks. It was designed to respond to research questions I and II, and part of research question III. This area was designed to respond to research question I: " What is the scope of cultures and subcultures presented to better understand foreign cultures from a variety of perspectives?" More specifically, it was devised to answer its sub-question: "What appear to be the topics, problems and interests of the conversations and the activities that the characters carry on in the dialogs and readings?"

Question II deals with the sub-cultures selected as representatives of each individual culture presented in the textbooks: "What sub-cultures are selected as representative of Chinese culture and foreign cultures to achieve the goal of crossculture awareness and understanding stated by the Ministry of Education of Taiwan?" 
Area II expands that question to ask its sub-questions: (A) "What groups of people appear in the textbooks' dialogs and readings in terms of their national origins and social backgrounds that represent that culture and society?" and (B) "What appear to be the topics, problems and interests of the conversations and the activities which the characters carry on in the textbooks' dialogs and readings that represent that culture and society?"

In addition, Area II continues to explore the issues in research question III; "What types of conversational topics were discussed between Chinese and foreign characters? Chinese and Chinese characters? Foreign and foreign characters?"

Area II was designed to look at the dialogs among characters. The dialogs therefore were operated as recording units. According to Weber (1985), a recording unit is "the basic unit of text to be classified" (p. 22). The "identification variables" included the total dialog number, unit dialog number, textbook number, unit number, page number, and the coder's initial (see Chart 4). The specific area variables were: the nationalities of characters, conversation topics, problem-concerns, interests, and activities which the character performed. This set of specific variables was designed to look not only at the topics, problems and interests of the conversations, and the activities the characters performed in texts, but also the geographical settings where the interactions occurred. Several categories were assigned to each specific variable. For example, in order to identify conversation topics which occurred among characters from a specific country, coders chose one of ten categories listed under 
the variable of conversation topics: trivia, business, school, daily life, work related, sports, personal issues, ideas which included values, beliefs, philosophical and moral issues, and entertainment. (See Appendix A for complete information.)

\section{Chart 4}

\section{Area V. Manner of Presentation}

\begin{tabular}{|c|c|c|c|c|c|c|c|}
\hline \multicolumn{6}{|c|}{ IDENTIFICATION } & \multicolumn{2}{|c|}{ Manner } \\
\hline $\begin{array}{c}\text { Total } \\
\text { Questio } \\
n \\
\text { No. }\end{array}$ & $\begin{array}{l}\text { Unit } \\
\text { Ques } \\
\text { tion } \\
\text { No. }\end{array}$ & \begin{tabular}{|c|} 
Text \\
boo \\
$\mathbf{k}$ \\
No.
\end{tabular} & $\begin{array}{l}\text { Unit } \\
\text { No. }\end{array}$ & $\begin{array}{l}\text { Page } \\
\text { No. }\end{array}$ & $\mid \begin{array}{l}\text { Coder } \\
\text { Initial }\end{array}$ & uestion & Stance \\
\hline $\begin{array}{llll}0 & 0 & 1 \\
\end{array}$ & $\begin{array}{l:l}0 & 1 \\
\end{array}$ & 1 & $\begin{array}{lll}0 & 1 \\
\end{array}$ & $\begin{array}{llll}0 & 0 & 2 \\
\end{array}$ & $\mathrm{v}$ & 1 & 1 \\
\hline $010: 2$ & $0: 2$ & 1 & $\begin{array}{l:l}0 & 1 \\
\end{array}$ & $\begin{array}{ll:l}0 & 0 & 2 \\
\end{array}$ & $\mathrm{v}$ & 1 & 1 \\
\hline $0: 0: 3$ & $\begin{array}{llll}0 & 3 \\
\end{array}$ & 1 & 0,1 & $\begin{array}{ll:l}0 & 0 & 2 \\
\end{array}$ & $\mathrm{v}$ & 1 & 1 \\
\hline
\end{tabular}

There were two coding procedures for this area. In the first procedure, coders were asked to identify the variables of conversational topics, problems, interests, and activities by using a list of very specific categories developed by Hernandez, e.g., designing advertisements, and car problems, then added additional categories that could not be found in Hernandez' list but applied to our textbooks, like borrowing something, repairing a tape recorder, and bathing (see distribution of variables and the definitions of categories section in Appendix for complete information). However, since coders sometime came up with slightly different terms for additional categories, for example, coder $\mathrm{A}$ identified the conversational topic of Paul, Sara, and Judy in textbook I, lesson 9 as moving, but coder B identified it as 
helping neighbors, and coder $\mathrm{C}$ coded it as meeting neighbors. Therefore, the coders were asked to categorize these specific categories into a list of broader categories (see additional codes of area II in Appendix A). In this case, the broader category for this conversational topic was trivia (see sample on p. 55 for definitions.) The following illustrates the second procedure which we used to receive our findings.

Now, let me also use Joe's example in the situation where he interacted with Tony to explain the coding process. A sample of the distribution of conversational topics' categories (p. 54) and their definitions (p. 55) is provided. However, because the whole list of the definitions of the categories under the variables of problems, interests and activities is long and very similar to the definitions of conversational topic's categories, please see Appendix A for the complete information. The procedure of categorization of Joe and Tony's conversational topic, problems, interests, and activities was as following. After coders filled out the identification section using the same process as area I, coders started to identify the specific variables of this area (see Chart 4): (1) nationality, because coders already identified all the characters' national origins, coders only copied characters' identification codes of national origins from area I; (2) conversational topics, because Joe and Tony were making a schedule about their weekend, their conversational topic was categorized into daily life with the identification code "04"; (3) problem, because there was nothing either Joe and Tony appeared to be or stated as being worried about, they were categorized as "no problem" with the identification code "09"; (4) interests, 
because Joe and Tony were planning and showing interest in playing football during the weekend, both of their interests were categorized as sports with the identification code "04"; (5) activities, because Joe and Tony were making a schedule, their activities were categorized as daily life with the identification code "02." All the specific categories we have identified in the first procedure then were categorized into the broader category of "trivia" in the second procedure: these included fixing friends' tape recorder, moving to Taipei, inviting friends for dinner, not having electricity, spring vacation, too busy to eat, controling buget, asking friend to deliever newspapers, being sick, transportation management. The concept of "trivia" as defined here was drawn directly from Hernandez (1986). This is a default category in that it is designed to be a broad cover term for variety of topics which are less critical than the other categories.

Categorization of Conversational Topics (After Hernandez, 1986)

1. Trivial: Topics that are not school related, about business, daily life, work related, sports, personal issues, ideas, and entertainment.

2. Business: Topics which are about business

3. School: Topics on school related matters.

4. Daily Life: Topics related to daily routines (ie. eating, planning, bathing, grocery shopping, house cleaning, family life, etc.)

5. Work Related: Topics related to employment and to the workplace.

6. Sports: Topics related to any kind of sport issues.

7. Personal Issues: Topics related to family relationship or friendship issues.

8. Ideas: values, beliefs, philosophical or moral issues.

10.Entertainment: activities related to party, music, dance, travel, etc.

Area III

Area III, interpersonal relations of the interlocutors and the context of 
interaction in readings and dialogs responds to research question III: "What is the nature of the interaction between characters with respect to their cultural, gender and inter-personal relationships, conversational topics, and geographical setting in the textbooks?" Interlocutors in this area refers to the characters who participated in interactions. More specifically, this area was designed to respond to the following: (A) when interactions occurred, did they occur most often between Chinese and foreign characters, or between Chinese and Chinese characters, or foreign and foreign characters; (B) what type of interpersonal relationships occurred the most frequently between Taiwanese characters and foreign characters, friends, family members or others; (E) where did the interactions occur?

In Area III, the interactions between each pair of interlocutors were assigned as recording units. The "identification variables" included the total interaction number, textbook number, unit number, page number and the coder's initial. The specific area variables were: characters' nationalities, cross-culture, inter-gender, types of inter-personal relationships, country, area of the country, and setting in which interactions occurred. As in the other areas, several categories were assigned to each specific variable. For example, in order to identify cross-culture relationships between each pair of interlocutors, coders chose one of the three categories under the variable of cross-culture. They were: Chinese-foreign, Chinese-Chinese, and foreignforeign. In addition, in order to identify the type of relationship between the Chinese and foreign characters, coders chose one of the ten categories under the variable of 
type inter-personal relationships. These included: family members, friends, playmates, schoolmates, work mates, incidental, student-teacher, unspecified, and others. (See Appendix A for complete information.)

Area IV

Area IV, explicit information and historical dimension of readings, was designed to look at the section of readings, and to respond to research question IV and part of research question V. In addition to exploring "the level(s) of culture that junior high English textbooks deal with," as addressed in the research question IV, this area was also designed to identify the approach the textbooks apply when presenting cultural information, the issue addressed in research question V. More specifically, it attempted to answer the following questions addressed by research question $\mathrm{V}(\mathrm{A})$ : Do the texts portray culture using a synchronic approach, i.e., is the cultural material included described in the present, and fixed in a given point in time? Do the texts portray culture using a diachronic approach, i.e., is the cultural material included described historically, looking at developments of the culture?

In area IV, the reading section of the texts was used as the recording unit. The "identification variables" included the cumulative reading number, textbook number, unit number, page number and the coder's initial. Specific area variables were: topical area, emphasis on the level(s) of the culture, specific topical area, and time that was the perspective of historical dimension the text applied. These specific 
variables were designed to look at the level(s) of culture the texts deal with, as well as the approach the textbooks apply in readings. A set of categories were assigned to each specific variable. For example, in order to identify emphasis of the level of cultural elements in readings, coders chose one out of three listed under the variable of emphasis: surface culture, deep culture, and the link of surface and deep cultures. (See Appendix A for complete information.)

A statistical problem I had when I tried to identify the time variable on the reading topics which were identified as dealing with "character description," was to identify whether the reading provided characters' background information or not. This problem occurred because sometimes there were multiple characters in one reading without consistent information on characters' background, and sometimes information was presented on some but not all characters. To resolve this issue, the dominant character's time dimension was taken following procedures explained latter in this section. What follows first is an explanation of how the category of character description was identified.

The category of character description was identified when a reading introduced and described a character by giving basic information about him or her. The variable of time (see Chart 5) looked at whether the background information (past life) of the character was provided within this category of character description. The recording unit was based on each reading; however, sometimes one reading had more than one character, yet, the characters' background information was presented 
inconsistently.

\section{Chart 5}

Area IV. Explicit Information and Historical Dimension (Original Coding Sheet)

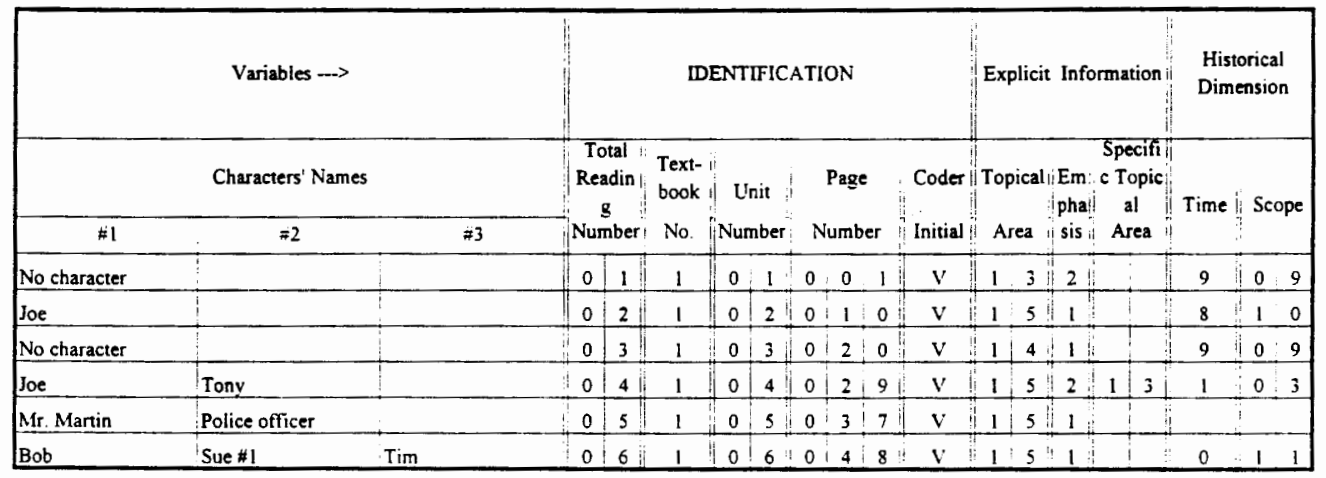

The way I handled this problem was to draw out all the characters from those readings which were coded as character description and code these characters separately on a different coding sheet, called "character description sheet." (see Chart 6) Therefore, in addition to the "original coding sheet" for those readings' topical areas were identified as variables other than "character description," I had a "character description sheet," (see Chart 6). When coders identified a reading's topical area as character description under the variable of "topical area," (see Chart 5) coders stopped the coding procedure on the original coding sheet, and switched the coding process to the character description sheet (see Chart 6). First of all, coders numbered the characters in the order they appeared in the readings then continued the usual coding process. However, coders had to give the same number to the same character. After coders finished coding the time variable of all the characters in the 
character description sheet, I then took the dominant character's time variable and transferred the dominant code from the character description sheet to the original sheet.

Let me exemplify this process. The reading of lesson 6 was identified as character description. In the reading, Bob, Tim, and Sue \#1 were the characters (there was another character with the same name who appeared in a later lesson and was numbered as Sue \#2). In the reading, neither Bob's or Tim's background information (see Figure 3) was offered through readings; however, the background information on Sue \#1 was offered. Therefore, by the coding process developed, Bob and Tim were identified respectively as having no background information with the identification code "0," and Sue \#1 was identified as having background information and was given the identification code " 8 " in the character description sheet. Then, according to the coding procedure, because the dominant code was " 0, " the code which was chosen to transfer back to the original coding sheet under the time variable in this reading was "0." However, I still had a problem. I could not take the dominant code when there were two characters in one reading, for example, and one of them had background information but the other did not. Fortunately, I had only one reading like this situation, Mr. Martin and the police officer, therefore, my decision was to code a zero in time dimension on this when percentages were calculated. 


\section{Chart 6}

Area IV. Explicit Information and Historical Dimension (Character Description

Sheet)

\begin{tabular}{|c|c|c|c|c|c|c|c|c|c|c|c|c|c|c|c|}
\hline \multirow{2}{*}{$\begin{array}{c}\text { Variables -..-> } \\
\text { Character's Name }\end{array}$} & \multicolumn{9}{|c|}{ IDENTIFICATION } & \multicolumn{3}{|c|}{$\begin{array}{c}\text { Explicit } \\
\text { Information }\end{array}$} & \multicolumn{3}{|c|}{$\begin{array}{l}\text { Historical } \\
\text { Dimension }\end{array}$} \\
\hline & $\begin{array}{r}\text { To } \\
\text { Cha } \\
\text { e } \\
\text { Num }\end{array}$ & $\begin{array}{l}\text { tal } \\
\text { ract } \\
\text { nber }\end{array}$ & $\begin{array}{c}\text { Text- } \\
\text { book } \\
\text { No. }\end{array}$ & $\begin{array}{l}\text { Un } \\
\text { Num }\end{array}$ & & & $\begin{array}{l}\text { Page } \\
\text { Jumb }\end{array}$ & & $\begin{array}{l}\text { Coder } \\
\text { Initial }\end{array}$ & $\begin{array}{l}\text { har } \\
\text { escr }\end{array}$ & acte & $\begin{array}{l}\text { Em } \\
\mathrm{ph} \\
\mathrm{a}- \\
\mathrm{sis}\end{array}$ & Time & Sc & ope \\
\hline Joe & 0 & 1 & 1 & 0 & 2 & 0 & 1 & 0 & $\mathbf{v}$ & 1 & 5 & 1 & 8 & 1 & 0 \\
\hline Mr. Martin & 0 & 3 & 1 & 0 & 5 & 0 & 3 & 7 & $\mathrm{v}$ & 1 & 5 & 1 & 8 & 0 & 8 \\
\hline Police officer & 0 & 4 & 1 & 0 & 5 & 0 & 3 & 7 & $\mathrm{v}$ & 1 & 5 & 1 & 0 & 1 & 2 \\
\hline Bob & 0 & 5 & 1 & 0 & 6 & 0 & 4 & 8 & $\mathrm{v}$ & 1 & 5 & 1 & 0 & 1 & 2 \\
\hline Sue \#1 & 0 & 6 & 1 & 0 & 6 & 0 & 4 & 8 & $\mathrm{v}$ & 1 & 5 & 1 & 0 & 1 & 2 \\
\hline Tim & 0 & $7 \|$ & 1 & 0 & 6 & 0 & 4 & 8 & $\mathrm{v}$ & 1 & 5 & 1 & 0 & 1 & 2 \\
\hline
\end{tabular}

Area $\mathrm{V}$

Area $\mathrm{V}$, manner of presentation of post-reading questions, explored the questions posed after readings in the textbook, and was designed to respond to research question $V$. It was meant to seek whether the questions emphasize mnemonic processes or heuristic understanding. More specifically, it was designed to look at the following two questions addressed by research questions (B): (1) Are most post-reading questions of a factual nature or a reflective nature, requiring critical analysis?; (2) Do most post-reading questions call for mere recall, cross-cultural comparisons, or inductive reasoning and synthesis?

In area $\mathrm{V}$, the post-reading questions were used as recording units. The "identification variables" included the total question number, unit question number, 
textbook number, unit number, page number and the coder's initial. The specific area variables were type, the type of question, and stance, the way the questions were presented. A set of categories was assigned to each specific variable. For example, under "identify the type of information," a question required coders to choose one category out of three listed under the variable of emphasis: factual nature, reflective nature, and vocabulary or linguistic items. (See Chart 7 sample or Appendix A for complete information.)

\section{Modification of Hernandez's Coding System}

In attempting to use Hernandez's coding system, the researcher encountered a range of difficulties because of the following important differences between Hernandez' and this study:

1. Different organization of the textbooks.

2. Different characters and context the textbooks depicted in terms of their sociocultural backgrounds:

Hernandez: American society; people who live in the U.S.

This study: Chinese society in Taiwan; people who live in Taiwan.

3. The different measures of demographic characteristics of the characters:

Hernandez: a comparison with the American Census.

This study: the frequency of the individual groups out of the total number of characters. 
4. The focus of the socio-cultural portrayal in terms of the appearance of the characters:

Hernandez: Examining at the correspondence of the U.S. socio-cultural portrayal with U.S. census data.

This study: Examining at the correspondence of the goal of cross-culture understanding proposed by the government, with the socio-cultural portrayal of Chinese and foreign characters in the textbooks.

Modifications therefore were made to Hernandez's system in order to use it for this study. The modifications were to ensure the likelihood of finding codable, distinguishable information, and to account for Taiwanese data which differs from the type of information Hernandez gathered. In addition to the modifications made to his system, some additional focuses were added due to my personal interests. The following summarizes the modifications which have been made to the coding system. Among the modifications, the modification in Area IV was the most tedious, timeconsuming, and yet, important process. In order to discover the level of cultures and the way the characters were portrayed, I designed two sets of coding sheets for Area IV to overcome limitations due to the conflict between Hernandez's coding system and the way this set of textbooks is organized. I also added the category of "unspecified" under most variables in order to avoid forced choices which the coders arbitrarily coded. The strength of this choice allows a realistic characterization; however, the weakness is that some data which was categorized as "unspecified" will 
not be able to be used. My choices have been consistent with the methodology Hernandez followed. Modifications are summarized in the following list. Specific modifications, and the reasons and the process taken to make them, are provided in Appendix B.

(1) Combined categories; added variables; added categories; deleted variables; deleted categories.

(2) Characters: changed the definition of characters; made assumption of characters' nationalities by their appearance; numerous characters have the same name

(3) Added items to be evaluated: added reading sections to Area III to be evaluated; coded every post-reading question in Area V; counted the exact frequency of type of post-reading questions of Area $\mathrm{V}$.

(4) Separated Area I.

(5) Combined Areas IV and V.

(6) Changed coding units of Areas III and V; changed total dialog number to total interaction number; changed total reading number to total question numbers, respectively. (See Appendix B for the list of modifications.)

Coding Procedures

\section{$\underline{\text { Co-Coders }}$}

In addition to myself as the main coder of this study, two co-coders were 
chosen to evaluate eighty five percent of the data analyzed by the researcher. There were two reasons for having three coders. First, the researcher tried to reach a higher reliability for this study. Second, because the amount of the data chosen to be analyzed was not as large as the researcher would like to have, the extra co-coder's analysis added to the quantity of data collected for this study.

One of the coders was a female American who was working on her master's degree in Applied Linguistics. The second coder was a male Chinese working on his master's degree in American Studies. These two coders were selected because they were interested in my study, and because we had different socio-cultural backgrounds in terms of gender, age, culture, and specialization. By having the combination of the different characteristics of coders, I hoped to reduce the effect of coders' bias of interpretations due to their socio-cultural backgrounds. In addition, the researcher was interested in seeing the differences in coding results between the coders in terms of their socio-cultural backgrounds. These differences will be interesting to explore further in future study. Choosing co-coders took a period of three weeks.

\section{Pilot Form of Coding System}

\section{Developed and Modified Coding System to Meet the Purposes of the Study}

In this stage, a pilot form of the coding system was developed. The pilot was based on Hernandez' study and modified to respond to the research questions of this 
study. The parts which were modified in the coding system include recording units, variables, categories, definitions of categories, coding instructions, and coding sheets. The coding sheets were initially done manually by the researcher then entered into a computer using Microsoft Excel. Sample coding sheets are provided in Appendix C .

This was the stage where I worked on a modification of Hernandez' methodology to adjust to my needs. I considered whether the design of Hernandez' coding system could answer all my questions, to what degree modifications should be made, and how they should be done in order to get my research questions answered. This stage took a period of eight weeks.

\section{Initial Trial of Coding System on Sample Text by Researcher}

I first tested the pilot coding system on a small, randomly chosen sample from the texts to be researched. The results of the initial trial on these sample texts were used to make further modifications to the coding system. This stage took a period of three and a half weeks.

\section{Revised Coding System}

Several modifications were made to the coding sheets based on the results of the initial trial of the sample text. The modifications included: adding categories and definitions; modifying coding instructions to fit the organization of this set of textbooks; and re-formatting coding sheets in several areas due to the changes of the coding instructions. This stage of modification took a period of six weeks. 


\section{Initial Trial by Co-coders}

\section{Initial Trial of Coding System on Sample of Text by Co-coders}

After the initial trial of the coding system, a training session was held by the researcher and the two co-coders. The use of the coding instructions, coding sheets, and distribution of variables and definitions of categories was explained and demonstrated on a sample text by the researcher during the coders first meeting. The co-coders also tried coding a sample text and raised questions to the researcher during the meeting. After the meeting, coders coded each area on a small sample text independently. The results were collected by the researcher and discussed in the following meeting. The same process was repeated until a similar frame of reference had been established. There were eight meetings in total during the whole coding process, and this training session itself took a period of three weeks.

\section{Revised Coding System}

From the process and coding results of the training session, I took questions, comments and suggestions from co-coders to re-evaluate and improve the coding system. This revising process started during the training session and it took a period of six weeks before starting the final data collection on the texts chosen for this study. 


\section{Final Data Collection}

Researcher and Co-coders Coded All the Texts Chosen for this Study

This was the stage where I coded all the texts chosen for this study and the co-coders coded an average of eighty five percent of the texts. In the beginning of the session, each coder received a copy of the texts, a booklet with instructions, a material identification code sheet, a code booklet (distribution of variables and categories), and coding tabulation sheets. Each coder coded the materials independently. Coders completed one area before they continued to the next area. Once co-coders completed coding each area in their coding tabulation sheets, the tabulation sheets were collected by me.

In this area, the five areas of data I collected were entered in fifteen coding tabulation sheets and thirteen coding tabulation sheets for each of the co-coders. For area I, each co-coder analyzed 43 characters and I analyzed 51 characters across the variables of this area. For area II, each co-coder identified 68 interactions and I identified 75 interactions between characters. For area III, each co-coder coded 17 dialogs and I coded 23 dialogs. For area IV, each co-coder classified 18 readings and I classified 25 readings. For area $\mathrm{V}$, each co-coder evaluated 172 questions and I evaluated 244 post-reading questions. The following chart illustrates the distribution of the units in each area coded by myself and the co-coders. 
DISTRIBUTION OF UNITS CODED BY RESEARCHER AND CO-CODERS

\section{Researcher Co-coders}

Area/Unit

$\begin{array}{lll}\text { Area I/Character } & 51 & 43\end{array}$

Area II/Interaction $\quad 75 \quad 68$

$\begin{array}{lll}\text { Area III/Dialog } & 23 & 17\end{array}$

Area IV/Reading $\quad 25 \quad 18$

\begin{tabular}{lll} 
Area V/Question & 244 & 172 \\
\hline
\end{tabular}

\section{Revised Coding Instructions}

Although coders had done the initial trial on sample texts, questions and problems still occurred when they started working on the larger body of texts because there were situations which did not occur in the sample texts they had coded earlier. Therefore, co-coders were allowed to clear up their questions and problems about the coding instructions with me during the process of coding. This also allowed me, as a researcher, to make clearer instructions. Area III and Area IV were examples where I made major revisions by taking the comments, questions and suggestions from the cocoders and from myself as well. Although the research goal of the coding process was to have cleared up any questions during our trial run, this appeared to be unrealistic in my case. Some situations which did not emerge during the trial period occurred in coding the larger body of texts. Therefore, additional decisions on instructions had to be made to meet the needs of the study. I made this decision because I thought that it was important to have co-coders understand the instructions and to make additional changes to meet the new needs of the study so that co-coders 
could consistently collect the data and valuable information would not be lost.

The last two stages took a period of five months to complete. These were the stages where I encountered minor, major, less difficult, and very difficult coding technical problems because of the modifications that had to be made. This was also the period where I invested the most time because I was trying to discover a way to bridge the theories I used to develop the study with the raw materials I planned to analyze. Testing, coding, and revising the coding system was repeated several times for each section.

Input Coding Data into Computer

The collected data for each area was input into databases by the researcher and co-coders. The entire process of coding took a period of seven months.

\section{Statistical Procedures}

The statistical procedures for this study included finding inter-coder reliability; discovering the consensus of the data collected among three coders; and analyzing the data collected. The index of inter-coder reliability used to measure the reliability of the study and the statistics used to analyze the collected data were based on Hernandez's statistics procedures. In addition, finding consensus among the data collected by the three coders was based on rules established by the researcher. These procedures were conducted by using the software package of Statistical Package for the Social Science (SPSS) (1995), and were processed in the statistics lab of Portland 
State University.

\section{Inter-coder Reliability}

According to Hernandez, "reliability is a function of the agreement achieved among coders regarding the assignment of units to categories" (p. 104). There are different ways to test reliability in Content Analysis. Inter-coder reliability was used as a measure in this study because the disagreement among coders reflected both "intra-observer inconsistencies and inter-observer differences in the way recording instructions are interpreted" (Hernandez 1986, p. 103). For categorical data, Cohen's Kappa is the most frequently used index to measure inter-coder reliability. According to Krammer, Cohen's Kappa "is a measure of association used to describe and to test the degree of agreement (reliability or precision) in classification" (1982, p. 352).

The function of Cohen's Kappa is to look at instances when different coders agree and then subtract from that the probable number of instances when agreement would be expected to occur due to chance. The remaining number shows the number of times coders probably actually agreed. In other words, Cohen's Kappa doesn't simply look at the percentage the coders agree upon, it throws out the agreements that could be due to chance. Therefore, Cohen's Kappa is considered a rather conservative measure.

In this study, Cohen's Kappa was used to analyze agreement among three coders. However, according to Bob Fountain, director of Portland State University Statistics consulting Laboratory, although Cohen's Kappa can be used for more than 
two simultaneous coders, SPSS does not contain a feature that allows users to make this calculation. Also, the list of responses must be the same for each pair of coders in order for SPSS to calculate Cohen's Kappa, even in the two-coder case. For this study's data set, the lists of responses were not always the same for each pair of coders, so many of the two-way Cohen's Kappa values had to be hand-calculated. The three-way Kappa would have required a very time-consuming hand calculation. For this reason, the measure of reliability for the three coders was calculated by averaging the three pairwise Cohen's Kappas. This is the type of reliability measure that is often used in the case of many coders, as the multi-way Cohen's Kappa is not found as a feature in any mainstream statistical software package. According to the report of the inter-coder reliability of this study measured by Cohen's Kappa, the agreement between coder $\mathrm{A}$ and myself was $93 \%$; between coder B and myself was $91 \%$; and between coder $\mathrm{A}$ and coder $\mathrm{B}$ was $90 \%$. The mean of the agreement of three coders was $92 \%$.

\section{Consensus of Coders}

The consensus of the data collected among three coders was evaluated according to the rules I established. There were two rules used as guide lines: (1) If either two out of three, or all three, coders agree on one answer, then that answer is taken; (2) If none of the coders agree, then the researcher's answer is taken. This process was done by using the "If...then" statement which was put in the SPSS software. The number of choice depends on the number of categories under each 
variable. For example, the gender variable has two choices of categories: male and female. The education level variable has five choices of categories: college, high or junior high school, less than high/junior high, others, and unspecified.

\section{Data Analysis}

In the process of data analysis, two types of statistical procedures were used; descriptive statistics based on one-way frequency distributions, and cross tabulations based on two-way frequency distribution.

\section{Descriptive Statistics Based on One-way Frequency Distributions}

These statistics were used to observe the basic characteristics of each single variable in terms of its occurrence, for example, how often the variable of Chinese characters appears in the textbooks, or how many times the characters appearing in the textbooks possessed a college degree.

\section{Cross tabulations}

Cross tabulations were used to look at the responses of certain pairs of variables and the responses are shown in a pair-wise frequency table (see p.31). It is a two-way table: the row represents one variable and the column represents the second variable. Into each cell in the table goes a frequency, or the number of the times that particular pair variable responses came up. Cross tabulations were used to further explore the distribution of specified portrayal categories between pair variables. This helped to look at the type of relationships between pair variables in terms of their 
specified portrayal categories. As illustrated in Table A, a two-way frequency table on the relationships between characters' nationalities and genders was broken down in rows that represent the variable of nationalities, and columns that represent the variable of genders. For example, in order to see the frequency of the female characters presented as American characters, one would look for the cell determined by the categories of female which was listed under the variable of topics represented by column, and the category of American, which was listed under the variable of nationality represented by row.

\section{Table A}

\begin{tabular}{|l|l|l|}
\hline & Chinese & American \\
\hline Male & 55.6 & 58.3 \\
\hline Female & 44.4 & 41.7 \\
\hline
\end{tabular}

\section{Validity}

"A measure is valid if it measures what it is intended to measure" (Johnson, 1992). In this study, the coding system was the measure and the research questions were what was to be measured. The coding system was designed to evaluate the cultural elements in five areas. The five areas were developed from the research questions. Therefore, the coding system was designed to measure the research questions. The detailed description about how the five areas were designed and how 
they measured the research questions were provided in the section of "purposes and designs of each area" (Chapter III, pp. 9-18).

In addition to looking at validity from the aspects of how the coding system was designed, and how the coding system was designed to respond to the research questions of this study, validity was approached from three angles: semantic validity, sampling validity, and construct validity. According to Krippendorf (1980), semantic validity estimates the degree of the sensitivity of the method to the symbolic meanings that are relevant within a context. Hernandez' study approached semantic validity by keeping the semantics of the data languages, the categories and their definitions, close to the source and the context from the textbooks analyzed. This study adopted $95 \%$ of the categories and the definitions of the categories from the model study. The rest of the $5 \%$ of the categories and definitions emerged from the analysis of the textbooks the researcher made instead of imposing them from external sources. For example, the category of the Chinese characters was created and defined by the researcher because there was no such category in the model study, but they appeared throughout the textbooks of this study.

According to L. Frey (1992), in order to achieve a high level of sampling validity, it is important to strive to select a representative sample--that is, to select a sample of texts that is fairly representative of the universe of relevant texts. In my study, however, textbooks volume 5 and 6 were chosen not because they were considered representative of the universe of the texts but because they were 
specifically designed to teach cultural information, and this meets the purpose of this research. In addition, one lesson of textbook volume 3 was randomly chosen for evaluation because I was interested in whether the textbook still transmitted cultural information when it was not attempting to do so.

As to construct validity, the coding system was used successfully in Hernandez's dissertation. According to Hernandez, the overall model adopted in his study has been successfully employed by Anderson (1978) and De Meo (1980) in their foreign language textbook analyses. The analytical construct developed for the evaluation and intended inferences has also been used by Sussman (1945), Berelson (1946), Defleur (1964), Rinaldy (1980) and the Royal Commission of the Press (1949). Thus, the system used for this thesis does possess construct validity.

\section{Limitation of the System}

\section{Unspecified Category}

In order to avoid forced choices that the coders arbitrarily coded, the category of unspecified was also used. Therefore, the limitation is that sometimes as much as $34 \%$ of the data was unspecified in a particular dimension. In that case, $34 \%$ of the data to be coded was lost. However, the strength of this choice allows a realistic characterization of data because this would avoid forced choices. My choices have been consistent with the methdology Hernandez followed. 
Time Issue

The detailed and time consuming coding system including adjustment of Hernandez' coding system is another limitation of this study. The investment of time and the approach of coding process could vary in terms of researchers' styles of personality and research management. However, the strength of this limitation is that because this is such a detailed coding process, the researcher is allowed to get into the textbooks characters' world, bring out an in-depth depiction of each character, and draw a pattern of their presentation from a broad scope.

\section{Summary}

This chapter has presented the design of the study including the description of the objects, the coding instrument used for data analysis, the coding system developed through Hernandez' study, the modifications made to adjust to the needs of this study, the coding procedure taken to collect the data, the statistical procedure used in analyzing the data collected, and the research questions of the study. The following chapter presents the description and analysis of the data. 


\section{CHAPTER IV \\ THE ANALYSIS OF THE DATA}

\section{Introduction}

This chapter presents the results from the analysis of the data collected. The results are organized according to the order of research questions. This chapter is divided into five sections, with the first looking at the results of the variety of cultures and sub-cultures presented in terms of the characters' national backgrounds and the conversational topics, problems, interests and activities the characters were involved in. The next section presents the results of the analysis of the types of sub-cultures selected to represent Chinese culture and foreign cultures in terms of the characters' socio-cultural backgrounds, and the conversational topics, problems, interests, and activities each individual cultural group favored. The third section presents the type of interaction exchanged between characters in terms of their interpersonal relationships, as well as the types of conversational topics the characters discussed. The fourth section present the level(s) of cultures the textbooks dealt with. The final section presents the textbook's manner of the presentation of socio-cultural information. 


\section{Section I}

Characters' National Origins, Social Backgrounds, Conversational Topics, Problems, Interests, and Activities

This and the following sections present the results of the analysis of the national origins and social backgrounds of the 51 characters as well as the topics, problems, and interests that appeared in their conversations, and the activities that they carried on throughout the readings and dialogues of 25 lessons. Three types of frequency are used in the following tables: absolute frequency is used to show the absolute number of occurrences of each category; relative frequency is to used to show the proportion of the occurrence of each category; adjusted frequency is used when the variable is unspecified, that is, when it is not be able to be classified into any of the categories. In that case, the relative frequency is adjusted by looking only at the proportion of each specified category. For example, when I looked at the distribution of characters' national origins (see Table 2), $17.5 \%$ characters can not be specified. In order to observe the distribution of Chinese and American characters within the Chinese and American population, the occurrences of Chinese and American characters were calculated without looking at the occurence of the characters whose nationalities could not be specified. 


\section{Characters' National Origins and Social Backgrounds}

\section{Distribution of Characters by Textbooks}

As indicated in Table 1, a total of 51 characters were coded through three sets of textbooks. Textbook 1 had 30 characters, a mean of $58.8 \%$ of the total characters; textbook 2 had 15 characters, a mean of $29.4 \%$ of the total characters; and textbook 3 had 6 characters, a mean of $11.7 \%$ of the total characters.

\begin{tabular}{lcc}
\hline \hline \multicolumn{2}{c}{ Table 1 } \\
& DISTRIBUTION OF CHARACTERS BY TEXTBOOK \\
\hline \multicolumn{3}{c}{ Absolute Freq. } \\
Textbook No. & & \\
& & \\
Textbook 1 & 30 & 58.8 \\
Textbook 2 & 15 & 29.4 \\
Textbook 3 & 6 & 11.7 \\
\hline Total & 51 & 100.0 \\
\hline \hline
\end{tabular}

\section{Distribution of All Characters by National Origin}

The distribution of the national origins of characters using the categories of the Europa World Year Book 1994, shows that only two national origins out of 192 nations listed in the Year Book were presented. The textbooks presented a larger percentage of Chinese characters, some percentage of American characters and some of the characters' national origins were unspecifiable. The national origin of the characters who were identified, as Table 2 presents, includes about $69.2 \%$ Chinese from Taiwan and 30.8\% American. As mentioned in the list of modifications made 
to Hernandez' study in Appendix B, because the textbooks were written for learners in Taiwan, characters were assumed to be Chinese when the characters had Asian appearance but no other explicit information was given about their national origin. This situation happened for two of the characters which have been coded. As for Chinese characters from Taiwan, they are specified by the illustration and/or the context of the readings and dialogs; for example, when the character appeared in a junior high school uniform, or expressed that he or she worked in a supermarket in Taipei. This has been consistent with the methodology Hernandez followed. In his study, he defined the setting as U.S. when there was no explicit reference given.

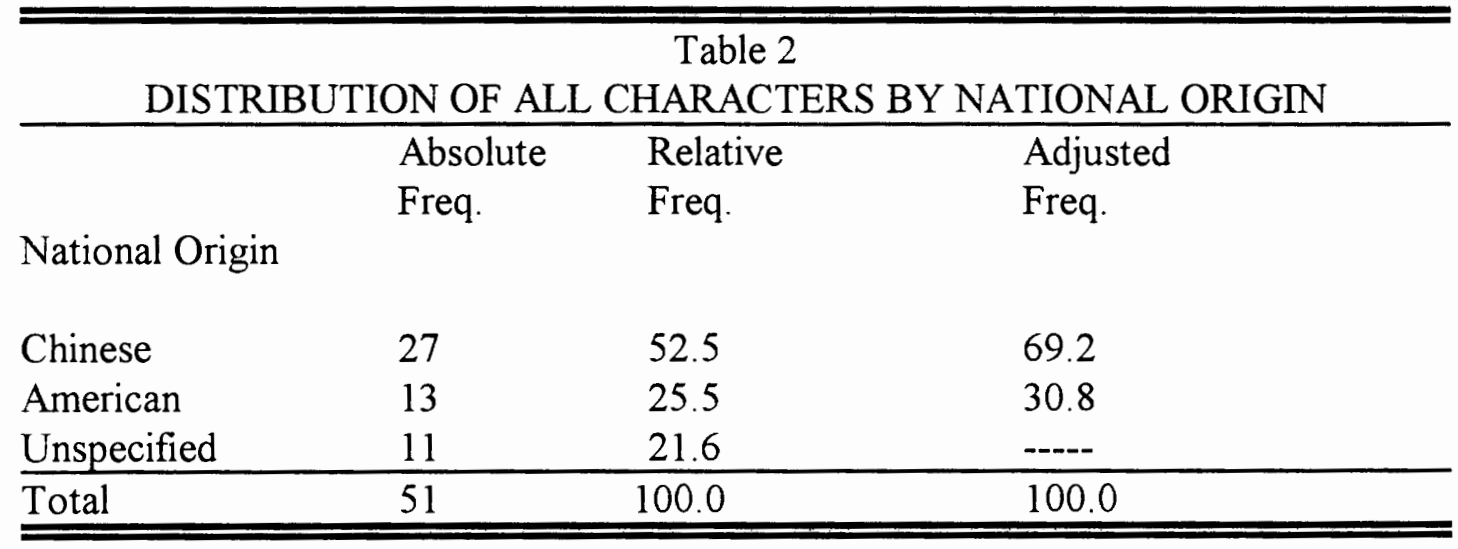

\section{Distribution of All Characters by Gender}

The overall representation of male characters was higher than female characters as indicated in Table 3, with males accounting for $56.9 \%$ of all characters. 


\section{Table 3}

DISTRIBUTION OF ALL CHARACTERS BY GENDER

\begin{tabular}{llll}
\hline & $\begin{array}{l}\text { Absolute } \\
\text { Freq. }\end{array}$ & $\begin{array}{l}\text { Relative } \\
\text { Freq. }\end{array}$ & $\begin{array}{l}\text { Adjusted } \\
\text { Freq. }\end{array}$ \\
Gender & & & \\
Male & 29 & 56.9 & 56.9 \\
Female & 22 & 43.1 & 43.1 \\
\hline Total & 51 & 100.0 & 100.0 \\
\hline \hline
\end{tabular}

Distribution of All Characters by Occupation

As indicated in Table 4, there were 13 different kinds of occupations

represented in the textbooks, with most characters being students. The representation and the frequency of occurrence indicated by the numbers in parenthesis are shown in the order of presentation in the texts following: student (55.0\%), businessman ( $12.5 \%)$, musician, cartoonist / film maker (5.0\% each), and cashier, clerk, police officer, president/ executive, writer, housewife, fisherman, owner of company/ store $(2.5 \%$ each $)$. 


$\begin{array}{lll}\text { Absolute } & \text { Relative } & \text { Adjusted } \\ \text { Freq. } & \text { Freq. } & \text { Freq. }\end{array}$

Occupation

\begin{tabular}{lrrr} 
Student & 22 & 43.1 & 55.0 \\
Businessman & 5 & 9.8 & 12.5 \\
Cartoonist & 2 & 3.9 & 5.0 \\
Musician & 2 & 3.9 & 5.0 \\
Cashier & 1 & 2.0 & 2.5 \\
Clerk & 1 & 2.0 & 2.5 \\
Police Officer & 1 & 2.0 & 2.5 \\
President/Executive & 1 & 2.0 & 2.5 \\
Writer & 1 & 2.0 & 2.5 \\
House Wife & 1 & 2.0 & 2.5 \\
Fisherman & 1 & 2.0 & 2.5 \\
Co./store owner & 1 & 2.0 & 2.5 \\
Unspecified & 12 & 23.5 & $-\cdots$ \\
\hline Total & 51 & 100.0 & 100.0 \\
\hline \hline
\end{tabular}

Distribution of All Characters by Age

Table 5 presents the results of the analysis of the age distribution of overall characters. The age group distribution of the characters suggests an emphasis on young adults and middle age, with $56.9 \%$ of the characters between ages 19 and 59 years. About $33.3 \%$ were teenagers between the ages of 13 and 18 , and only $5.9 \%$ of the characters were infants/children between the age of 0 to 12 . People 60 and over, and descriptions of people who had died, were the least represented, with only $2.0 \%$ each. 


\begin{tabular}{lll}
\hline & Absolute & Relative \\
& Freq. & Freq. \\
Age & & \\
& 1 & 2.0 \\
0 & 3 & 5.9 \\
$0-12$ & 17 & 33.3 \\
$13-18$ & 29 & 56.8 \\
$19-59$ & 1 & 2.0 \\
$60+$ & 51 & 100.0 \\
\hline Total & & \\
\hline \hline
\end{tabular}

\section{Distribution of All Characters by Educational Level}

Table 6 shows the emphasis on high school and junior high school educational levels. About $64.1 \%$ of the characters' educational levels were identified as high school or junior high school, $33.3 \%$ of the characters were college level, and about $2.6 \%$ were less than junior high or high school level.

\section{Table 6}

DISTRIBUTION OF ALL CHARACTERS BY EDUCATIONAL LEVEL

$\begin{array}{lll}\text { Absolute } & \text { Relative } & \text { Adjusted } \\ \text { Freq. } & \text { Freq. } & \text { Freq. }\end{array}$

Education

\begin{tabular}{lrrr} 
College & 13 & 25.5 & 33.3 \\
Junior/high school & 25 & 49.0 & 64.1 \\
Less than Junior/high & 1 & 2.0 & 2.6 \\
Unspecified & 12 & 23.5 & ---- \\
\hline Total & 51 & 100.0 & 100.0 \\
\hline \hline
\end{tabular}




\section{Distribution of All Characters by Role Type}

The last variable analyzed in this area was the role type of the characters. As Table 15 shows, all the characters were classified as active role types, ie., all the individuals are shown using physical or mental power to change or cause action. None of them are shown watching, waiting or being idle; they are all presented as being involved in activities.

\section{Table 7}

DISTRIBUTION OF ALL CHARACTERS BY ROLE TYPE

\begin{tabular}{lll}
\hline & Absoulte & Relative \\
& Freq. & Freq. \\
Role Type & & \\
& 51 & 100.0 \\
Active & 0 & 0.0 \\
Passive & 51 & 100.0 \\
\hline Total & & \\
\hline \hline
\end{tabular}

\section{Summary of the Characteristics of National Origin and Social Background}

The textbooks presented only two type of characters in terms of their national origins, Chinese being the native characters, and American characters representing foreign characters. The Chinese characters comprised $69.2 \%$ of all characters, compared with the American characters comprising 30.8\%.

\section{Topics, Problems, and Interests of the Conversations and the Activities of All}

\section{Characters}

Table 8 shows that the dominant conversational topic was trivia $(46.7 \%$, for example, not having electricity), followed by topics of daily life ( $20 \%$, for example, 
bathing), and personal issues ( $13.3 \%$, for example, friendships). Although most of the characters were presented as students, school related topics did not appear in their conversations

Table 8

DISTRIBUTION ALL CHARACTERS BY CONVERSATIONAL TOPIC

$\begin{array}{ll}\text { Absoulte } & \text { Relative } \\ \text { Freq. } & \text { Freq. }\end{array}$

Topic

Trivial

Daily Life

Personal Issue

Sports

Ideas

Entertainment

Business

School

Work Related

Total
10

5

3

1

1

1

0

0

0
46.7

20.0

13.3

6.7

6.7

6.7

0.0

0.0

0.0

$21-100.0$

As to the problems that the characters talked about or tried to solve, Table 9 indicates that most of the characters, about $56.7 \%$, expressed no problem, and $20 \%$ of the characters were shown having problems in their daily life. Characters expressed trivial concerns unrelated to any of the above $16.7 \%$ of the time. Again, no school related problems were expressed. Also, although $13.3 \%$ of characters discussed topics about personal issues, only $3.3 \%$ of the characters considered this as a problem. 


\section{Table 9}

DISTRIBUTION OF ALL CHARACTERS BY PROBLEM

$\begin{array}{ll}\text { Absolute } & \text { Relative } \\ \text { Freq. } & \text { Freq. }\end{array}$

Problem

None

Trivial 24

56.7

Daily Life

16.7

Personal Issue

20.0

Ideas

Business

9

3.3

3.3

0.0

School

$0 \quad 0.0$

Work Related

Total

0

0.0

0

0.0

100.0

Characters' interests were more evenly distributed. Table 10 shows that $28.1 \%$ of the characters appeared to have no interests, $18.8 \%$ of the characters showed interests in arts, sports and consumerism, $12.5 \%$ on family and friends, $3.1 \%$ on food and dress, and none on entertainment. 


\begin{tabular}{lcc}
\hline \multicolumn{2}{c}{ Table 10 } \\
& Absolute & Relative \\
& Freq. & Freq. \\
& & \\
& & \\
Interests & & \\
& & \\
None & 12 & 28.1 \\
Arts & 8 & 18.8 \\
Sports & 8 & 18.8 \\
Consumerism & 8 & 18.8 \\
Family/friends & 5 & 12.5 \\
Food \& dress & 1 & 3.1 \\
Entertainment & 0 & 0.0 \\
Total & 42 & 100.0 \\
\hline \hline
\end{tabular}

Table 11 shows characters were mostly frequently involved in daily life $(59.1 \%)$. Only $3.9 \%$ of the characters were involved in sports activities, although sports was expressed as an interest by $18.8 \%$ of the characters (see Table 10). 


\section{Table 11}

DISTRIBUTION OF ALL CHARACTERS BY ACTIVITIES

$\begin{array}{ll}\text { Absolute } & \text { Relative } \\ \text { Freq. } & \text { Freq. }\end{array}$

Activities

Daily Life

25

59.1

Entertainment

8

15.6

Work Related

3

7.8

Not appreciable

3

7.8

Special Events

Sports

2

5.8

School Related

1

3.9

Intellectual

Total

0

0.0

0

0.0

\section{Section II}

Selected Sub-Culture as Representatives of Chinese and Foreign (American) Culture

Groups of People that Represent their Cultures in Term of Their Social

Backgrounds

\section{Distribution of Chinese and American Characters by Gender}

Table 12 presents the representation of gender of the characters from specific cultural groups. For the Chinese characters alone, the representation of male 
characters was slightly higher than female characters. As indicated in Table 12, about $55.6 \%$ of characters were male, and about $44.4 \%$ of characters were female. Similar characteristics occurred in the American characters.

\begin{tabular}{lllll}
\hline \hline \multicolumn{5}{c}{ Table 12 } \\
DISTRIBUTION OF CHINESE \& AMERICAN CHARACTERS BY GENDER \\
\hline $\begin{array}{l}\text { Abs. Freq. } \\
\text { of Chns. }\end{array}$ & $\begin{array}{l}\text { Rel. Freq. } \\
\text { of Chns }\end{array}$ & $\begin{array}{l}\text { Abs. Freq. } \\
\text { of Amcn. }\end{array}$ & $\begin{array}{l}\text { Rel. Freq. } \\
\text { of Amcn }\end{array}$ \\
Gender & 15 & 55.6 & 7 & 58.3 \\
Male & 12 & 44.4 & 5 & 41.7 \\
Female & 27 & 100.0 & 12 & 100.0 \\
\hline Total & & &
\end{tabular}

\section{Distribution of Chinese and American Characters by Occupation}

As Table 13 indicates, for the Chinese and American characters there was apparent emphasis on student as occupation. In terms of the Chinese group, there were eight kinds of occupations represented with the exclusion of the unspecified category :student $(58.3 \%)$, businessman ( $18.2 \%)$, and cashier, clerk, president/ executive, fisherman, owner of company/ store ( $4.5 \%$ each).

As for the American group, there were five kinds of occupations represented: student (57.0\%), musician (20.7\%), housewife, and cartoonist/film maker (11.6\% each). 


\section{Table 13}

DISTRIBUTION OF CHINESE \& AMERICAN CHARACTERS BY OCCUPATION

\begin{tabular}{|c|c|c|c|c|c|c|}
\hline \multirow[b]{2}{*}{ Occupation } & \multirow[t]{2}{*}{$\begin{array}{l}\text { Abs. Frq. } \\
\text { of Chns. }\end{array}$} & \multirow[t]{2}{*}{$\begin{array}{l}\text { Rel. Frq. } \\
\text { of Chns. }\end{array}$} & \multirow[t]{2}{*}{$\begin{array}{l}\text { Adj. Frq. } \\
\text { of Amcn. }\end{array}$} & \multirow[t]{2}{*}{$\begin{array}{l}\text { Abs. Frq } \\
\text { of Amcn. }\end{array}$} & \multirow{2}{*}{\multicolumn{2}{|c|}{$\begin{array}{l}\text { Rel. Frq. Adj Frq. } \\
\text { of Amcn. of Amcn. }\end{array}$}} \\
\hline & & & & & & \\
\hline Student & 13 & 48.2 & 58.3 & 6 & 50.0 & 57.0 \\
\hline Businessman & 4 & 14.8 & 18.2 & 0 & 0.0 & 0.0 \\
\hline Cashier & 1 & 3.7 & 4.5 & 0 & 0.0 & 0.0 \\
\hline Clerk & 1 & 3.7 & 4.5 & 0 & 0.0 & 0.0 \\
\hline President & 1 & 3.7 & 4.5 & 0 & 0.0 & 0.0 \\
\hline Fisherman & 1 & 3.7 & 4.5 & 0 & 0.0 & 0.0 \\
\hline Co. Owner & 1 & 3.7 & 4.5 & 0 & 0.0 & 0.0 \\
\hline Musician & 0 & 0.0 & 0.0 & 2 & 16.7 & 20.7 \\
\hline Housewife & 0 & 0.0 & 0.0 & 1 & 8.3 & 11.6 \\
\hline Cartoonist & 0 & 0.0 & 0.0 & 1 & 8.3 & 11.6 \\
\hline Unspecified & 5 & 18.5 & $-\cdots-$ & 2 & 16.7 & $-\cdots$ \\
\hline Total & 27 & 100.0 & 100.0 & 12 & 100.0 & 100.0 \\
\hline
\end{tabular}

\section{Distribution of Chinese and American Characters by Age}

Table 14 shows that the characteristic of the age distribution among the Chinese characters was similar to the age distribution among American characters. Chinese between the ages of 19 and 59 made up $55.6 \%$, and teenagers made up $33.3 \%$. Only $7.4 \%$ of the characters were infants/children, and another $3.7 \%$ of elderly people for the age of 60 and over. For the American characters, the concentration in adulthood appeared again with $66.7 \%$, and teenagers made up $25 \%$, while infants, children, and the elderly are not to be found. Curiously, $8.3 \%$ of American characters were deceased. 
Table 14

DISTRIBUTION OF CHINESE \& AMERICAN CHARACTERS BY AGE

Abs. Frq. Rel. Frq. Abs. Frq Rel. Frq.

of Chns. of Amcn. of Amcn. of Amcn.

Age

\begin{tabular}{lrrrr}
0 & 0 & 0.0 & 1 & 8.3 \\
$0-12$ & 2 & 7.4 & 0 & 0.0 \\
$13-18$ & 9 & 33.3 & 3 & 25.0 \\
$19-59$ & 15 & 55.6 & 8 & 66.7 \\
$60+$ & 1 & 3.7 & 0 & 0.0 \\
\hline Total & 27 & 100.0 & 12 & 100.0 \\
\hline \hline
\end{tabular}

Distribution of Chinese and American Characters by Educational Level

Table 15 shows that the educational level of junior high or high school was emphasized in both groups. College and junior/ high school were the only two levels presented. About $80 \%$ of the Chinese characters had junior high or high school degrees, and $20 \%$ were at the college level. In terms of the American characters, the percentage for college level education was slightly higher, with $60.0 \%$ of the characters having college degrees, and $40.0 \%$ having junior high or high school degrees. 
Table 15

DISTRIBUTION OF CHINESE \& AMERICAN CHARACTERS BY EDUCATIONAL LEVEL

\begin{tabular}{|c|c|c|c|c|c|c|}
\hline Education & $\begin{array}{l}\text { Abs. Frq. } \\
\text { of Chns. }\end{array}$ & $\begin{array}{l}\text { Rel. Frq. } \\
\text { of Chns. }\end{array}$ & $\begin{array}{l}\text { Adj. Frq. } \\
\text { of Chns }\end{array}$ & $\begin{array}{l}\text { Abs. Frq } \\
\text { of Amcn. }\end{array}$ & $\begin{array}{l}\text { Rel. Frq. } \\
\text { of Amcn. }\end{array}$ & $\begin{array}{l}\text { Adj Frq. } \\
\text { of Amcn }\end{array}$ \\
\hline College & 4 & 14.8 & 20.0 & 6 & 50.0 & 60.0 \\
\hline Junior/high & 16 & 59.3 & 80.0 & 4 & 33.3 & 40.0 \\
\hline $\mathrm{K}-6$ & 0 & 0.0 & 0.0 & 0 & 0.0 & 0.0 \\
\hline Unspecified & 7 & 25.9 & ----- & 2 & 16.7 & $-\cdots--$ \\
\hline Total & 27 & 100.0 & 100.0 & 12 & 100.0 & 100.0 \\
\hline
\end{tabular}

$\underline{\text { Summary of the Social Background of Chinese Characters and American Characters }}$

Among the Chinese characters, male characters (55.6\%) were presented slightly more often than female characters (44.4\%). There were eight kinds of occupations represented by the Chinese characters, but the concentration was in student $(58.3 \%)$. As to the age, Chinese characters were mostly adults $(55.6 \%)$ between the ages of 19 to 59 , and teenagers (33.3\%) between the ages of 13 to 18 . The elderly constituted of only $3.7 \%$ of characters. In terms of the educational level, it appeared that most Chinese characters had only the education level of junior high or high school (80.0\%), some characters had college education (20.0\%), and no one had an educational level lower than junior high school.

As to the American characters, the representation of male characters (58.3\%) was higher than female characters $(41.7 \%)$ as indicated in Table 12 . The distribution of occupation in American characters also shows an apparent emphasis on student with the frequency of $57.0 \%$. Most of the American characters were between 19 and 
$59(66.7 \%)$, with some between $13-18(25.0 \%)$. The concentration in adulthood appeared again, as infants, children or elderly disappeared from the American population. Similarly with the Chinese characters, there were only two levels of education presented. However, the occurrence of college level (60.0\%) was higher for Americans than the occurrence of the junior/ high school level (40.0\%). There was no representative of the educational level lower than junior/ high level.

Topics, Problems and Interests of the Conversations and the Activities that Represent that Culture and Society

Conversational Topics by Chinese and American Characters

As Table 16 shows, trivia made up half of the conversational topics $(50 \%)$ among Chinese characters. Topics related to daily life made up 13.6\%. Sports, personal issues, ideas, and entertainment each take $9.1 \%$. Business and school were not discussed by the Chinese characters. American characters also talked about the trivial (37.5\%), but daily life (37.5\%) was equally represented. Business, school, work, sports, ideas, and entertainment were not discussed by the American characters. 


\section{Table 16}

DISTRIBUTION OF CHINESE \& AMERICAN CHARACTERS BY CONVERSATIONAL TOPIC

\begin{tabular}{lcccc}
\hline & $\begin{array}{c}\text { Abs. Frq. } \\
\text { of Chns. }\end{array}$ & $\begin{array}{c}\text { Rel. Frq. } \\
\text { of Amcn. }\end{array}$ & $\begin{array}{c}\text { Abs. Frq } \\
\text { of Amcn. }\end{array}$ & $\begin{array}{c}\text { Rel. Frq. } \\
\text { of Amcn. }\end{array}$ \\
Topic & 11 & 50.0 & 3 & 37.5 \\
Trivial & 0 & 0.0 & 0 & 0.0 \\
Business & 0 & 0.0 & 0 & 0.0 \\
School & 3 & 13.6 & 3 & 37.5 \\
Daily Life & 0 & 0.0 & 0 & 0.0 \\
Work Related & 2 & 9.1 & 0 & 0.0 \\
Sports & 2 & 9.1 & 2 & 25.0 \\
Personal Issue & 2 & 9.1 & 0 & 0.0 \\
Ideas & 2 & 9.1 & 0 & 0.0 \\
Entertainment & 2 & 100.0 & 8 & 100.0 \\
\hline Total & 22 &
\end{tabular}

Table 17 indicates that more than half of the business characters had no problems to discuss (54.5\%). $22.7 \%$ of the Chinese characters discussed problems related to daily life, and $13.6 \%$ of Chinese characters discussed trivial matter unrelated to any of the problems specified. Most of the American characters (62.5\%) appeared to have no problems to discuss either, while $25 \%$ of the American characters expressed problems in the trivial category, and $12.5 \%$ in daily life. 
Table 17

DISTRIBUTION OF CHINESE \& AMERICAN CHARACTERS BY PROBLEM Abs. Frq. Rel. Frq. Abs. Frq. Rel Frq.

of Chns of Chinese of Amcn. of Amcn

Problem

\begin{tabular}{lrrrr} 
None & 12 & 54.5 & 5 & 62.5 \\
Trivial & 3 & 13.6 & 2 & 25.0 \\
Daily Life & 5 & 22.7 & 1 & 12.5 \\
Business & 0 & 0.0 & 0 & 0.0 \\
School & 0 & 0.0 & 0 & 0.0 \\
Work Related & 0 & 0.0 & 0 & 0.0 \\
Personal Issue & 1 & 4.5 & 0 & 0.0 \\
Ideas & 1 & 4.5 & 0 & 0.0 \\
\hline Total & 22 & 100.0 & 8 & 100.0 \\
\hline \hline
\end{tabular}

Table 18 shows that $36.4 \%$ of Chinese characters expressed no interests,

while $27.3 \%$ of the characters were interested in sports, followed by $18.2 \%$ of interest in consumerism. American characters appeared to be mainly interested in arts, with $20 \%$ interested in family and friend relationships, and another $20 \%$ in consumerism.

\begin{tabular}{|c|c|c|c|c|}
\hline DISTRIBUTI & OF CHIN & $\begin{array}{r}\text { Tabl } \\
\text { SE \& AMER }\end{array}$ & 8 & TERS BY INTERESTS \\
\hline & $\begin{array}{l}\text { Abs. Frq. } \\
\text { of Chns }\end{array}$ & $\begin{array}{l}\text { Rel. Frq. } \\
\text { of Chinese }\end{array}$ & $\begin{array}{l}\text { Abs. Frq. } \\
\text { of Amcn. }\end{array}$ & $\begin{array}{l}\text { Rel Frq. } \\
\text { of Amcn. }\end{array}$ \\
\hline Interests & & & & \\
\hline Arts & 2 & 9.0 & 3 & 40.0 \\
\hline Family/friends & 2 & 9.1 & 2 & 20.0 \\
\hline Sports & 6 & 27.3 & 4 & 0.0 \\
\hline Consumerism & 4 & 18.2 & 8 & 20.0 \\
\hline None & 8 & 36.4 & 1 & 10.0 \\
\hline Total & 22 & 100.0 & 8 & 100.0 \\
\hline
\end{tabular}

Table 19 shows that the Chinese characters were most frequently involved 
with entertainment (33.3\%). About $41.7 \%$ of characters were involved in daily life activities, mostly in shopping, and $16.7 \%$ of characters were involved in work related activities. As for the American characters, daily life appeared to be the only type of activity they were involved with in the dialogues.

\section{Table 19}

DISTRIBUTION OF CHINESE \& AMERICAN CHARACTERS BY ACTIVITIES Abs. Frq. Rel. Frq. Abs. Frq. Rel Frq.

of Chns of Chinese of Amcn. of Amcn.

Activities

\begin{tabular}{lcccc} 
Daily Life & 9 & 41.7 & 8 & 100.0 \\
Entertainment & 7 & 33.3 & 0 & 0.0 \\
Work Related & 4 & 16.7 & 0 & 0.0 \\
Sports & 2 & 8.3 & 0 & 0.0 \\
Special Events & 0 & 0.0 & 0 & 0.0 \\
Intellectual & 0 & 0.0 & 0 & 0.0 \\
School Related & 0 & 0.0 & 0 & 0.0 \\
\hline Total & 22 & 100.0 & 8 & 100.0 \\
\hline \hline
\end{tabular}

\section{Section III}

The Nature of the Interaction between Inter-cultural and Intra-cultural Groups with Respect to their Cultural, Inter-personal Relationships, Conversational Topics and Settings of the Interaction.

This section presents the results of the analysis of several issues. First of all, 
it presents the most frequent interaction among intra-cultural and inter-cultural groups: Chinese and American characters; Chinese and Chinese characters; American and American characters. Second, it presents the spectrum of the types of relationships in three types of cross-cultural interactions. Third, it also presents the scope of the relationships in three types of cross-cultural interactions. Fourth, it presents the spectrum of the types of conversational topics discussed in cross-cultural interactions. Finally, it presents the types of geographical setting where the crosscultural interactions occurred.

Does Interactions Occur Mostly between Chinese-Chinese Characters, ChineseAmerican Characters? Or American-American Characters?

The Chinese characters appeared to have very little interaction with foreign characters, who are represented by American characters in the textbook sample chosen for analysis. Table 20 shows that only $19.3 \%$ of the interactions involved Chinese with American characters through all the cross cultural interactions. American characters interacted mostly with Americans (45.6\%), and Chinese characters mostly interacted with Chinese (35.1\%). 
Table 20

DISTRIBUTION OF ALL CHARACTERS BY INTER-CULTURAL \& INTRACULTURAL INTERACTIONS
Abs. Frq.
Rel. Frq
Rel Frq.

Inter-Cultural \&

Intra-Cultural Int.

\begin{tabular}{llcc} 
American-American & 26 & 34.7 & 45.6 \\
Chinese-Chinese & 20 & 26.7 & 35.1 \\
Chinese-American & 11 & 14.7 & 19.3 \\
Unspecified & 18 & 24.0 & ----- \\
\hline Total & 64 & 100.0 & 100.0 \\
\hline \hline
\end{tabular}

Types of Interpersonal Relationships Presented Between the Characters of ChineseAmerican, Chinese-Chinese, and American-American Chinese-American Characters

Table 21 shows the results of the types of relationships presented between Chinese and American characters with friendship most often presented. The friendships were $81.8 \%$ of interactions, and only $18.2 \%$ were presented as incidental, which was the case when two strangers were involved in interactions by accident. Relationships of family members, playmates, schoolmates, work mates, business, and student-teacher relationship were not represented.

Chinese-Chinese Characters

A broader spectrum of relationship types was presented between Chinese characters. Table 21 reveals that about $20.0 \%$ were family, another $20.0 \%$ were friends, $15.0 \%$ were schoolmates; $10.0 \%$ were work mates, and $35.0 \%$ were incidental. Only playmate and teacher-student relationships were not presented. 


\section{American-American Characters}

The analysis of the types of relationships that occurred between two foreign characters shows that the friend relationship most frequently occurred between American characters (38.5\%), followed by family members (34.6\%) and schoolmates (23.1\%) (see Table 21). Playmates, work mates, business, and teacher-student were not represented.

\section{Table 21}

TYPES OF RELATIONSHIPS PRESENTED IN CHINESE-CHINESE AMERICAN-AMERICAN, CHINESE-AMERICAN

Abs. Frq. Rel. Frq. Abs. Frq. Rel. Frq. Abs. Frq. Rel. Frq.

Ch-Am Ch-Am Ch-Ch Ch-Ch Am-Am Am-Am

Type

\begin{tabular}{lrrrrrr} 
Family Members & 0 & 0.0 & 4 & 20.0 & 9 & 34.6 \\
Friends & 9 & 81.8 & 4 & 20.0 & 10 & 38.5 \\
Schoolmates & 0 & 0.0 & 3 & 15.0 & 6 & 23.1 \\
Work mates & 0 & 0.0 & 2 & 10.0 & 0 & 0.0 \\
Incidental & 2 & 18.2 & 7 & 35.0 & 1 & 3.8 \\
Teacher-student & 0 & 0.0 & 0 & 0.0 & 0 & 0.0 \\
Playmates & 0 & 0.0 & 0 & 0.0 & 0 & 0.0 \\
Business & 0 & 0.0 & 0 & 0.0 & 0 & 0.0 \\
Others & 0 & 0.0 & 0 & 0.0 & 0 & 0.0 \\
\hline Total & 11 & 100.0 & 20 & 100.0 & 26 & 100.0 \\
\hline \hline
\end{tabular}

Types of Conversational Topics Discussed between Chinese-American Characters;

\section{Chinese-Chinese Characters; American-American Characters}

Table 22 indicates that the conversational topics between Chinese characters had more variety than other groups. A total of six kinds of topics were discussed between Chinese characters, where topics about trivia dominated the conversations 
$(50 \%)$. The conversational topics between Chinese-foreign characters concentrated on trivia (50\%) and daily life (50\%). Foreign characters talked about the trivial $(33.3 \%)$, daily life (33.3\%) and personal issues (33.3\%) (see Table 33$)$. In general, trivia appeared to be a common topic within each group. Sports appeared to be more popular in Chinese-Chinese conversations than in the other two groups.

Table 22

CONVERSATIONAL TOPICS BY INTER-CULTURAL \& INTRA-CULTURAL INTERACTIONS

Abs. Frq. Rel. Frq. Abs. Frq. Rel. Frq. Abs. Frq. Rel. Frq.

Ch-Am Ch-Am Ch-Ch Ch-Ch Am-Am Am-Am

Topics

\begin{tabular}{lrrrrrr} 
Trivial & 5 & 50.0 & 1 & 50.0 & 1 & 33.3 \\
Business & 0 & 0.0 & 0 & 0.0 & 0 & 0.0 \\
School & 0 & 0.0 & 0 & 0.0 & 0 & 0.0 \\
Daily Life & 1 & 10.0 & 1 & 50.0 & 1 & 33.3 \\
Work Related & 0 & 0.0 & 0 & 0.0 & 0 & 0.0 \\
Sports & 1 & 10.0 & 0 & 0.0 & 0 & 0.0 \\
Personal Issues & 1 & 10.0 & 0 & 0.0 & 1 & 33.3 \\
Ideas & 1 & 10.0 & 0 & 0.0 & 0 & 0.0 \\
Entertainment & 1 & 10.0 & 0 & 0.0 & 0 & 0.0 \\
\hline Total & 10 & 100.0 & 2 & 100.0 & 3 & 100.0 \\
\hline
\end{tabular}

Types of geographical locations where interactions occurred

This section looks at the geographical locations in which the interactions took place from three levels. The three levels of geographical locations were: country, area, and setting. In terms of country location, only $16 \%$ of the interactions occurred 
in the U.S., and $84 \%$ were in Taiwan (see Table 23 ). As to the areas, only $5.3 \%$ of interactions occurred in rural areas, the remaining $94.7 \%$ of interactions were classified in urban areas (see Table 24). There were a variety of settings in which the interactions took place: schools, workplaces, recreational establishments, homes, city streets, transportations, wilderness, and stores. However, the most popular setting in which the characters had interactions appeared to be the home (58.7\%), followed by recreational establishments (24.0\%) (see Table 25$)$. Only $1.3 \%$ of interactions took place in school setting even though student was the dominant character occupation $(55.5 \%)$ (see Table 4).

\section{Table 23}

GEOGRAPHICAL LOCATION - COUNTRY

$\begin{array}{lll}\text { Absolute } & \text { Relative } & \text { Adjusted } \\ \text { Freq. } & \text { Freq. } & \text { Freq. }\end{array}$

Country Location

\begin{tabular}{lrrl} 
Taiwan & 52 & 69.3 & 84.0 \\
U.S. & 8 & 10.7 & 16.0 \\
Unspecified & 15 & 20.0 & ---- \\
\hline Total & 75 & 100.0 & 100.0 \\
\hline \hline
\end{tabular}

Table 24

GEOGRAPHICAL LOCATION - AREA

$\begin{array}{lll}\text { Absolute } & \text { Relative } & \text { Adjusted } \\ \text { Freq. } & \text { Freq. } & \text { Freq. }\end{array}$

Geographical Area

\begin{tabular}{lrrr} 
Urban & 71 & 94.7 & 94.7 \\
Rural & 4 & 5.3 & 5.3 \\
\hline Total & 75 & 100.0 & 100.0 \\
\hline \hline
\end{tabular}


Table 25

GEOGRAPHICAL LOCATION - SETTING

$\begin{array}{lll}\text { Absolute } & \text { Relative } & \text { Adjusted } \\ \text { Freq. } & \text { Freq. } & \text { Freq. }\end{array}$

Setting

Home 44

58.7

58.7

Recreational Establish

18

24.0

24.0

City Street

5.3

5.3

Stores

4

4.0

4.0

Wilderness

2.7

2.7

Workplace

2.7

2.7

School

1.3

1.3

Transportation

Total

$\begin{array}{rrr}1 & 1.3 & 1.3 \\ 75 & 100.0 & 100.0\end{array}$

1.3

\section{Section IV}

The Explicit Cultural Information Presented and Level(s) of Culture the Textbooks Dealt with

It took two steps to evaluate the information regarding the types of explicit culture and the level(s) of culture the readings dealt with. First, the readings were classified by topical areas such as history, economy, daily life, values of a country, or a description about a character with or without addressing some cultural aspects, or topics of a country. For those readings that were classified as a description about a character with some cultural aspects or topics of a country, the part of cultural aspects or topics was further analyzed by using the categories of specific topical 
areas. For instance, when a reading was classified as a character description with a cultural aspect regarding a value of a country, the reading was categorized as a description of a character first, then it was evaluated as a reading dealing with a value of a specific culture. The second step was to evaluate the level(s) of culture the reading dealt with. Therefore, once the topical area of each reading was determined, the readings were analyzed by their emphasis on surface or deep culture, depending on whether the culture elements the reading topic addressed were observable or not.

\section{Topical Areas the Readings Deal With}

As mentioned earlier, surface culture is defined as the observable elements of a people's culture, such as dress style, foods, and shopping habits. Deep culture is defined as values, assumptions, beliefs, and motivations that underlie the surface culture elements. Table 26 shows that the topical areas the readings dealt with were scattered in several areas: character description only $(28.0 \%)$, character description with cultural aspects or topics (24.0\%), language (16.0\%), values of culture in general $(12.0 \%)$, values of a specific culture $(8.0 \%)$, social events $(4.0 \%)$, social, political, intellectual trends (4.0\%), and global topics (4.0\%). However, emphasis was placed on the development of characters with or without addressing some cultural aspects or topics. Values of culture in general and culture in specific were also addressed to some degree. Topics such as history, fine arts, geography, social/political problem issues, historical figures, economy and linguistic items were not presented. The textbooks neither presented reading that mainly dealt with 
vocabulary or linguistics item. Table 27 shows that when the readings dealt with character description with the combination of cultural aspect, the emphasis was on the values of culture in general $(66.7 \%)$.

\begin{tabular}{|c|c|c|c|}
\hline TOPIC & $\begin{array}{r}\text { Table } 26 \\
\text { AREA OF }\end{array}$ & EADINGS & \\
\hline & $\begin{array}{l}\text { Absolute } \\
\text { Freq. }\end{array}$ & $\begin{array}{l}\text { Relative } \\
\text { Freq. }\end{array}$ & $\begin{array}{l}\text { Adjusted } \\
\text { Freq. }\end{array}$ \\
\hline Topic & & & \\
\hline History & 0 & 0.0 & 0.0 \\
\hline Fine Arts & 0 & 0.0 & 0.0 \\
\hline Language & 4 & 16.0 & 16.0 \\
\hline Social Event & 1 & 4.0 & 4.0 \\
\hline Daily Life & 0 & 0.0 & 0.0 \\
\hline Geography & 0 & 0.0 & 0.0 \\
\hline Social/political issues & 0 & 0.0 & 0.0 \\
\hline Historical Figures & 0 & 0.0 & 0.0 \\
\hline Economy & 0 & 0.0 & 0.0 \\
\hline Social, political, intellect. trends & 1 & 4.0 & 4.0 \\
\hline Values of a Specific Culture & 2 & 8.0 & 8.0 \\
\hline Values of culture in general & 3 & 12.0 & 12.0 \\
\hline Linguistic & 0 & 0.0 & 0.0 \\
\hline Global Topics & 1 & 4.0 & 4.0 \\
\hline Character Description Only & 7 & 28.0 & 28.0 \\
\hline Character Descript. w/Culture & 6 & 24.0 & 24.0 \\
\hline Total & 25 & 100.0 & 100.0 \\
\hline
\end{tabular}




\begin{tabular}{lcl}
\hline \hline \multicolumn{2}{c}{ Table 27 } \\
\multicolumn{1}{c}{ READING COMBINING CHARACTER DESCRIPTION WITH CULTURAL } \\
& ASPECTS OR TOPICS & \\
\hline & Fbsolute & Adjusted \\
& Freq. & Freq. \\
Topic & & \\
Fine Arts & 1 & 16.6 \\
Values of a Specific Culture & 1 & 16.6 \\
Values of culture in general & 4 & 66.7 \\
\hline Total & 6 & 100.0 \\
\hline \hline
\end{tabular}

Does the Textbook Deal With Surface Culture or Deep Culture Only? Or Does the

Textbook Attempt to Link Both Surface and Deep Culture Aspects?

As Table 28 indicates, the emphasis of the readings was on surface culture.

About $64 \%$ of the readings emphasized the surface culture elements of the topic treated, $32 \%$ of the readings addressed the topics on a deep level. Only $4 \%$ of the reading attempted to present the topics by linking both deep and surface cultural aspects.

\begin{tabular}{lcll}
\hline \hline \multicolumn{3}{c}{ Table 28 } & \\
& CULTURAL AREA EMPHASIZED IN READING \\
\hline & Absolute & Relative & Adjusted \\
& Freq. & Freq. & Freq. \\
& & & \\
Emphasis & & & \\
& 8 & 32.0 & 32.0 \\
Deep Culture & 16 & 64.0 & 64.0 \\
Surface Culture & 1 & 4.0 & 4.0 \\
Link of Surface \& Deep Culture & 25 & 100.0 & 100.0 \\
\hline Total & & & \\
\hline \hline
\end{tabular}




\begin{abstract}
Section V
Manner of Presentation of Socio-cultural Information

Do Textbooks Portray Socio-cultural Information Using a Synchronic Approach or a

Diachronic Approach?

This section looks at the historical dimension which the reading dealt with from two aspects. It looks at the variable of time, which is the perspective of the historical view, and scope, which is the nature of the historical view. Based on the results of the topical area categorizations of the readings in Table 26, the topical areas of the readings were regrouped into two bigger categories: topics and character description. The aspects of time was analyzed based on these two groups of categories.
\end{abstract}

Table 29 and 30 present the results of the evaluation on the readings from what I learn the time perspective. The readings were first categorized as "culture specific topics" and "character description." Table 29 shows that most readings on specific topics presented the socio-cultural information by attempting to link both past and present time perspectives (60\%); $20 \%$ of the reading treated the topics from a present perspective and another $20 \%$ presented them from a past perspective. As to the readings which were categorized as character description, Table 30 indicates that all the characters' past life background information were provided for in the readings in order to give the readers a sense of the historical view of the characters. 


\section{Table 29}

TIME PERSPECTIVE FOR CULTURE SPECIFIC TOPICS

$\begin{array}{ll}\text { Absolute } & \text { Relative } \\ \text { Freq. } & \text { Freq. }\end{array}$

Perspective

\begin{tabular}{lll} 
Present Only & 1 & 20.0 \\
Past Only & 1 & 20.0 \\
Past \& Present Combined & 3 & 60.0 \\
\hline Total & 5 & 100.0 \\
\hline \hline
\end{tabular}

\begin{tabular}{lcc}
\hline \hline \multicolumn{3}{c}{ Table 30 } \\
TIME PERSPECTIVE FOR CHARACTER DESCRIPTION \\
\hline & Absolute & Relative \\
& Freq. & Freq. \\
& & \\
Time Perspective & & \\
& 13 & 100.0 \\
Character Background & 0 & 0.0 \\
No Character Background & 13 & 100.0 \\
\hline Total & & \\
\hline
\end{tabular}

Do the Post-Reading Questions Emphasize Mnemonic Processes or Heuristic

\section{Understanding?}

As the results show in Table 31 , in the total of 234 follow-up comprehensive questions of the readings, only 11 of the questions ( $4.7 \%)$ had a focus on reflective nature which required critical analysis, and the rest of the 223 questions were simply factual nature (95.3\%) questions. A similar characteristic was shown in the stance 
presented by the questions. Table 32 indicates that only $4.7 \%$ of the questions were considered as inductive reasoning and synthesis, for the emphasis of the remaining $95.3 \%$ questions required mere recall.

\begin{tabular}{llll}
\hline \hline & \multicolumn{3}{c}{ Table 31 } \\
& \multicolumn{3}{c}{ TYPE OF EXERCISE } \\
\hline & Absolute & Relative & Adjusted \\
& Freq. & Freq. & Freq. \\
Type & & & \\
& & & \\
Factual Nature & 223 & 95.3 & 95.3 \\
Reflective Nature & 11 & 4.7 & 4.7 \\
\hline Total & 234 & 100.0 & 100.0 \\
\hline \hline
\end{tabular}

\begin{tabular}{|c|c|c|c|}
\hline \multicolumn{4}{|c|}{ Table 32} \\
\hline & $\begin{array}{l}\text { Absolute } \\
\text { Freq. }\end{array}$ & $\begin{array}{l}\text { Relative } \\
\text { Freq. }\end{array}$ & $\begin{array}{l}\text { Adjusted } \\
\text { Freq. }\end{array}$ \\
\hline \multicolumn{4}{|l|}{ Stance } \\
\hline Recall Only & 223 & 95.3 & 95.3 \\
\hline Cross Cultural Comparison & 0 & 0.0 & 0.0 \\
\hline Inductive \& Synthesis & 11 & 4.7 & 4.7 \\
\hline Total & 234 & 100.0 & 100.0 \\
\hline
\end{tabular}




\title{
CHAPTER V \\ CONCLUSION
}

\author{
Introduction
}

This chapter discusses the results presented in chapter IV. It looks at to what degree there is clear articulation between the government's stated culture learning goals in the foreign language classroom and the actual textbook content, and concludes with implications for textbook writers and language education planners in Taiwan. It also includes a general discussion about the cultural information in a randomly chosen lesson, lesson 2 in textbook III.

\section{Discussion}

The discussion of the results is organized following the order of research questions presented in chapter III: (I) what is the scope of the cultures and subcultures presented and to what degree does the information presented enable students to better understand the individual cultures appearing in textbooks; (II) what subcultures are selected as representative of Chinese culture and American culture to achieve the goal of cross-culture awareness and understanding stated by the Ministry of Education of Taiwan; (III) what is the nature of the interactions between characters with respect to their cultural, gender, inter-personal relationships, 
conversational topics the characters discuss and the geographical setting in which the interactions occur in the textbooks; (IV) what levels of culture do the junior high English textbooks deal with; and (V) what is the manner of presentation of the sociocultural information?

\section{Section I}

Scope of the Cultures and their Sub-cultures Presented

\section{Characters' National Origins and Social Backgrounds}

This section looks at the spectrum of cultural groups and what Byrd (1993) called "tributary culture" groups presented in the textbooks. It also discusses whether there is different emphasis placed on different groups. Stereotyping is one of the most commonly found problems in textbooks when presenting socio-cultural groups. Thus, it is important to look at the socio-cultural presentation with this concern.

Stereotyping could occur when there are limited socio-cultural groups presented in a textbook. Stereotyping could also occur when one group is emphasized more than others. As Byrd (1993) suggests, "authentic communication," which incorporates verbal and nonverbal interaction, would help strip away stereotyping and labels on groups, and enable people to know the uniqueness of an individual or the reality of a group (p.50). However, authentic communication is impossible when "reference group affiliations become dysfunctional to the extent that they encourage feelings of superiority that lead to the oppression of others" (p. 5). 
According to Byrd, a reference group can be defined, for example, by race, ethnicity, gender, socioeconomic level, and age. The verbal and nonverbal authentic communication could succeed or fail in the interaction between textbooks and learners. When textbooks present a few highly selected socio-cultural groups, or place emphasis on a few groups explicitly or implicitly, feelings of superiority are encouraged for those groups .

Therefore, in order to enable students to achieve authentic communication with the individual cultures presented in textbooks, it is important to introduce students to a variety of individual cultural groups and give each group equal status. In addition, it is also important to introduce students to a broad spectrum of subcultures or "tributary cultures" within each individual culture, and give each individual group equal time as well. However, the findings of the analyzed data show that the textbooks present only a few groups and ignore or de-emphasize others. In some cases, they present only a narrow scope of individual cultures and their sub-cultures: For example, American culture is the only representative of foreign cultures in the textbooks. In other cases the textbooks present several groups but promote only a few culture or sub-culture groups: For instance, although the textbooks present American characters with a variety of age groups, the young adult group is greatly promoted.

\section{Over-all Characters' Cultural Backgrounds}

The textbooks present a narrow scope of characters' cultural backgrounds and 
unequal emphasis on one cultural group. In the presentation of characters' cultural backgrounds only two types of nationalities are presented. One is the Chinese group from Taiwan and the other is American. In the presentation of foreign cultures, American characters are the only representatives of all foreign culture characters, although according to The Europa World Year Book 1994, there are one hundred and ninety two countries in the world.

This presentation is problematic when the goal of the textbooks is to reach cross-cultural communication with the variety of foreign countries. From a World English perspective, studying a foreign language, especially English, gives students a key to open the doors of the world. According to The Cambridge Encyclopedia of Language (1987), by a conservative estimate, English is used not only by around 300 million mother tongue speakers, but also used by another 300 million people as a second language, and 100 million people who use it as a foreign language. It is commonly agreed that the nature of language and culture are interrelated. As Brown (1987) remarks, "a language is part of a culture, and a culture is a part of language" (P. 123). Today, English is no longer only used by its original owners, the inner circle of English speaking people. It is also used by another 400 million people, the Outer Circle, those countries who once colonized the U.S. or Great Britain and Expending Circles, those countries where English is taught as a foreign language of English speaking people. Therefore English will also reflect the Outer Circle and Expanding Circle peoples' cultures. Learning English, then, should provide students with some 
grasp of the many cultures using this language. However, this set of English textbooks analyzed presents foreign cultures through the lenses of only one culture, American. This limits students' view of the world while they learn English as an universal language, since the idea of cross-cultural awareness is not transmitted to the students. Since it is impractical to present all the cultures in the world in two textbooks, maybe introducing the top ten major trading partners with Taiwan would be reasonable.

As mentioned in chapter II, English links Taiwan to the world of business and enables it to stay in touch with the most recent advances from such diverse fields as medicine and education. When textbooks provide a variety of cultural information they prepare students for the challenge of cross-cultural communication. English's status in Taiwan is as Kachru (1986) described: "knowing English is like possessing the fabled Aladdin's lamp, which permits one to open, as it were, the linguistic gates to international business, technology, science, and travel" (p.1). While Kachru's linguistic perspective is correct, and language and culture interact, these textbooks provide only a narrow presentation of culture, and therefore prevent the students from learning other valuable cultural information that would amplify their crosscultural communication in their future fields of international business, technology, science and travel for example.

In addition to instrumental purposes, English language education also aims to empower learners to self-examine, to enable learners to acquire "a new insight into 
self and native surrounds" (Byram, 1988). As Byram points out, the educational purpose of foreign language study is to "offer the opportunity for emancipation from the confines of learners' native habitat and culture, with the development of new perceptions and insights into foreign and native cultures alike" (p. 1). However, because the presentation of foreign culture is limited to Americans, students are deprived of the development of new perceptions and insights into cultures other than America. This would also effect learning a new perception about student's own culture. Instead of seeing themselves and their society in the eyes of the rest of the world, they are allowed to see it only from the American's eyes.

As to the presentation of emphasis on Chinese characters, this presentation conflicts with De Meo's (1980) theory about the portrayal of effective textbook characters. De Meo argues theoretically that a foreign language textbook portrays two types of characters. The first type are the characters who symbolically represent the students who use the textbooks. These are the characters whom the students, in this case Taiwanese junior high students, are expected to identify with. The second type are characters perceived by the students as representative of the target culture, in this case the American characters. As De Meo (1980) suggests, a successful portrayal of the American characters, who are seen as sources of information about the American culture in general, needs to be more fully defined than the Chinese characters in order to provide insights into significant aspects of American culture. However, the textbooks present these two types of characters in a converse way that, 
according to De Meo, would not facilitate students to study culture. In addition, De Meo also argues that in order to gain insights into the significant aspects of the target cultures, it is important for textbooks to present interactions between the characters of the symbolic representatives of the students and target culture characters. However, the textbooks examined in this study overemphasize the Chinese group. , presenting $69.2 \%$ of characters is Chinese and $30.8 \%$ American (see Table 2). This concentration on the Chinese group limits the possibility of cross-cultural interactions between Chinese and American characters.

\section{Over-all Characters' Social Backgrounds}

As to the characters' over-all social backgrounds, although the characters are presented at various ages, the age groups of young (33.3\%) and middle-aged $(56.9 \%)$ adults are overemphasized (see Table 5). As to occupation and educational level, the findings show that a hefty majority of characters possess junior high or high school education (64.1\%--see Table 6), and a small majority of characters are students (55\%--see Table 4). By concentrating on these groups, children and senior age groups are rarely represented. This presentation could encourage students to be "life stage centrists" (LSC). The LSC, according to Byrd, has little contact with people who are not in their age group, and may not be aware of, or deny the life experience of, people in other stages by oppressive thoughts or actions. 


\section{Over-all Characters' Conversational topics, Interests, Problems, and Activities}

Most people agree that culture affects our way of life in what we do and what we think. In addition to characters' socio-cultural information, it is also interesting to know what those characters talk about, their interests, their problems, and their favorite activities. Both the Chinese and American characters discussed more trivial (46.7\%) and daily life topics (20\%) than other topics e.g., topics related to ideas, beliefs or intellectual issues (6.7\%) (see Table 8 ). For example, a majority of characters discussed issues such as fixing a tape recorder, being sick, shopping, delivering newspapers, house cleaning, and running out of gas. Not only did they did not talk about school, business and work, in addition a significant majority of characters appear to have no problems of concern (56.7\%--see Table 9). When they express their concerns, they are limited to trivial (16.7\%) and daily life (20\%) concerns. Characters also appeared to be involved more in the activities related to their daily life routines (59.1\%) than being involved in other activities (see Table 11).

As discussed earlier, the Chinese students in the textbooks are the characters whom the students expected to identify with, and the American characters are the resources for American culture. The activities of the characters not only represent their cultures but also affect the kind of cultural information that enters the students' minds. Students would learn more objectively and realistically about the culture when characters are involved in a broader variety of activities and when each activity is given a more equal emphasis. Although the results show that characters are involved 
in various activities, none of the characters are involved with the activities related to school, e.g., reading, discussing topics they learn, and homework. The majority of characters are involved in daily life activities, e.g.., shopping, dinning, repairing, cleaning, and financial plaining. Most students using the textbooks spend lots of time studying in order to pass the competitive entrance examinations in Taiwan. They may wonder how their peers, especially in other countries, spend time at school, what they study, and how they learn. However, the textbooks provide no information about schooling and intellectual development.

\section{Section II}

Selected Sub-cultures as Representatives of Chinese and American Cultures Chinese Characters' Conversational Topics, Problems, Interests and Activities A majority of the Chinese characters' social backgrounds can be specified as primarily students, teenagers and middle-aged adults, and people who have the educational level of junior high or high school. $58.3 \%$ of characters were students, $33.3 \%$ of characters were teenagers, $55.6 \%$ were young, middle-aged adults, and $80 \%$ of the characters have a junior high or high school level of education (see Table 13,14 , and 15). These characters appear to prefer to talk about trivial issues (50\%-see Table 16$)$, and the majority of them have no expressed problems (54.5\%--see Table 17). When they do express their problems, most concerns are on trivial (13.6\%) and daily life subjects (22.7\%--see Table 17). More Chinese characters also 
appear to lack breadth in their interests $(36.4 \%)$, or have interests limited to sports $(27.3 \%)$ or consumerism (18.2\%--see Table 18$)$. The activities they are associated with are mostly daily life (41.7\%), entertainment, work related activities (16.7\%) and sports $(8.3 \%$--see Table 19$)$.

The textbooks neither portray a broader spectrum of Chinese characters' social backgrounds nor at least present a picture of characters' social backgrounds that actually responds to the demographic profile of Taiwan at this time. For example, the population over 60 presented in the textbooks was only $3.7 \%$. However, according to the data from Interior Statistics Year Report of Taiwan, R. O.C. 1995 , in 1995 , people over 65 years old accounted for $11 \%$ of the population of Taiwan. Although Chinese culture is usually considered a culture which respects elders, among the total of 51 characters, only one character appears who is over 60 .

In addition, the narrow band of elderly characters and children under twelve are not shown interacting with individuals between the ages of twelve and sixty. They interact with each other only. This limited interaction could promote ageism and increases the possibility and the degree of stereotyping for the way students see these two groups.

Since this set of textbooks is written for students, it is obviously important to present characters who are also students, so that the audience can closely identify themselves with those characters. Therefore, characters and their discussions should be life-like and deal with events and values associated with student life. From a 
quantitative analysis, the Chinese characters are primarily characterized as students, but from a qualitative analysis, they do not appear to be involved with school related activities nor do they discuss school related topics.

In comparison with other types of jobs, business related occupations dominate the textbooks. Although Chinese characters are represented by eight kinds of occupations, with the exception of student and fisherman, the rest of the jobs are directly related to business, e.g., cashier, clerk, company owner. This representation appears to reflect the business oriented society in Taiwan. However, as with the emphasis on student, this presentation ignores hundreds of other kinds of jobs, and seems to promote the value of business perhaps at the expense of other careers.

The American Characters' Conversational Topics, Problems, Interests, and Activities

A pattern similar to the presentation of Chinese characters' ages and occupations occurred in the depiction of American characters' social backgrounds. Most American characters appear to be teenagers (25\%) or young adults $(667 \%$--see Table 14). There are no American characters represented over the age of 60 . This invisibility is not an accurate portrayal of the current U.S. demographic profile. As to the American characters' occupations, for those jobs that can be specified, only three are presented. The results shows that a majority of the American characters are students (57\%), a small percentage are housewives (11.6\%), and the rest of the American characters are presented as artists (32.3\%--see Table 13), for instance, 
musicians and cartoonist; none of their jobs are directly related to business. American characters appear to like to talk about personal (25\%), trivial (37.5\%), and daily life issues (37.5\%--see Table 16$)$. They do things only related to daily life ( $100 \%$--see Table 19), they favor art (40\%--see Table 18), and a majority of them seem to have no problems of concern $(62.5 \%$--see Table 17$)$.

The over-emphasis on the young and the ignoring of American senior citizens seems to reinforce Chinese people's stereotype about the American culture. When the textbooks do not give students a chance to come in contact with a varied group of American people, it leaves them with an inaccurate picture of the U.S. Without this information, it is clearly not possible for students to better understand for example elderly Americans. Yet, the Ministry's goal states without question that it expects young learners to gain a better understanding of foreign cultures through these textbooks. In addition, the high presentation of American artists fails to depict a realistic picture about this population; forty percent of the American population are not artists. Student might get an inaccurate picture of the role of art in American culture.

As to American peoples' education level, a large percentage (60\%) of American characters appear to posses higher educational degrees. This presentation seems to reflect closely the educational level of most Americans who travel in Taiwan. Local people usually see these travelers as representatives of the American people back at home. In fact, this presentation gives only a partial picture of the 
Americans and reinforces this positive stereotype about American peoples' education. Education is an important value for most Chinese people. According to the Statistical Abstract of the United States 1995 (p.157), only $22.2 \%$ of Americans posses college degrees.

The results also show that the American character's conversational topics, the interests and the problems they express, as well as the activities they are involved in, present a very small picture about American culture from these perspectives. This presentation gives students only a narrow picture about American culture.

That the American characters' favorite topics were about personal issues is interesting to me. Although American characters appear to like to talk about trivial and daily life issues which is similar to the Chinese characters, the Americans seem to talk more about personal issues, e.g., the relationships with friends or family. This seems to show that the American people feel more comfortable or appropriate talking about their feelings, and they are more open to talk about the issues of friends and family relationships than Chinese people would be. This presentation mirrors my personal impression about Chinese and American cultures.

There is one particular problem I see in the presentation of problem-free American and Chinese characters in terms of my personal cultural experience. Textbooks' oversimplifying and romanticizing American and Chinese cultures not only distorts both cultures, but also prevents students from learning American culture by observing how the American and Chinese people solve their problems. In my 
personal experience, through conflicts or problems with people from other cultures, I have learned much about cultural values and beliefs of those other cultures as well as my own. I observed how different people solved their problems, and I have also learned that different cultural values and assumptions usually underlie our daily life behaviors. This problem solving process gives me a chance to get to know my own "culturally-induced behaviors" as well as the culturally-induced behavior of others (Tomalin, 1993). Therefore, when both the Chinese and American characters express their problems, students who use the textbooks are given chances to observe how the characters deal with problems and why they choose to solve them a certain way. However, the textbooks fail to demonstrate such problem solving processes.

De Meo (1980) argues that learners are expected to identify themselves with the characters from the native culture, and look at the target culture characters as resources of the target culture. Therefore, a successful target culture character is necessarily more fully defined than the native character (p. 70). Consequently, it is important to introduce students to various and adequate resources of the target cultures in order to enable to students to see the culture from different angles and therefore better understand that culture. Characters themselves certainly are important cultural resources in terms of their socio-cultural backgrounds. In addition, the variation of their conversational topics, their interests, problems and the activities they do would also provide insights into significant aspects of American culture. Therefore, it is important that the textbooks, one of the essential culture bearers in 
language classrooms, introduce a broad spectrum of these cultural elements to students. However, as the above discussion indicates, the textbooks fail to do so.

\section{Section III}

Nature of the Interactions presented between Characters with Respect to their Crosscultural, Inter-personal Relationships, and Conversational topics

As De Meo (1980) indicates, the insights into significant aspects of the target culture emerge from the interaction of the native culture characters and target culture characters. However, the nature of interaction may vary, in terms of the variety of the topics people discussed, whom they talked to, and where they talked. In turn, these may affect the range and depth of the target culture that students learn. People may talk and behave differently in terms of what they talk about, whom they talk with, and where they talk. People discuss different topics, or an issue in different degrees, depending on the types of relationships they have and/or the place where they interact. In an ideal textbook, variety would be key: learners would gain more insights into the target culture by having more interactions with people; interacting with people from the target cultures who have different relationships with learners; having varieties of conversational topics when cross-cultural communication occurred; and having interactions in different settings. Therefore, it is important for textbooks to provide a variety of interactions between native and target culture 
characters with respect to their cultural, inter-personal relationships, conversational topics, and the geographical setting which the interactions occur. Yet the interactions in the textbooks analyzed are much narrower than those discussed above, and by extension, less realistic.

Does Most Interactions Occur between Chinese-Chinese group? Chinese-American group? or American-American group?

As mentioned earlier, the insights into significant aspects of the target culture emerge from the interaction of the target culture characters, the American characters in the textbooks, with the symbolic representatives of the culture of the students, the Chinese characters in the textbooks. However, the textbooks present little interaction between Chinese and American characters (19.3\%), less than one fifth of the total characters' interactions. This prevents students from gaining insights into significant aspects of American culture. In addition, the emphasis on the interactions of Chinese characters with other Chinese characters (35.1\%) and American characters with other American characters (45.6\%--see Table 20) seems to discourage cross-cultural communication. For the characters from different cultural groups, the proposed goal of promoting cross-cultural understanding is not promoted because little contact is offered.

Types of Interpersonal relationships presented between American and Chinese Characters, Chinese and Chinese Characters, American and American Characters

These three inter-cultural and intra-cultural interactions presented five types of 
relationships. The results show that the common relationships between characters within inter-cultural and intra-cultural interactions are friends and incidental. Interestingly, these two types of relationships are also the only types presented in inter-cultural relationships. Family relationship occurred only between ChineseChinese characters and American-American characters (see Table 21). Work mate relationships are presented only in Chinese-Chinese interactions

Different types of cross-cultural relationships may bring in different kinds of cultural perspectives. For example, the way I see American culture through the discussion of academic issues with my teacher is different from the way I see the American culture through working with my boss on business issues. What I know about American culture is different from living with my host family and from a conversation with people at a party. Therefore, it is important to give students opportunities to build up various relationships with American characters they encounter through Chinese characters in the textbooks. By doing so, students would understand the American culture better from different perspectives. Meanwhile, they might be aware of their own culturally-induced behavior through a comparison with a variety of perspectives. However, the textbooks fail to do this. The textbooks present only friend and incidental relationships between Chinese and American characters. Also, the emphasis of a few types of relationships depicts a very unrealistic portrayal of Chinese-Chinese interaction in Taiwan. The presentation of the relationships of friends and incidentals between Chinese and Americans seems to 
closely parallel the types of relationships between Chinese and American people in Taiwan. Although the foreign teacher-Taiwanese student relationship is also a popular one, it is not presented. There is a cost for this conservative presentation from the perspective of reaching the goal of cross-cultural communication.

Conversational topics discussed in inter-cultural and intra-cultural interactions

The results show that there is a broader spectrum of conversational topics discussed in Chinese-Chinese character interaction than in the interactions of American-American and Chinese-American. Six kinds of topics were discussed between Chinese and Chinese characters; three kinds were discussed between American and American characters, and two kinds were discussed between Chinese and American characters. The topics related to trivial and daily life are the only two types of conversational topics Chinese characters and American characters talk about. Personal issues are only discussed between American characters and between Chinese characters (see Table 22). When students do not see examples of deep cross-cultural friendships modeled in their textbooks, they are unlikely to see these friendships modeled in their own lives if for example, their families are not international business people, they will be unable to engage in such behavior themselves. As Amir ( 1976) indicates, without culture contact, there is no possibility of attitude change toward members of the other culture. 


\section{Where do the Interactions Occur?}

The results show that $84 \%$ of the interactions occurred in Taiwan and $16 \%$ in the U.S. (see Table 23 ); $94.7 \%$ of the interaction occurred in urban areas and only $5.3 \%$ occurred in rural areas (see Table 24). Although characters' interactions occurred in several types of settings, $58.7 \%$ of interactions occurred in a home setting (see Table 25). People interact differently in different contexts, for example, the contexts of country location, geographical area (urban or rural) and setting. People in Taiwan and people in the U.S. might talk about the same issue, for example, China's military practice in the Taiwan Strait in March 1996, but from different perspectives. This could happen in inter-cultural interaction and it could even happen in intracultural interaction. That is, the Chinese people in Taiwan might have somewhat different ideas from the Chinese people in the U.S., and the Americans in the Taiwan might also hold different pictures about this issue than the Americans at home. The way people greet each other in the countryside might also be different from the way people do so in big cities. People might also discuss different topics with their classmates at school than with their colleagues at the work place. The variation of conversational topics, different perspectives, and different ways of greetings are important information students could use to learn about American culture and reflect back on their own.

These variations are important tools that help students going through stages of stereotyping. However, according to the results, the textbooks place an over- 
emphasis on Taiwan urban areas and the home setting. This presentation does not offer students adequate information about the breadth and diversity of Chinese culture in Taiwan. Neither necessary quantity information is given nor necessary quality information about American culture to help students understand different tributary cultures in the U.S. and elsewhere. My personal experience might help to explain this. I experienced culture shock when I arrived at Portland years ago. I was surprised to see even strangers greet each other on the street. My impression before I came here was that most American people were too busy to say hello.

\section{Section IV}

Level(s) of Culture Dealt with in the Junior High English Textbooks What Topical areas do the readings deal with?

The results show that the focus of the reading topics are in the areas of "character description" (52\%) and issues about cultural values. When the readings describe characters' background information, about half the time they discuss it with the combination of some cultural perspectives (24\%). When the readings dealt with cultural values, they usually dealt with the topics related to the values of culture in general $(12 \%)$ more often than culture in specific $(8 \%)$ (see Table 26$)$. When the readings address culture in specific, they discuss only Chinese culture.

There are several problems with this presentation. Culture is commonly believed to be a total way of life. The emphasis on the characters' daily life and trivial 
topics left out other important cultural components like the history, economy, and social political problems that would offer students an outline of that culture

\section{Levels of Culture Readings Dealt with}

The readings addressed more surface culture $(64 \%)$ than deep culture $(32 \%--$ see Table 28). The readings emphasized character description from a surface cultural perspective, like shopping and vacations. Only very few of them attempted to link those more overt behavioral and cultural features with their underlying values, assumptions and motivations.

Surface culture is one of the important culture elements when learning foreign cultures, and it is usually the first information students learn from their first contacts with foreign cultures. From that piece of overt information and their own culture values, students make an hypothesis and draw a picture based on this blue-print of the hypotheses about that culture. These first steps bring students to the door of a new world. However, these steps could also trap them for life in a stereotyped image about that culture, if they don't move on through that door toward the level of deep culture. From deep culture students learn explanations for overt behavior so that they can re-evaluate and reformulate their prior hypothesis to learn what people in other cultures do and to understand why things are done certain ways. At the same time, they might also learn to understand, tolerate, and respect other cultures, so that they can see themselves and their society in the eyes of the rest of the world.

People can embrace a new culture as they gain insight into themselves. 
However, people could also lose or resent that target culture when they know only the tip of the iceberg of that culture and when one day, or most days, they bump into the big ice under the water. The reading in these junior high school English language textbooks provide students very little American information. Within this limited information, the readings only introduce students to the surface level of American culture. They ignore the parts below the surface. This kind of presentation is dangerous because it gives students a stereotypical image about American culture and can damage cross-culture communication. Topics like vacations and outdoor activities give students superficial and stereotyped images of American culture. For example, when a reading dealt only with overt topics about overt shopping behavior, it probably only reinforced stereotyped ideas about American capitalism, but did nothing to help students to understand why the American people respect some successful businessmen as heros.

The over-emphasis on Chinese surface level culture does not allow students to learn Chinese values in a reflective way--- by comparing Chinese values with the values of other cultures. From my schooling experience, I believe that students are taught Chinese values through other courses. However, these courses are usually taught only from an insider's view. In addition, although the American culture is the only foreign culture represented in the textbooks, the readings present very little information about this culture. Students will not be able to see the American culture as a whole when they are only offered a partial profile. 


\section{Section V \\ The Manner of Presentation of Socio-cultural Information \\ Do the readings portray culture from a historical view?}

For those people like me who believe that culture is a pattern of life for a group of people, history is the key to learn about that culture in depth. If culture is described as static, we can only understand from a grasp of the moment of its existence. According to De Meo (1980), if the objects of culture can be described as the moment of their existence that one wishes to grasp, then they can be described synchronically. However, "inevitably the past passes into the present where it again becomes active; thus the dimension comes necessarily to inhabit the synchronic moment; both will be necessary if the full intelligibility of the object is to be grasped" (De Meo, p.6). According to the results, the majority of readings which discuss cultural issues are viewed from an historical dimension (60\%--see Table 29). Those readings attempts to link the present with past perspectives on the subject addressed and this presentation helps to elucidate the present. All the readings give the information about the past life of the characters (100\%--see Table 30$)$ to help students understand the characters' present status. In general, there is an attempt to develop a history of the topics of a culture and the history of the characters as well. 
Do the questions related to the readings emphasize mnemonic processes or heuristic understanding?

Post reading questions put an extreme emphasis on mnemonic processes rather than heuristic understanding. In the total of 234 follow-up comprehensive questions of the readings, only eleven of the total questions called for reflection, and inductive and synthesis reasoning. Emphasis on factual recall of questions discourages students from discovering new insights into themselves because the comprehension questions were not set up in a way to stimulate reflective thinking.

\section{Section VI}

Other Issues

\section{$\underline{\text { About Book III }}$}

According to the proposed goal by the Ministry of Education of Taiwan, textbook three is not supposed to be the place where the Chinese and Western cultures appear. However, according to the results of the randomly chosen lesson, cultural information occurred in this lesson, although that information is stereotyped and on a surface level. For example, there are American characters who are presented as young, blond haired, blue eyed, problem free, and apparently possessing a higher education. The results suggest that even when the goal of foreign language study is not officially focused on culture study, cultural messages might still be given. 


\section{Conclusion}

The textbooks fail to reflect the cultural study goal of promoting a true understanding of the societies and the cultures of the Republic of China and other countries. The textbooks provide a narrow spectrum of socio-cultural elements. They fail to recognize the other countries, at least the ten major trading countries with Taiwan, as members of this planet by presenting the U.S. as the only representative of foreign cultures. This presentation does not reflect the culture studies goal, and neither confirms De Meo's theory, or Byram's educational goal of culture study.

Although American culture is the only foreign culture presented, the textbooks do not provide in-depth insights into American culture. American characters were presented only as a small population of all characters. In addition, American culture is presented on a surface level through the characters' oversimplified and romanticized images. American characters seems to be involved only with a daily life routine and they discuss basically trivial and daily life issues. For example, bathing, house cleaning, and fixing radio, etc. The image of American culture is stereotyped. The American characters are predominantly young, students, artists, problem free, interested in arts, and highly educated.

Although Chinese culture appears to be promoted by the accentuating of Chinese characters' occurrences, Chinese culture is also depicted superficially. Chinese characters are primarily involved in daily life and entertainment, and they basically discuss trivial issues. For example, delivering newspapers, scheduling 
weekend, and shopping, etc. The portrait of Chinese people is also stereotyped. They appear to be young, students, with no interests, problem free, and possess junior high or high school level education.

De Meo (1980) suggests that the insights about target culture emerge from the interaction between the native and target culture characters. A successful target culture character should be defined more fully than the native characters so that students are allowed to invest themselves in the native character, and to be provided with more adequate information about the target culture. However, the Taiwanese English textbooks do not conform to her theoretical scheme. They present only a small portion of American characters and provide very little interaction between Chinese and American characters. When they interact with each other, they interact on a rather simplistic and superficial level. They are confined to friend and incidental relationships, and they discuss only trivial and daily life issues with no discussion on American culture bearers. Family and intimate relationships occurred only between two Chinese characters and two American characters. Personal issues were also only discussed between these intra-cultural groups. The textbooks not only fail to conform to De Meo's theory, but also seem to promote intra-cultural communication and discourage the inter-cultural communication which is necessary in order to reach the cultural study goal of understanding the socio-culture of Chinese and others.

In addition to the presentation through characters' social backgrounds and interactions, the readings also emphasized surface level culture, and only very few of 
them attempt to link those overt behavioral and cultural features with their underlying values, assumption, and motivations. Most readings describe characters' background information. About half of the readings that describe characters' information address it from some culture aspects. More readings dealt with culture in general rather than culture in specific.

As De Meo suggests, "the culture of a society at a given time functions within a matrix defined by past actions which are still felt and by a wide variety of current actions oriented towards a future goal" $(1980$, p. 5). Therefore, it is important to see a culture from a vertical view in order to gain the in-depth insight of that culture. The textbooks tend to present the socio-cultural information by linking the past and present. Most of the readings regarding a specific culture are described from a historical view, and all the characters are presented with the support of their past life information. De Meo also suggests that the post-reading questions will guide students to a heuristic understanding of the significant aspects of the culture students learn. However, the post-reading questions presented in the textbooks focus extremely on a factual nature, and the way the questions are posed is from the stance of recall. This presentation would not help students to a heuristic understanding, but only reinforce the superficial and stereotyped information they learned through the readings.

This analysis of the textbook content has provided measurable descriptions of how culture is taught in junior high school English classes in Taiwan. The 
descriptions of what is lacking are designed to provide a base for curriculum planners to work from should revision of this material be undertaken.

\section{Implication}

Textbook writers need to work more effectively to include a broader range of characters representing a more accurate spectrum of English language users whom Taiwanese students are likely to encounter in the Pacific Rim. 


\section{BIBLIOGRAPHY}

Aries R.(1982). The textbook as curriculum, 11-33 in Theodore V. H. (ed.) Curriculum, competence, and the foreign language teacher. American Council Language Education Series. Skokie, IL: National Textbook.

Asia Society. (1976, May). Asia in American Textbooks. New York: Author. (ED 127 232).

Botan, C.H., Frey, R.F., Friedman, P.G. and Kreps, G.L. (1992). Interpreting communication research: A case study approach. Englewood Cliffs, NJ:

Prentice Hall.

Byram, Michael (1988) "Foreign Language Education and Cultural Studies." Language, Culture and Curriculum 1: 15-31 McGraw-Hill.

Byrd, M.L. (1993). The Intra cultural communication book. New York:

Carroll, F. W. (1978). The limits of my language are the limits of my world, 49-60. In R. Freudenstein, (ed.), The role of women in foreign language textbooks: A collection of essays. Ghent, Belgium: Association International pour la Recherche et la Diffusion des Methods Audio-Visualles et Structuro-Globales (ED 209 914).

Cradall, J., Kearny, E.N.\& Kearny, M.A. (1984). The American way: An Introduction to American culture. Englewood Cliffs, NJ: Prentice-Hall Regent.

Damen, L. (1987). Culture learning: The fifth dimension in the language classroom. Reading, MA: Addison-Wesley.

De Meo, Patricia (1980). Individual culture, objective culture, and the foreign language textbook (Doctoral dissertation, UCLA, 1980). Dissertation Abstracts International, $41,3459 \mathrm{~A}$.

Department of Elementary Education of Ministry of Education of Taiwan (1983). Kuo Min Chung Hsueh Ko Cheng Piao Chun [The curriculum criterion of junior high school]. Taipei, Taiwan: Cheng Chung Book.

Department of Secondary Education of Ministry of Education of Taiwan (1983). Kao Chi Chung Hsueh Ko Cheng Piao Chun [The curriculum criterion of senior high school]. Taiwan: Cheng Chung Book. 
Fisher, F. L. (1968). Influences of Reading and Discussion on the Attitudes of Fifth Graders Toward American Indians. The Journal of Educational Research 62: 130-34.

Haugh, O. M. (1952). The Relative Effectiveness of Reading and Listening to Radio Drama as Ways of Imparting Information and Shifting Attitudes. The Journal of Educational Research 45: 489-98.

Hall, E. (1977). Beyond Culture. Garden City, N.Y.: Anchor Press / Doublenday 17.

Hernandez V., Jorge Enrique (1986). The socio-cultural content of English as a foreign language textbooks used in Costa Rican public secondary schools: Relationship to national educational goals and the development process (Doctoral dissertation, University of Minnesota, 1986). Dissertation Abstracts International, 47, 2437A.

Jacoby, N. (1966). U.S. Aid to Taiwan: A Study of Foreign Aid, Self-Help, and Development. New York: Frederick A. Praeger, Inc.

Joiner, E. (1974, September-October). Evaluating the cultural content of foreign language texts. The Modern Language Journal, pp. 242-4.

Keenan Barry C. \& Chen Theodore H.E. (1971). "China: History of Chinese Education." Encyclopedia of Education, 2, Ed. Delighton, L.C. 10 vols. New York: The Macmillian \& the Free Press.

Kerlinger, F. (1973). Foundations of Behavioral Research (2nd ed.). New York: Holt, Rinehart and Winston.

Kennedy J. Kennedy (1977). A study of the educational system of the Republic of China and a guide to the academic placement of students in educational institutions of the United States. A Service of the International Education Activities Group of the American Association of Collegiate Registrars and Admissions Office.

Kraemer H. C. (1982). Kappa Coefficient. Encyclopedia of Statistical Sciences, 4: 352-54.

Quillen, I. J.(1950). Textbooks Contribute to World Understanding. Educational Leadership, 8:36-40. 
Riordan, C. (1978). Equal-status interracial contact: a review and revision of the concept. International Journal of Intercultural Relations, 161-185.

Robinson, Gail L. "The Magic-Carpet-Ride-to-Anther-Culture Syndrome: An International Perspective." Foreign Language Annuals 11(1978): 135-46.

Rothenberg P.(1988). Racism and sexism: An integrated study. New York: St. Martin's Press.

Scarcely, R. (1990). Teaching language minority students in the multi cultural classroom. Englewood Cliffs, NJ: Prentice Hall

Schmitz, Betty. (1975). Sexism in French language textbooks. In R. Lafayette (Ed.), The Cultural Revolution in foreign language teaching (pp.119-130). Report of the Cintral States Conference on Foreign Language Education. Lincolnwood, IL: National Textbook Co.

Stotsky, S.(1992, April). Academic criteria for conceptualizing multiethnic and multi cultural literature programs in American schools. Paper presented at the meeting of the American Educational Research Association, San Francisco, CA, April 20-24, 1992. (ED 288 772).

Stempel, G.H., III (1989). Content analysis. In G.H. Stempel III and B.H. Westly (Ed.), Research methods in mass communication (2nd ed, pp. 124-129). Englewood, Cliffs, NJ: Prentice Hall.

Teaching English in Taiwan (1994). [Author unknown. This paper was received from my advisor who was a blind reader for the TESOL Quarterly board. There is no further information available on this manuscript].

Weber, R.P. (1985). Basic content analysis. Beverly Hills, CA:Sage.

Wirtenberg, J, et al. (1980). Characters in textbooks: A review of the literature. Washington, D.C.: Commission on Human Rights. (ED 190 718.)

Yang C.K. (1959). Some Characteristics of Chinese Bureaucratic Behavior In David S. Nivision \& Arthur F. Wright (ed.), Confucianism in Action. Stanford, California: Stanford University Press.

Yee, Albert H. (1973) "Myopic Perceptions and Textbooks: Chinese Americans Search for Identity." Journal of Social Issues 29:99-113. 
APPENDIX A

CODING MATERIALS 


\title{
APPENDIX A
}

\author{
Coding Materials Notes
}

The Materials you will be Given

1. Three textbooks of levels 5,6 and 3 .

2. A list of instructional units and the sections in them that need to be coded for the different major areas of information.

3. A list of codes to identify the materials (Material identification codes).

4. A set of general instructions applies to the all areas.

5. A set of specific instructions for each area.

6. A booklet with specific definitions and codes for each category within the variables of each major area (Distribution of variables, codes and definitions of the categories under each area).

7. Tabulation sheets where you are to write your coding of the materials in the appropriate coelum. 


\section{$\underline{\text { Sample of Instructional Units and Their Selected Sections for Analysis }}$}

Area I The National Origin and Social Backgrounds of Characters

Textbook 5 Units 1-12

Readings

Textbook 6 Units 1-12

Readings

Textbook 5 Units 1-3/ 5-7/9-11

Dialogue

Textbook 6 Units $1-3 / 5-7 / 9-11$

Dialogue

Textbook 3 Units 6

Reading/Dialogue

\section{Area II Interpersonal Relations}

Textbook 5 Units 1-12

Textbook 6 Units 1-12

Textbook 5 Units $1-3 / 5-7 / 9-11$

Textbook 6 Units $1-3 / 5-7 / 9-11$

Textbook 3 Units 6
Readings

Readings

Dialogue

Dialogue

Reading/Dialogue

Area III Conversational Topics, Problems-Concerns, Interests and Activities

Textbook 5 Units 1-3/5-7/9-11 Dialogue

Textbook 6 Units 1-3/5-7/9-11 Dialogue

Textbook 3 Units $6 \quad$ Dialogue

Area IV Explicit Information and Historical_Dimension

Textbook 5 Units 1-12

Textbook 6 Units 1-12

Readings

Textbook 3 Units 6

Readings

Reading

\section{Area V Manner of Presentation}

Textbook 5 Units 1-12 Post-reading questions

Textbook 6 Units 1-12 Post-reading questions

Textbook 3 Units $6 \quad$ Post-reading questions 


\section{Material Identification Codes}

Codes

Textbooks

1. textbook 5

2. textbook 6

3 textbook 3

Instructional Units

\begin{tabular}{|c|c|}
\hline 01. unit 1 & 07. unit 7 \\
\hline 02. unit 2 & 08. unit 8 \\
\hline unit 3 & 09. unit 9 \\
\hline unit 4 & unit 10 \\
\hline unit 5 & anit 11 \\
\hline unit 6 & 12. \\
\hline
\end{tabular}

Page Numbers

Use the three column to write the numbers.

Use two zeros before a 1 digit number.

Use one zero before a 2 digit number.

001

010

099

100

150

Unit Dialogue Number

For units that have more than one dialogue.

1. Dialogue 1 in the unit.

2. Dialogue 2 in the same unit.

Total Dialogue Number

A cumulative record of dialogues through the coded textbooks.

From 01.

10 .

99.

Character Number

A cumulative record of characters through the coded textbooks.

From $001 \ldots$

010.

099.

100 


\section{Reading Numbers}

A cumulative record of reading. From 01 ...

$$
10
$$

99

\section{Unit Post-Question Numbers}

01 Post-question 1 in the unit

02 Post-question 2 in the unit

03 Post-question 3 in the unit

04 Post-question 4 in the unit

05 Post-question 5 in the unit

06 Post-question 6 in the unit

07 Post-question 7 in the unit

08 Post-question 8 in the unit

09 Post-question 9 in the unit

10 Post-question 10 in the unit

\section{Total Post-Question Numbers}

A cumulative record of dialogues through the coded textbooks From $001 \ldots$

$010 \ldots$

100 .

$101 \ldots$

100 . 


\section{GENERAL INSTRUCTIONS}

There are five major areas of information to be gathered from the sections of readings and/or dialogues and/or post questions of selected lessons of the textbooks given through coding and analysis:

1. The national origin and social backgrounds of characters. (from readings $\&$ dialogues)

2. Interpersonal relations (from readings \& dialogues)

3. Conversational topics, problems-concerns, interests and activities. (from dialogues)

4. Explicit information and historical dimension. (from readings)

5. Manner of presentation. (from post-reading questions)

\section{Definition of characters}

The characters, in readings or dialogues in the instructional units of textbooks, who are (1) actually appear in the illustrations and at least one of the following: (2) identify by name or involved in dialogues or whom information is provided in the reading. The use of the label "Mr. or Mrs." followed by a last name and family/ relative relations (e.g. father, cousin etc.) or occupation (police officer, shop owner) will also constitute a character. Also anyone identified as an elected public official using the name of the position held (i.e. governor, senator). Anyone mentioned by name only but not presented in any of the illustrations should not be taken as a character.

\section{Instructions}

1. Characters who are students and who also work are classified students if most of their appearances are in a school setting. Characters who are students but for whom most appearances take place in the workplace setting should be classified according to the identified occupation.

2. Characters who are repeated throughout the readings and dialogues in the units of textbooks should be identified by name the first time that they are introduced in either a dialogue or a reading. The rest of their appearances throughout the units should be used to gather information on the character, in order to do the coding for that character in the various categories of classification.

3. To do the coding for the five major areas of information, you should proceed in the order given above and following the instructions that appear in the first page of your codes booklet for each of the five major areas of information. 
4. If you don't have enough information about a character, leave the check box in blank. Wait till you finish the coding of all instructional units and if you still don't have information about him/her then code it as category "unspecified" (\#9). 


\section{CODING INSTRUCTIONS FOR AREA I: THE NATIONAL ORIGIN AND SOCIAL BACKGROUNDS OF CHARACTERS}

This is the first section you should code.

1. Read the definitions, codes, and specific instructions that are provided for Area I in the booklet labeled "Distribution of variables, codes and definitions of categories under each variable" of area I. Clarify any doubts before you begin coding.

2. Check the list of sections you are to use for the coding of this area. Code only the sections of reading and dialogue(s) from the selected units.

3. Read the readings and dialogues that appear in the list of sections selected for analysis in each textbook. First code the characters who appear in the readings of texts 1,2 and 3 ; then code those who appear in dialogs of texts 1,2 and 3 .

4. Write the name of the character on the left side of the tabulation sheets for this area. Remember that the characters to be coded are only the individuals who (1) actually appear in the illustrations and (2) are at least one of the following: identified by name, who are actually involved in dialogues, or about whom information is provided in the reading.

5. Characters who are repeated throughout the readings and dialogues in the units of textbooks should be identified by name the first time that they are introduced in either a dialogue or a reading. The rest of their appearances throughout the units should be used to gather information on the character in order to do the coding for that character in the various categories of classification. In other words, you do not code the same characters who are repeated in later units. Therefore, when characters have the same name, you have to first try to identify whether they are the same character. If they are the same character, code him or her only for the first appearance and use the rest of the information as extra information for that character. If they are not the same person, then code all of them and label them by number, e.g. Joe \#1, Joe \#2, Joe \#3 and so on.

6. Follow the characters through the material. As you proceed through the material and gather information about the characters, fill in the box in the tabulation sheet with the code that corresponds to your choice for each character and variable. If you do not have sufficient information to code a given variable for a character, leave the space blank and come back later to place your code after you gathering more information by going through the units in the textbook. Sometimes you may need to go through the entire book before you gather all the information about a character. 
7. To code a character in the entire set of variables for Area I you may need, in some cases, to look at illustrations very carefully in order to follow a character through the units of a textbook or even from one level to the next (i.e., a character who first appears in textbook 5 then appears later in textbook 6). Use both the names and illustrations in order to follow them through.

8. Look at illustrations for additional help for coding. If a character has an Asian appearance but no other explicit information about their national origin is given, assume he or she is a Chinese from Taiwan.

9. Under the "Identification" section marked on the tabulation sheet you need to write: (1) the character number beginning with number 001 for the first character whose name you code and proceeding to give numbers to them cumulatively as you identify each new character; (2) the textbook number you are coding; (3) the unit number, which is the lesson number; (4) the page number in which the character is described in a reading or dialog for the first time; and (5) your initial as a coder. Refer to the codes in "Materials Identification Codes" to make these classifications.

10. Always review the definitions of the categories for the variables before you code a character into a category for that variable. 


\section{CODING INSTRUCTIONS FOR AREA II \\ INTERPERSONAL RELATIONS}

This is the second section you should code.

1. Read the definitions, codes, and specific instructions that are provided in the booklet labeled "Distribution of variables, codes and definitions of categories under each variable" for area II. Clarify any doubts before you begin the coding.

2. Check the list of sections you are to use for the coding of this area. For this section, you will need to work only on the sections of readings and dialogue(s) of the selected units in textbooks. Complete the coding reading section of a selected unit before proceeding to the dialogue section in the same unit.

3. Because you are coding the same characters already identified in section I "The National Origin \& Social Backgrounds," you only need to copy their names you have coded in area I into the column of the left side of the tabulation sheet for this Area.

4. Under the "Identification" section marked on the tabulation sheet you need to write (1) total reading number beginning with number 01 for the reading \#1 of unit \#1 of textbook \#1, and continue the successive numeration as the readings appear; (2) textbook number you are coding; (3) unit number; (4) page number in which the character appears for the first time; (5) your initial as a coder. Refer the codes in "Materials Identification Codes" to make these classifications.

5. Because you are coding the national origin of the same characters already identified in section I "The National Origin \& Social Backgrounds," you only need to copy the codes of the variable, "national origin" which you have coded into the column under variable "nationality of characters" on the middle of the tabulation sheet for this Area.

6. Always review the definitions of the categories for the variables before you code a character into a category for that variable.

7. Repeat instruction $\# 5$ through $\# 8$ for coding dialogue sections (except substitute reading as dialogue).

8.Look at illustrations for additional help for coding. 


\section{CODING INSTRUCTIONS FOR AREA III: \\ CONVERSATIONAL TOPICS/ PROBLEMS-CONCERNS/ \\ INTERESTS/ACTIVITIES}

This is the third area of analysis.

1. Read the definitions, codes, and specific instructions that are provided in the booklet labeled "Distribution of variables, codes and definitions of categories under each variable" for area III. Clarify any doubts before you begin the coding.

2. Check the list of sections you are to use for the coding of this area. To code this area, you only need to look at the dialogues in the selected units.

3. Because you are coding the same characters already identified in section I "The National Origin \& Social Backgrounds," you only need to copy their names you have coded in area I into the column of the left side of the tabulation sheet for this Area.

4. Under the "Identification" section marked on the tabulation sheet you need to write (1) total dialogue number beginning with number 01 for the dialogue \#1 of unit \#1 of textbook \#1, and continue the successive numeration as the dialogue appear;(2) unit dialogue number (3) textbook number you are coding; (4) the unit number; (5) the page number in which the dialogue appears for the first time; (6) your initial as a coder. Refer the codes in "Materials Identification Codes" to make these classifications.

5. Because you are coding the national origin of the same characters already identified in section I "The National Origin \& Social Backgrounds," you only need to copy the codes of the variable, "nationality" which you have coded into the column under variable "national origin" on the middle of the tabulation sheet for this Area.

6. Always review the definitions of the categories for the variables before you code a character into a category for that variable.

7. Look at illustrations for additional help for coding. 


\section{CODING INSTRUCTIONS FOR AREA IV: \\ EXPLICIT INFORMATION AND HISTORICAL DIMENSION}

This is the forth area of analysis.

1. Read the definitions, codes, and specific instructions that are provided in the booklet labeled "Distribution of variables, codes and definitions of categories under each variable" for area IV. Clarify any doubts before you begin the coding.

2. Check the list of sections you are to use for the coding of this area. To code this area, you only need to look at the readings in the selected units.

3. Under the "Identification" section marked on the tabulation sheet you need to write (1) total reading number beginning with number 01 for the reading \#1 of unit \#1 of textbook \#1, and continue the successive numeration as the readings appear, (2) textbook number you are coding; (3) unit number; (4) page number in which the character appears for the first time; (5) your initial as a coder. Refer the codes in "Materials Identification Codes" to make these classifications.

5. Always review the definitions of the categories for the variables before you code a reading into a category for that variable.

6. Look at illustrations for additional help for coding. 


\section{CODING INSTRUCTIONS FOR AREA V: \\ MANNER OF PRESENTATION}

This is the last section you code.

1. Read the definitions, codes, and specific instructions that are provided in the booklet labeled "Distribution of variables, codes and definitions of categories under each variable" for area V. Clarify any doubts before you begin the coding.

2. Check the list of sections you are to use for the coding of this area. To code this area, you only need to look at the dialogues in the selected units.

3. Under the "Identification" section marked on the tabulation sheet you need to write (1) the total question number beginning with number 001 for the question \#1 of unit \#1 of textbook \#1, and continue the successive numeration as the question appear; (2) the unit question number (3) the textbook number you are coding; (4) the unit number; (5) the page number in which the first question appears; (6) your initial as a coder. Refer the codes in "Materials Identification Codes" to make these classifications.

4. Always review the definitions of the categories for the variables before you code a question into a category for that variable. 


\section{DISTRIBUTION OF VARIABLES, CODES, AND DEFINITIONS OF THE CATEGORIES UNDER EACH AREA}

Area I

National Origin \& Social Backgrounds of Characters

See the general instructions to get a general idea of the coding process. Then you must read the specific instructions for each individual area. These are provided separately for each area of information along with the codes for each category of classification. In this area, you are to identify the characters appear in reading and dialog according to the definitions and codes below. Characters can be identified when the character explicitly express his or her nationality or from the references of his job, school, the place he lives, etc.

\section{National Origin}

Characters' national origins are identified according to the countries they from. The following information was cited from "The Europa World Year Book 1994." When the characters have an Asian appearance but have no other explicit information is given, assume that they are Chinese from Taiwan.

001 Afghanistan

002 Albania

003 Algeria

004 Andorra

005 Angola

006 Antarctica

007 Antigua and Barbuda

008 Argentina

009 Armenia

010 Australia

011 Austria

012 Azerbaijan

013 The Bahamas

014 Bahrain

015 Bangladesh

016 Barbados

017 Bearus

018 Belgium

019 Belize

020 Benin 
021 Bhutan

022 Bolivia

023 Bosnia and Herzegovina

024 Botswana

025 Brazil

026 Brunei

027 Bulgaria

028 Burkina Faso

029 Burundi

030 Cambodia

031 Cameroon

032 Canada

033 Cape Verde

034 The Central African Republic

035 Chad

036 Chile

037 China, People's Republic

038 China (Taiwan)

039 Colombia

040 The Comoros

041 The Congo

042 Costa Rica

043 Cote d,Ivoire

044 Croatia

045 Cuba

046 Cyprus

047 Czech Republic

048 Denmark

049 Djibouti

050 Dominica

051 The Dominican Republic

052 Ecuador

053 Egypt

054 El Salvador

055 Equatorial Guinea

056 Eritrea

057 Estonia

058 Ethiopia

059 Fiji

060 Finland

061 France

062 Gabon

063 The Gambia 


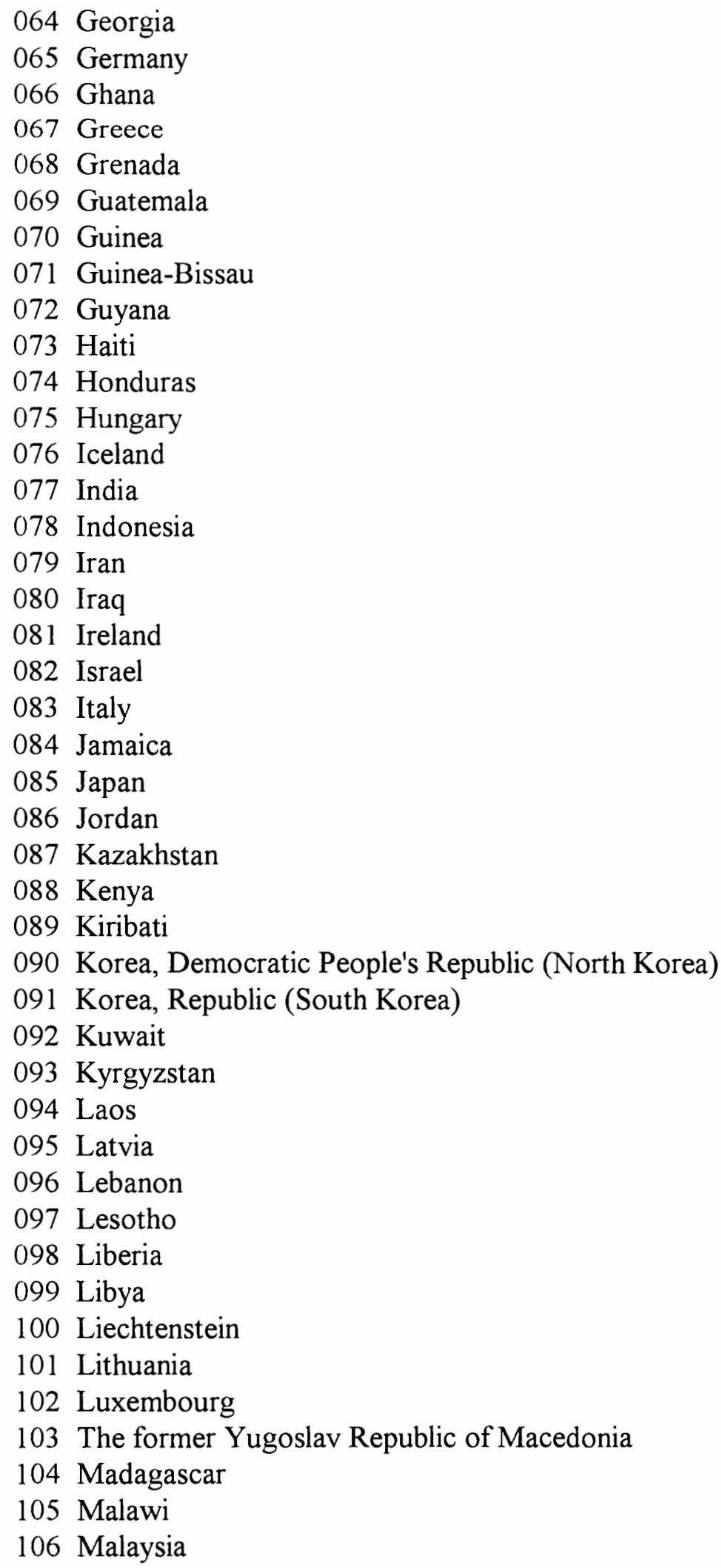


107 Maldives

108 Mali

109 Malta

110 The Marshall Islands

111 Mauritania

112 Mauritius

113 Mexico

114 The Federated States of Micronesia

115 Moldova

116 Moldova

117 Monaco

118 Mongolia

119 Morocco

120 Mozambique

121 Myanmar

122 Namibia

123 Nauru

124 Nepal

125 The Netherlands

126 New Zealands

127 Nicaragua

128 Niger

129 Nigeria

130 Norway

131 Oman

132 Pakistan

133 Panama

134 Papua New Guinea

135 Paraguay

136 Peru

137 The Philippines

138 Poland

139 Portugal

140 Qatar

141 Romania

142 The Russian Federation

143 Rwanda

144 Saint Christopher and Nevis

145 Saint Lucia

146 Saint Vincent and the Grenadines

147 San Marino

148 Sao Tome and Principe

149 Saudi Arabia 
150 Senegal

151 Seychelles

152 Sierra Leone

153 Singapore

154 Slovakia

155 Slovenia

156 Solomon Islands

157 Somalia

158 South Africa

159 Spain

160 Sri Lanka

161 Sudan

162 Suriname

163 Swaziland

164 Sweden

165 Switzerland

166 Syria

167 Tajikistan

168 Thailand

169 Togo

170 Tonga

171 Trinidad and Tobago

172 Tunisia

173 Turkey

174 Turkmenistan

175 Tuvalu

176 Uganda

177 Ukraine

178 The United Arab Emirates

179 The United Kingdom

180 The United States of America

181 Uruguay

182 Uzbekistan

183 Vanuatu

184 The Vatican City

185 Venezuela

186 Viet Nam

187 Western Samoa

188 Yemen

189 Yugoslavia

190 Zaire

191 Zambia

192 Zimbabwe 
999 Unspecified: When the country is not be able to identified because the lack of information

\section{$\underline{\text { Gender }}$}

1 Male: characters whose physical characteristics and names are those of a male.

2 Female: Characters whose physical characteristics and names are those of a female.

\section{Occupation}

Use the codes on the left column to identify the job in the tabulation sheet. For those jobs of the characters you identify with are not included in this list please add them and give them numbers starting from the next number of the last number of this list (No.

$60)$.

Please read the definitions of those occupations marked with an asterisk before you do any coding of occupations.

$\begin{array}{ll}01 & \text { actor } \\ 02 & \text { advertising, sales rep. } \\ 03 & \text { announcer, television } \\ 04 & \text { archeologist } \\ 05 & \text { architect } \\ 06 & \text { * armed forces } \\ 07 & \text { artist } \\ 08 & \text { athlete, professional } \\ 09 & \text { busboy (dinning room attendant) } \\ 10 & \text { businessman } \\ 11 & \text { cashier } \\ 12 & \text { clerk, general } \\ 13 & \text { computer programmer } \\ 14 & \text { computer terminal operator } \\ 15 & \text { construction inspector } \\ 16 & \text { construction worker } \\ 17 & \text { cook } \\ 18 & \text { diplomat (foreign service officer) } \\ 19 & \text { designer } \\ 20 & \text { doctor } \\ 21 & \text { editor } \\ 22 & \text { engineer }\end{array}$


23 farmer

24 Fashion designer

25 fire-fighter

26 flight attendant

27 forester

28 housekeeper

29 importer, whole sales

30 insurance, sales agent

31 janitor

32 lawyer

33 librarian

34 mail carrier

35 manger (any type of)

36 mechanic, auto

37 medical lab technician

38 nurse

39 painter (artist)

40 parking lot attendant

41 police officer

42 president/executive

43 producer, television

44 professor (college)

45 real estate sales agent

46 reporter

47 retired

48 secretary

49 service station attendant

50 student

51 supervisor (garment manufacture)

52 taxi driver

53 teacher (elementary/secondary)

54 tourist

55 truck driver

56 typist

57 unemployed

58 writer

59 waiter/waitress

$99 *$ unspecified

00 other (specify_add the category that you think is appropriate to this list and number it on the blank space below. Start with number 60)

* Armed forces: any character who is identified as working for the armed forces should simply be classified as armed forces. No further specification of occupation is 
necessary.

* Unspecified: this category is for those characters whose occupation is not possible to identify due to the lack of information. When no occupation is given code it as unspecified.

60 Housewife

61 Fisherman

62 Owner of a company/factory/store

63 Cartoonist, showman, film producer

64 Musician

Age

$1 \quad$ Infants and children: (0-12)

Characters who are portrayed as infants or whose age is explicitly stated and falls with the range of 1 to 12 . Also those characters who are presented as elementary school students.

2 Teenagers: (13-18)

Individuals who are explicitly identified as teenagers, and or who are presented as high school students.

Individuals whose age is directly given and falls within the range of 13-18.

$3 \quad$ Young adults/adults: (19-59)

Individuals presented as college students, employees of industries, factories, institutions, businesses.

Individuals whose age is explicitly given and falls within the range of 19-59.

4 Elderly: (60 and over)

Individuals who are presented as retired, or of retirement age. Characters who are explicitly described as being 60 years or older, and/or as elderly individuals.

9 Unspecified:

Individuals who by the above definitions can not be classified in the above categories due to lack of information.

0 Others:

When age variable is not apply to the individuals. For instance, for the characters described had passed away. 
Note: If no specific age is given use the age of one of the peers for whom an specific age is given. If no peer's age is given guess the age (in intervals of five) of the character on the basis of the given information on the character (i.e. occupation, education, friends, settings, activities).

\section{Educational Level}

\section{College:}

Individuals who are presented as college students or whose identified occupations requires college level preparation. Also those described as having had a college education regardless of the number of years in college.

2 High school/ junior high school:

Individuals who are explicitly identified in the texts as only having completed a high school education.

Individuals who are explicitly described as having less than a high school education, or those in a grade level lower than 9th grade and higher than 6th grade.

3 Less than junior high school

Individuals who are presented as students of kindergarten or elementary school (1th grade to 6 th grade) or no education.

\section{Unspecified:}

For whom not sufficient information is given to determine their educational level.

0 Other:

Individuals identified as having attended a middle level trade school (i.e. art school, etc. unless the school is identified/ associated with a high school or college, in which case another category applies.)

Individuals who do not fall in the above categories. (specify_ add the category that you think is appropriate to this list and number it on the blank space below. Start with number 3)

Note: If no specific educational level is given use the educational background of one of the peers for whom a specific educational level is given. If no peer's educational level information is given guess the educational level on the basis of the given information on the character(i.e. occupation, age, friends, settings, activities). 


\section{$\underline{\text { Role Type }}$}

Active:

(1) Individuals who are shown using physical or mental power to affect change or cause action (working serving, practicing, functioning, performing, playing, studying, operating, transacting, or engage in a conversation, or students attending a class)

(2) Individuals shown doing something:

Producers, processors of materials, artists, craft persons, sculptors, experimenters; anyone repairing, constructing or experimenting with materials.

(3) Individuals interacting in athletics, dramatic arts, or other physical activities

(4) Individuals operating machinery or equipment; serving people.

(5) Individuals who are leaders, directors, problem solvers, decision makers.

(6) Individuals rendering professional services (doctors, engineers, teachers, counselors, lawyers, dentists, etc).

2 Passive:

Individuals shown watching, waiting or being idle. Characters not actively involved in the principal action. (Look carefully at the illustrations before classifying a character in this category.) 


\author{
Area II \\ Conversation Topics, Problems-Concerns, Interests, and \\ Activities
}

These categories apply to characters' conversations occurs in dialogues only. See the general instructions to get a general idea of the coding process. Then you must read the specific instructions for each individual area.

\title{
Nationality of Characters
}

Please refer the code of "country" in Area I. If no explicit reference is given, assume the setting to be in Taiwan.

\section{Conversational Topics}

* This section refers to what the characters talk about. The topics of conversation of the characters in the dialogue.

* Read the dialog and try to categorize the topic in one of the following categories

* When there is more than one topic being addressed, select the topic that is dominant, that is, the topic that takes the most lines in the dialog.

Codes (The key word of the phrases are underlined)

01 accidents (car or job accidents)

02 designing advertisements

03 borrowing something

04 business (expanding it/ doing a transaction/ looking for a business location, etc)

05 busy schedules (restricted to one's job schedule)

06 buying consumer goods. Also going shopping

07 a car/ car problems

08 ones's childhood/ or about neighborhood where one used to live

10 going out dancing

11 a date

12 what one did or was doing the day/ night before

13 driving violations

14 the quality of their education/training 
15 public elections, a public speech, a public appearance

16 an exam

17 family

18 family relations

19 a female (when two males talk about a female character, towards which one of the males makes explicit romantic interest)

20 a film

21 going to listen to music (tapes, albums, etc)

22 food

23 history or historical events in the eh country

24 doing school homework and assignments

25 international relations issues

26 Inviting someone for dinner, a party, a trip, etc.

27 getting a good or better job

28 a lecture

29 one's major in school (on a superficial basis, simply mentions it, or when talking about the school one attends or the time at which one attends school)

30 a male (when two females talk about a male character, towards which one of the females make explicit romantic interest)

31 marriage

32 missing a class, a meeting, an appointment, etc.

33 moving

34 about someone's need for a machine, an appliance, school supplies, etc.

35 the newspaper

36 a party

37 another person (when the conversation is about a workmate, a classmate, a pen $\mathrm{pal}$, another individual close by, a pupil in one's own classroom or school)

38 photographs

39 a picnic

40 planning activities for students, classmates, etc.

41 political issues

42 preparing or giving a political speech

43 practicing a skill (i.e. practicing a second language)

44 interpersonal relations (other than family)

45 one's daily schedule

46 being on schedule with one's workload (restricted to the workload in one's job. Not for students doing school work)

47 being sick

48 social problems (ecology, poverty, unemployment, etc).

49 sports

50 being on time

51 being transferred in the job

52 a trip 
53 unemployment/being unemployed

54 day's work plans weekend plans (this refers to plans for future day/weekend

55 how one spent a weekend

56 problems at work (with office equipment; finding a document, etc, but not related to busy schedules)

57 writing to one's relatives, friends

58 one's personal problems (psychological, etc)

59 a class (see code 32 for missing a class)

09 Unspecified

when the information is so limited that it is not possible to identify.

$00 \quad$ Others

(specify_add the category that you think is appropriate to this list and number it on the blank space below. Start with number 60 )

59 bathing (but not swimming)

60 run out of gas

61 get ride of rain

62 not to get sick

\section{$\underline{\text { Problems/Concerns }}$}

This section refers to those things or events about which the characters appear to be or state as being worried about. Mostly, it is a specific issue that they wish to resolve or they are running away from. Look for the problems/concerns that drives from the majority of the dialog. See what most of the dialog is about and the main problem being addressed is. Keep in mind that in many cases there is a close correspondence between the conversational topic and the possible problem or concerns.

Code

09 none (when no specific concern or problem is discussed as such, or for which a solution is not being sought).

01 avoiding accidents

02 effective advertisement or publicity

03 not being able to talk to someone on the phone

04 missing a bus

05 how to expand a business

06 repairing a car/ car trouble

07 missing or being absent from a class (including finding out what went on in a class one has missed)

08 getting a driving violation citation 
family relationships

11 the financial future- one's need to make money to cover future expenses

12 friend relationships

13 health (one's health, a friend or a student's health condition- being or getting sick)

14 trying to get help from others for school work (to fall in this category, one needs to actually get assistance with their school work, etc)

15 international relations (issues of foreign policy or international conflicts)

16 interpersonal relations (other than family)

17 getting a good or better job

18 not having a job or dissatisfaction with one's situation

19 not being able to do a job correctly

20 being late to work or school

21 having the appropriate location for a business

22 marriage issues

23 performance of students in one's class

24 one's personal problems (psychological, etc)

25 political concerns (public authorities, public institutions, public policies)

26 the price of consumer goods

27 being able to read/ understand and academic text in a 2 nd language

28 being able to replace(a car, a lost possession, etc)

29 resting or needing rest (being tired)

30 retirement

31 not being on schedule (on one's job)

32 doing school work (including having to do school assignments, or not finishing school assignments on time)

33 needing to improve one's second language skills

34 social problems (crime, ecology, poverty, quality of education)

35 studying enough for an exam/ doing well on an exam

36 having success in one's work

37 not wanting to transferred to a new location (in one's job)

38 taking a trip

40 figuring how to organize for an event, a group of people, etc

41 the weather

42 work related problems (problems that occur at one's job, making decisions in one's job)

00 Others:(specify_ add the category that you think is appropriate to this list and number it on the blank space below. Start with number 43)

43 make plan for leisure time

44 finical issues (saving not spending)

45 housework

46 water is not hot

47 being on time for dinner 


\section{$\underline{\text { Interests }}$}

* This section refers to things, activities that one does, or like to do for enjoyment, for education, and self-fulfillment. These are activities like sports, entertainment (cinema, dance, music, T.V., parties) cultural events (art exhibitions, theater, concerts, lectures), volunteer groups, other people, in which the characters state an interest explicitly or implicitly.

* Do not consider for those things and activities that are one's occupation. For example, traveling for a reporter or a business person. Also activities related to a student's major in school should not be taken as interests.

* In order to do this section of the analysis, read the dialog in that unit, and try to see what is portrayal of the character. Do not identify the character simply find the interests being depicted and classify them accordingly.

Code (the key word is underlined)

09 no interest (when no interest is explicitly stated)

01 are (those shown going to/ talking about are galleries, or who like do paintings themselves)

02 business (making the best decision for one's business or meeting the needs of one's business

03 buying (various types of consumer goods)

04 cinema (for those presented as going to or interested in cinema)

05 dancing (those who go dancing, or express appreciation for dance)

06 entertainment (those who like parties with friends, etc.)

07 family relationships

08 farming or gardening

10 help other people (those in volunteer organizations)

11 international issues (problems, relations, etc)

12 interpersonal (friend) relationships (other than family)

13 inquiring about another person or asking about someone (this does not include teachers inquiring about students because that is considered job related)

14 learning a foreign/ second language

15 meeting other people (those who explicitly state their liking to meet other people frequently)

16 music (for those who like to listen to music or go to concerts, or play musical instruments)

17 outdoors (picnic, going to parks, etc)

18 politics (those directly involved in politics, running for public office, or who explicitly express an interest in the subject)

19 social problems (ecological, educational, racial, financing, poverty, unemployment, 
etc.)

20 sports

21 television (one who is portrayed as spending time watching television)

22 theater (those shown as theater goers)

23 traveling

00 Others

(specify _add the category that you think is appropriate to this list and number it on the blank space below. Start with number 24)

24 computer games

25 cleaning house

\section{Activities}

* Activities are the kinds of things, sports, activities, cultural events, performances, that the characters are shown doing in the illustrations that accompany the dialog and in the dialogs themselves.

* Individuals who appear doing several things in one dialog and the illustrations accompanying it will be classified by the activity that is most emphasized (covers most text lines and space and the majority of the illustrations)

* When the illustrations are evenly distributed between activities, select the activity in the following way: If the illustrations are organized vertically, select the last illustration showing an activity. If the illustrations are organized horizontally, select the last illustration to the right (that presents an activity and code accordingly.

Codes (the key word is underlined)

09 characters who are not shown in any particular activity. This code is for characters who appear talking about themselves but are not portrayed carrying out any particular activity.

01 attending class or attending school in general (actually being in class or in school. This is different from studying for a particular class or course. This code refers to attending class)

02 babysitting

03 celebrating a birthday, anniversary or some other special occasion

04 buying (shopping for clothes, a car, whatever)

05 campaigning

06 conversing (when no other activity is apparent and the character is simply talking to 
someone)

07 cooking

08 daily morning routines (i.e. dressing, breakfast, etc)

10 daily routines (one's routines throughout a day. This does not include what one does in the job)

11 dining (at a restaurant or cafeteria, but not the school cafeteria)

12 discussing their education in terms of benefits, the preparation for the future, future goals, or quality of their training

13 driving to work

14 eating (when the activity takes place in a school cafeteria or at home but only with immediate relatives)

15 entertainment (listening to music, watching T. V., a movie, or a game, going to a concert, or at a party)

16 exercising

17 entertaining guests at home (friends or relatives but When there is no eating involved)

18 exchanging objects in the classroom

19 looking for a job

20 planning an activity (any kind of activity)

21 going on a picnic

22 playing sports

23 resting at home

24 riding a bus

25 going to school

26 sharing with the family (having dinner, talking, eating with one's relatives at home.

This includes relatives other than the immediate family)

27 sightseeing (for tourists, see traveling)

28 being sick

29 traveling (use when no vacationing is explicitly mentioned. Or for a business person if portrayed as such)

30 vacationing (going on vacation)

31 waiting (for a friend, a bus, etc.)

32 working (in the workplace.) Playing as a professional athlete or working as a farmer should be include in this category. Neither a shop owner working at his/her business. When a student is hired to do some work whatever its nature, he/she should be categorized as working)

33 working for the community as a volunteer

34 writing/reading (not students)

35 studying, doing school work (at a library, dormitory, or at home) Not when studying a second language

36 studying a second language (this must be specific)

00 Others

(specify_ add the category that you think is appropriate to this list and number 
it on the blank space below. Start with number 37)

37 cleaning

38 bathing

39 riding home 


\section{Area II}

\section{ADDITIONAL CODES}

\section{Categorization of Conversational Topics}

1. Trivial: Topics that are not school related, about business, daily life, work related, personal issues, sports values.

2. Business: Topics which are about business

3. School: Topics on school related matters.

4. Daily Life: Topics related to daily routines (ie. eating, planning, bathing, shopping, cleaning, family life, etc.)

5. Work Related: Topics related to employment and to the workplace.

6. Sports: Topics related to any kind of sport issues.

7. Personal Issues: Topics related to family relationship or friendship issues.

8. Ideas: values, beliefs, or philosophical.

10. Entertainment: activities related to party, music, dance, travel, outdoor, etc 


\section{Categorization of Problem}

1. Trivial: Problems that are not school related, about business, daily life, work related, personal issues, sports values. Not one of the categories \#2 to \#7.

2. Business: Topics which are about business

3. School: Topics on school related matters.

4. Daily Life: Topics related to daily routines (ie. money saving/spending, cleaning, cooking, family life, etc.)

5. Work Related: Topics related to employment and to the workplace.

6. Personal Issues: Topics related to family relationship or friendship issues.

7. Ideas: values, beliefs, philosophical or moral issues

9. None: No specific concern or problem. 


\section{Categorization of Interests}

1. Arts and Performing arts: arts, cinema, theater and music, etc.

2. Entertainment: parties, going dancing, television, outdoors, traveling, etc.

3. Family/friends: family relationships or friendships.

4. Sports: Interests related to any kind of sport issues.

5. Consumerism: buying any kind of consumer goods.

9. None: No specific interest expressed. 


\section{Categorization of Activities}

1. School related: activities connected to schooling, language learning in a school setting, etc

2. Daily life: routine daily activities (i.e. shopping, eating, daily routines, dining, planning, going home, cooking, cleaning, family life etc)

3. Entertainment: activities related to traveling, vacation, sightseeing, television, parties, music, dance, and concerts, etc.

4. Sports: Activities related to any kind of sport issues.

5 . Work related activities: job activities, or any activity for which one is paid.

6. Special events (birthday, anniversaries, etc)

7. Intellectual: intellectual activities such as reading books, writing, but not as part of a school setting.

8. Not applicable: when no activity is portrayed, or when the activity portrayed does not apply.

Note: Activities apply that kind of things the characters are doing. Try gathering information from the description or demonstration about the things that characters are doing in the opening statements, the illustrations, and the dialogs to make a choice from codes \#1 to \#7. If you can't find any then code it as \#8. 
Area III

Interpersonal Relations

These categories apply to characters who appear interacting in reading and dialogues See the general instructions to get a general idea of the coding process. Then you must read the specific instructions for each individual area.

Nationality

Please refer the variable "country" in Area I "National origin \& social backgrounds."

\section{Cross-Culture}

Codes

1 Chinese (Taiwan)/ Foreign culture

When one of the characters in the interaction is an Chinese who come from Taiwan and the other one is an individual from a country other than Taiwan

2 Chinese (Taiwan)/ Chinese (Taiwan) culture

3 Foreign/ Foreign culture

9 Unspecified

When the characters' nationalities are not possible to identify due to lack of information.

\section{Intergender}

Identify the proper category according to the gender of the characters in the interaction. Notice that there are 2 levels of observation. First determine the genders involved in the interaction then use the two digit codes provided.

Code

\section{Female/Female}

\subsection{Friendship}

When the interaction occurs on the basis of friendship. This includes the interaction occurs between schoolmate and between playmate.

1.4 Occupational

When the interaction of the characters takes place in the workplace and it is linked to doing job related tasks. 


\subsection{Teacher/student}

1.6 Family

When the individuals in the interaction are relatives (other than husband and wife)

1.7 Incidental

When the interaction occurs on accidental encounters.

1.9 Unspecified

For whom not sufficient information is given to determine their relation. 1.0 Others

specify, and add the category that you think is appropriate to this list and number it on the blank space below. Start with number 1.8

\section{Male/Male}

\subsection{Friendship}

When the interaction occurs on the basis of friendship. This includes the interaction occurs between schoolmate and between playmate

2.4 Occupational

When the interaction of the characters takes place in the workplace and it is linked to doing job related tasks.

2.5 Teacher/student

2.6 Family

When the individuals in the interaction are relatives (other than husband and wife).

\subsection{Incidental}

When the interaction occurs on accidental encounters.

2.9 Unspecified

For whom not sufficient information is given to determine their relation. 2.0 Others

specify and add the category that you think is appropriate to this list and number it on the blank space below. Start with number 2.8)

\section{Female/Male}

3.1 Marital

When the characters in the interaction are husband and wife.

3.2 Intimate

When the characters are identified as talking about a date, going on a date, or as courting. 


\subsection{Friendship}

When the interaction occurs on the basis of friendship. This includes schoolmate and playmate.

3.4 Occupational

When the interaction of the characters takes place in the workplace and it is linked to doing job related tasks.

3.5 Teacher/student

3.6 Family

When the individuals in the interaction are relatives (other than husband and wife).

2.7 Incidental

When the interaction occurs on accidental encounters.

3.9 Unspecified

For whom not sufficient information is given to determine their relation

3.0 Others

specify and add the category that you think is appropriate to this list and number it on the blank space below. Start with number 3.8)

\section{Type}

Code

01 Family members

When the interaction takes place between relatives such as parent/child-

daughter-son, spouses, cousins, etc.

02 Friends

When the interaction takes place between 2 characters who are located in a place other than the workplace, the school grounds, the family home, or a sports facility. When there is no clear contextual background (i.e. a school setting), assume their type of relationship as friends unless school matters are discussed. Also intimate relationships are to be between friends.

03 Playmates

When the interaction takes place between two interaction takes place between two characters only while practicing a sport at a sport at a sports facility

04 Schoolmates

When the interaction takes place between characters who are located in the school premises, such as the cafeteria, library, classroom, school dormitories, or school grounds. Also when general or school matters are the subject of conversation of students, assume the relationship as schoolmates. Teacher/student interactions have a separate category. Also when individuals 
express themselves as schoolmates.

05 Work mates

When the individuals express themselves as Work mates or when interaction

takes place at a work place. This is the case of employee/employee,

employee/boss, or any other interaction between employees

06 Business

When the interaction take place between two individuals at an office, company building, etc and who are carrying out a business transaction, or businesses are being discussed. Also reporters who are doing their job at receptions, gatherings, etc.

07 Incidental

When strangers (not friends, Work mates or classmates) usually in street settings or in stores, requests services from other individuals, or ask for help or assistance on something from individuals they do not know or see on a regular basis.

08 Student/teacher

09 Unspecified

When the interaction can not be classified in any of the above categories 0 Others

specify_ add the category that you think is appropriate to this list and number it on the blank space below. Start with number 10

\section{Country}

The following categories (country, area of the country, and setting) are the specification of the geographical location in which the interaction take place. Use illustration of the dialogue and any clues from the dialogue or the reading in the unit to determine the location of the interaction.

Please refer the code of "country" in Area I. If no explicit reference is given, assume the setting to be in Taiwan.

1. Urban:

\section{Area of the country}

Places like business, office, entertainment areas, city park settings should be classified as urban.

2. Rural

When the setting is explicitly identified as being a farm or a small rural town.

9. Unspecified

When setting is not explicitly identified as rural, and there is insufficient information to classify it as urban (i.e. a beach setting). 


\section{Setting}

Note: When there is more than one setting being addressed, select the one which is dominant, that is, for example, the setting that takes the most lines in the reading or dialog.

01 School

Unless some other specific setting is identified, a student/ teacher or classmates interaction should be assumed to be in a school setting.

02 Workplace

This is confined to employee/employee or employee/ boss interactions within a company, business or organization (teachers who are teaching and nurses who are interacting will be placed in this category.

03 Recreational establishment

This includes a city park, a restaurant, cinema, sports facility, a hotel, etc. 04 Home

05 City streets when the city is shown as background or there are indicators such as bus stops, or city sidewalks.

06 Transportation

07 Party

When the setting is a party at someone's house, apartment or any other building. This code is different from 04 in a sense that there is a party.

08 Hospital

When the interaction occurs in a hospital and when at least one of the interlocutors does not work in a hospital.

10 Telephone conversation

09 Unspecified

when the information is so limited that it is not possible to identify.

00 Others

Any setting that can not be placed in any of the above categories

(specify add the category that you think is appropriate to this list and number it on the blank space below. Start with number 11)

11 Wilderness This includes national park, ocean, mountain, gorge, etc. 
Area IV

Explicit Information \& Historical Dimension

This is the fourth area of analysis. In this area you are to classify reading according to the definition and codes below. See the general instructions to get a general idea of coding process. Then you must read the specific instructions for the fourth area.

* First find the reading for each individual unit as indicated in the guide "selected sections for analysis." Read the reading carefully.

* Use the codes provided below to code the readings in the corresponding columns of the tabulation sheets.

\section{Topical Area}

\section{Note 1}

Whenever individual acts, or personal information about characters is described in a reading (where they live, their job, where they study, relatives, etc) and no attempt is made to give a sequence of events in one's life throughout the various parts of the day, assume the topic of the reading to be character description (code \#15 or \#16). Description of someone going on vacation should be taken as character description.

\section{Note 2}

Categories \#1 to \#12 are for the readings that address the following topics about a specific country. The country may be mentioned explicitly or it can be implied by either the form or the content of the text.

Code

01 Intellectual, social, political, military, religious history of a country. Also history of a language. The emphasis of a reading to fall in this category must be on history.

02 Fine Arts.

This section refers to readings of Fine Arts. It includes painting, sculpture, crafts, folk Arts, architecture, music, dance, drama, literature, and cinema of a country. The emphasis of this category is on the works or movements of Fine Arts.

03 Reading about languages (please distinguish it from 01 which is emphasized on the history of languages.)

04 Social events in a country: weddings, holidays, festivals, exhibitions, birthdays, etc.

05 Daily life in a country: leisure activities, eating habits, dress habits, shopping habits. Activities of an inhabitant in a typical day. 
06 Geography: places, regions, weather, topography, places of interest, cities, historical monuments of a country.

07 Social/political problems-issues of a country (strikes, unemployment, intellectual debates, political conflicts and life, government, crime, ecology, military conflicts, etc.)

08 Historical figures in the Arts, Literature, politics, etc. of a country) The emphasis in this category (to distinguish it from code 02) is on the artists, authors, politicians, scientists, and on the individuals per se rather than on examples of their work.

10 Economy: industrial development-products, scientific developments, technology of a country. Including the use of technology in any of its various applications.

11 Social, political, and intellectual trends (e.g.. trends of modernization, trends in religion, trends in education, trends in government)

12 values, assumptions, beliefs, morality, philosophy and motivations of a specific culture are explicitly stated or explained in reading (ie. for teaching what is right and wrong).

13 values, assumptions, beliefs, morality, philosophy and motivations of culture in general are explicitly stated or explained in reading (ie. for teaching what is right and wrong).

09 Reading deals mainly with vocabulary and linguistic items.

14 Reading is on a topic which is not specifically on the culture and society of one country. Or it focuses on global topics with a universal perspective, so where there is no effort to make any culture specific. (Notice the difference between \#13 and \#14).

15 Reading introduces/ describes a character or gives basic personal information about a character. The reading focuses on character background information If there is an attempt to sequence activities in a day (even if few or for only part of the day) check 04 .

16 Reading gives information about character(s), but it also addresses some cultural aspects/topics of a country. The topic must be treated to some extent beyond simple mentioning.

Note 3

If you code \#16 "character description with some cultural aspect" then continue coding "cultural aspect" according to the fallowing categories.

Note 4

If you code as \#15 "character description," These are the steps you should follow: (1) stop coding after you finish the coding of the variable "Emphasis." (2) Copy the information you have coded: the information of "Identification" section, "topical area, and "emphasis"" from the "Original Coding Sheet" (the sheet you are coding) to the "Character Description Sheet." Keep working on the rest of the variables of 
"Time" and "Scope" and code them on the "Character Description Sheet."

\section{Specific Topical Area}

01 Intellectual, social, political, military, religious history of a country.

Also history of a language. The emphasis of a reading to fall in this category must be on history.

02 Fine Arts.

This section refers to readings of Fine Arts. It includes painting, sculpture, crafts, folk Arts, architecture, music, dance, drama, literature, and cinema of a country. The emphasis of this category is on the works or movements of Fine Arts.

03 Reading about languages (please distinguish it from 01 which is emphasized on the history of languages.)

04 Social events in a country: weddings, holidays, festivals, exhibitions, birthdays, etc.

05 Daily life in a country: leisure activities, eating habits, dress habits, shopping habits. Activities of an inhabitant in a typical day.

06 Geography: places, regions, weather, topography, places of interest, cities, historical monuments of a country.

$07 \mathrm{Social} /$ political problems-issues of a country (strikes, unemployment, intellectual debates, political conflicts and life, government, crime, ecology, military conflicts, etc.)

08 Historical figures in the Arts, Literature, politics, etc. of a country) The emphasis in this category (to distinguish it from code 02 ) is on the artists, authors, politicians, scientists, and on the individuals per se rather than on examples of their work.

10 Economy: industrial development-products, scientific developments, technology of a country. Including the use of technology in any of its various applications.

11 Social, political, and intellectual trends (e.g. trends of modernization, trends in religion, trends in education, trends in government)

12 Values, assumptions, beliefs, morality, philosophy and motivations of a specific culture are explicitly stated or explained in reading (ie. for teaching what is right and wrong).

13 Values, assumptions, beliefs, morality, philosophy and motivations of culture in general are explicitly stated or explained in reading (ie. for teaching what is right and wrong).

\section{Emphasis}

Note: If the reading is classified as character description with the combination of some cultural aspects (code\#16), focus the emphasis on the cultural aspects and code them according to the following categories. 
Codes:

1. The emphasis is surface culture whether on the topics of culture specific topic, culture in general. The surface culture means the observable elements of a people's culture such as dress styles, customs, foods, physical aspects, house types, material possessions, concrete behaviors, shopping habits, holidays, birthdays, celebrations, leisure activities, tools, instruments, etc.

2. The emphasis is on deep culture whether of the topics of culture in general or culture in specific. The deep culture indicates something like social, political and intellectual trends; values, morality, philosophy, assumptions, beliefs, and motivations that underlie the surface culture elements.

3. The reading attempts to link both surface and deep cultural aspects of culture in general or culture in specific.

\section{Time}

Section A: The categories \#1-5 and are for the readings coded as culture specific or character description with some cultural aspects

code

1 The emphasis of the reading is on topics treated only from a present perspective. Content does not include background (historical data) on topic treated.

2 The emphasis of the reading is on topic only from a past perspective. For strictly cultural topics this means a treatment of subjects as if with no connection to the present.

3 The reading attempts to link the present with past perspectives on the topic presented which helps to elucidate the present. For strictly cultural topics this means linking the past and present on the subject addressed.

Section B: Categories \#9 is for the readings coded as vocabulary, linguistic items (\#9)

9 The readings are mainly about vocabulary, linguistic items, and the time variable does not apply. 
Section C: Categories \#6\& 7 are for the readings coded as daily life (\#5)

6 Daily life is presented in terms of the present time, and in relation to sequentially preceding daily practices.

7 Daily life is presented unlinked; as isolated events

Section D: Categories \#8 and \#0 are for the readings coded as character description (\#15)

8 The topic is character description and information about the past life of the character is given to help understand his present status. There is an attempt to develop a history of the character.

0 The topic is character description but no information is given about the past life of the character. The information about the character is strictly on a present time perspective.

\section{$\underline{\text { Scope }}$}

Section A: The categories \#1-3 are for reading which are classified as culture specific, culture in general, or character description with the combination of some cultural aspects.

1 The emphasis is on socio/cultural historical aspects (i.e. historical trends of a society of one country; causes or reasons for a literary trend; discussion of causes of a war; discussion of the historical reasons for the civil Rights Movement; etc.)

2 The emphasis is on physical aspects of history (i.e. the monuments in a city; the description of surface accomplishments of an individual; the description of material accomplishment of minorities; etc.)

3 The historical dimension is not dealt with in the reading.

Section B: the categories \#9 is for the readings coded as vocabulary, linguistic items, or non culture specific topics

9 The reading is about vocabulary or linguistic items, or about topics which are not culture in specific or culture in general, and the historical variable does not apply. 
Section C: the categories \#6 \& 7 are for the readings coded as daily life

6 Daily life is presented with some explanation of the origin and rationale for those daily practices.

7 Daily life is presented as is with no further explanation.

Section D: the categories \#8 and 10 are for the readings coded as character description

8 The background information (past life) on the character is mainly on intellectual, social and psychological aspects of the character's life.

10 The background information (past life) on the character is mainly on the material aspects and accomplishment of the character's life.

11 The background information (past life) on the character is on material aspects, accomplishment, intellectual, social and psychological aspects of the character's life.

12 No background information on the character is presented. 
Area V

Manner of Presentation

In order to do this section, you need to read the questions that follow the reading.

\section{Type of exercise}

Code

1 The post-reading questions are of a factual nature.

2 The post-reading questions are of a reflective nature, requiring critical analysis.

9 The post-reading questions are dealing with vocabulary or linguistic items.

\section{$\underline{\text { Stance }}$}

1 The post-reading questions call for mere recall.

2 The post-reading questions call for cross cultural comparisons.

3 The post-reading questions call for inductive reasoning and synthesis.

9 The post-read questions are dealing with vocabulary or linguistic items. 
APPENDIX B

SAMPLE CODING TABULATION SHEETS 
Area I, National Origin and Social Background (Reading Dialog)

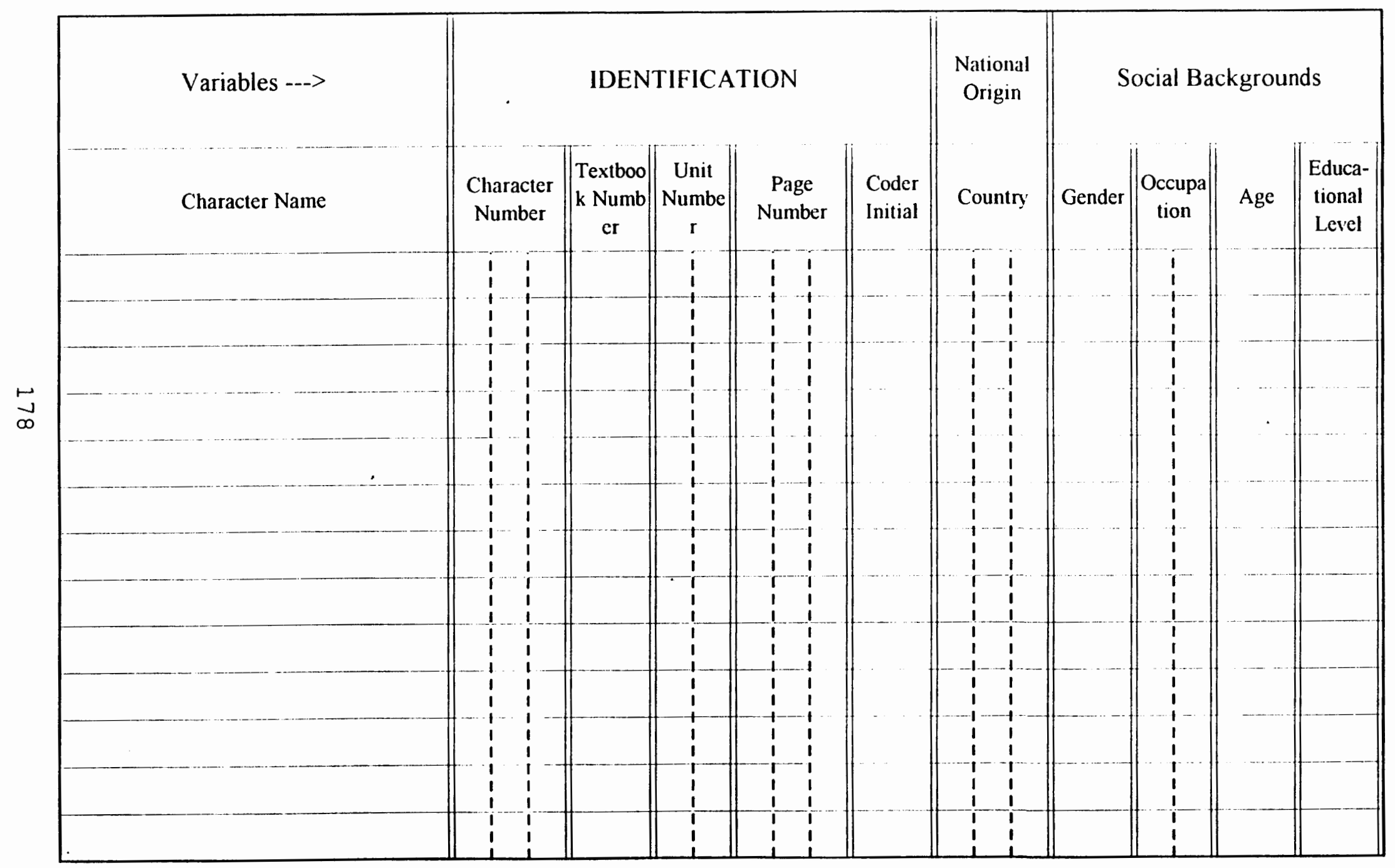


Area II. Conversation Topics, Problem-Concems, Interests and Activities

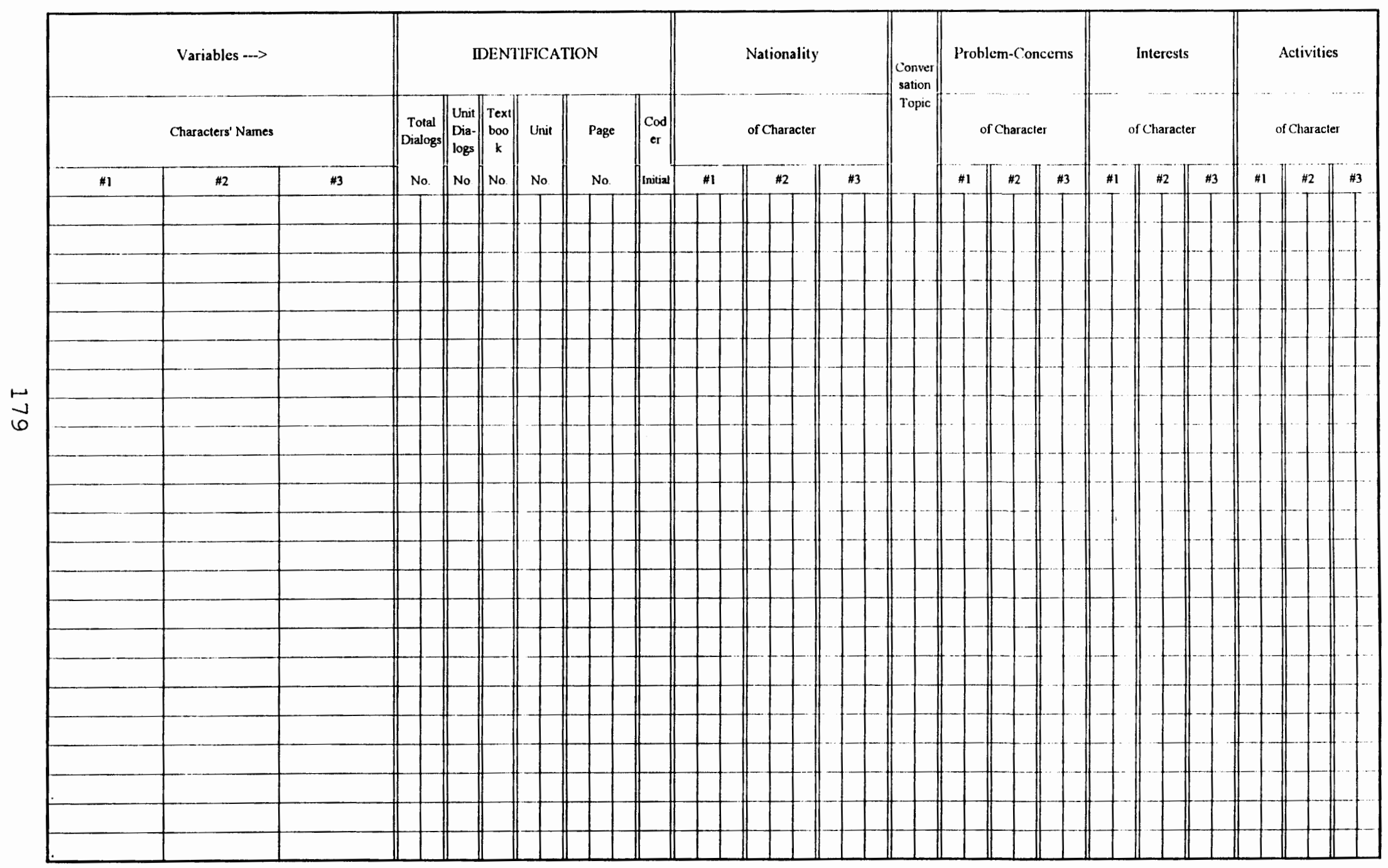


Area III. Interpersonal Relations (Reading Dialog)

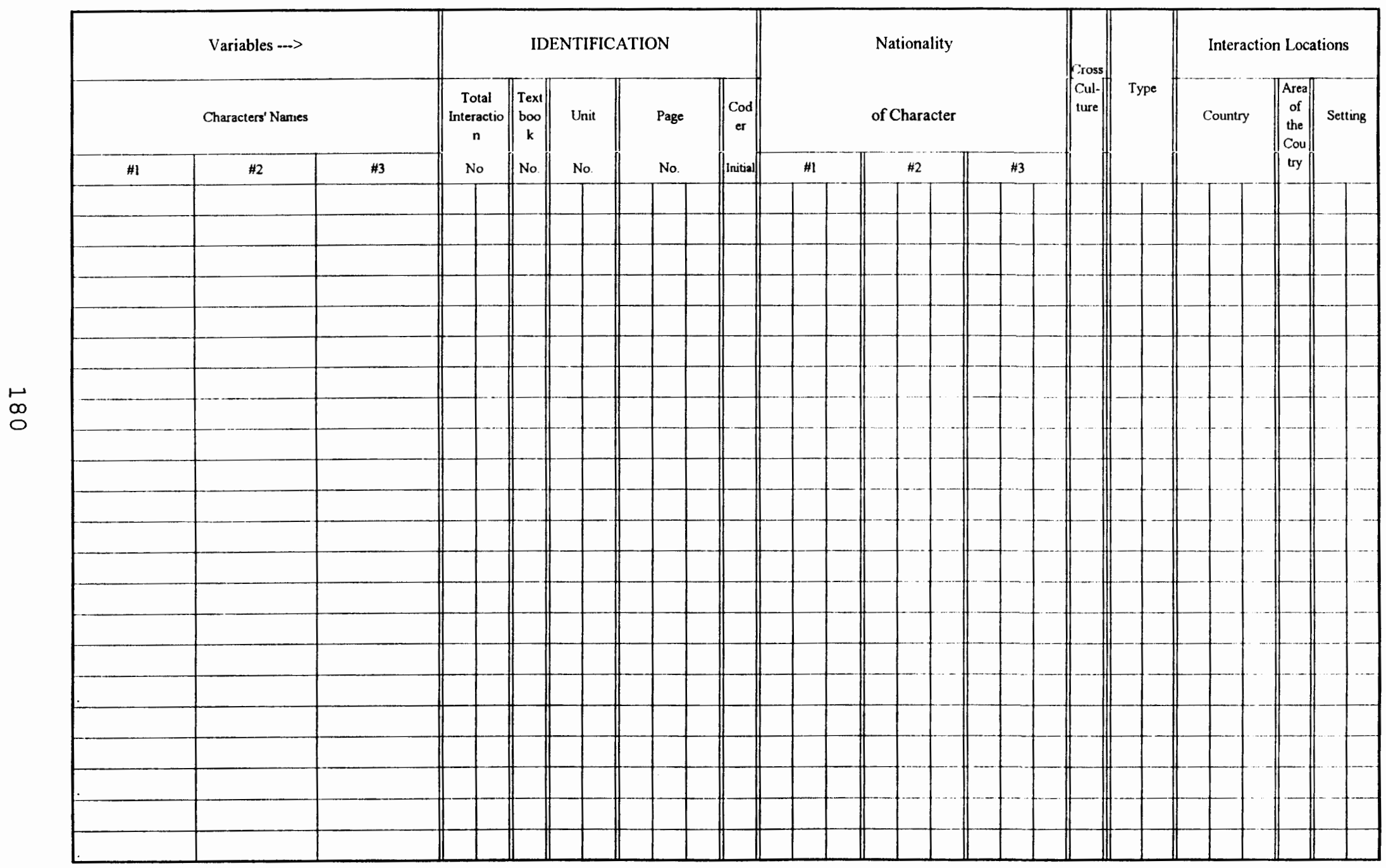

8/8/96 
Area IV. Explicit Information and Historical Dimension (Original Coding Sheet)

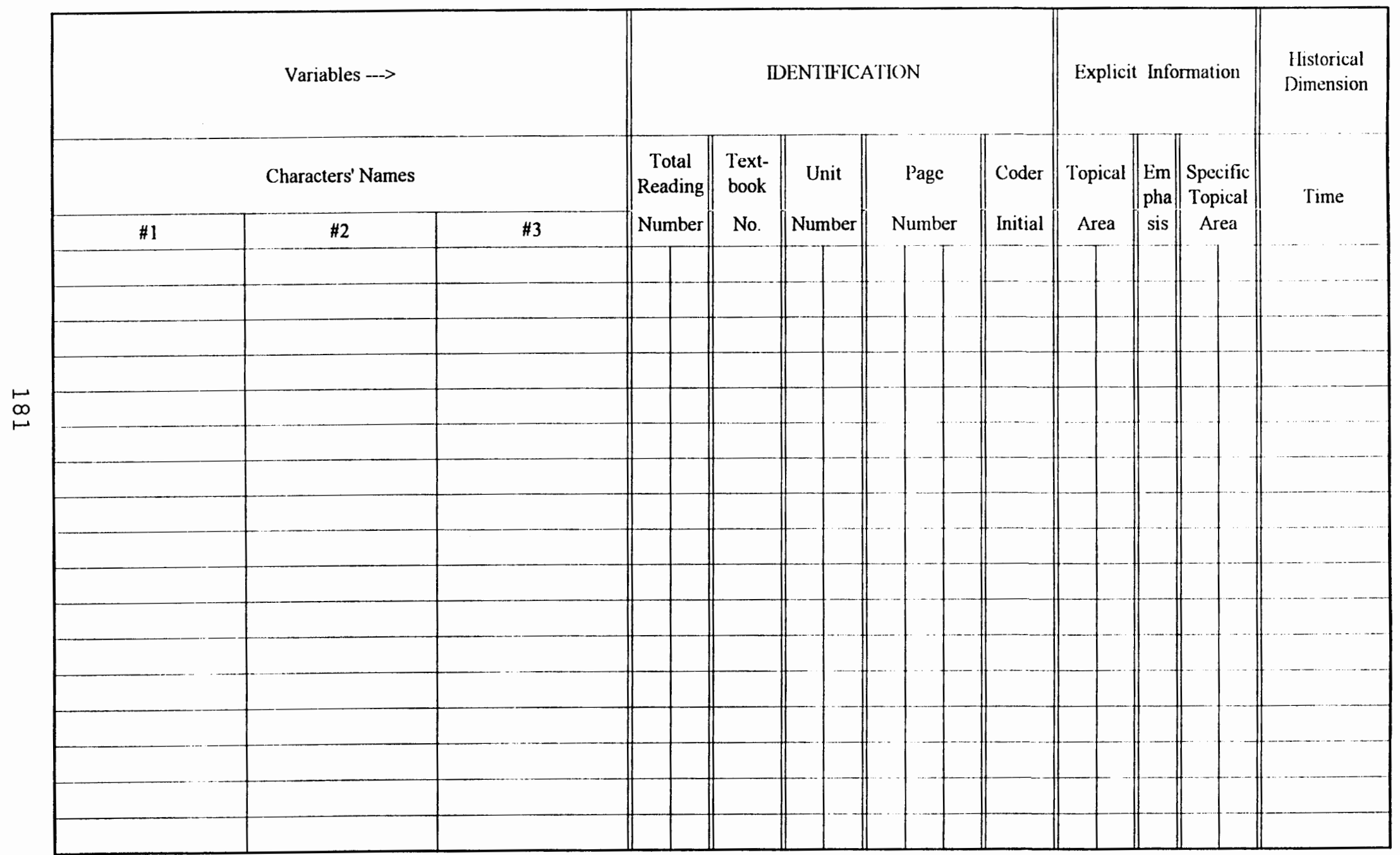


Area IV. Explicit Information and Historical Dimension (Character Description Sheet)

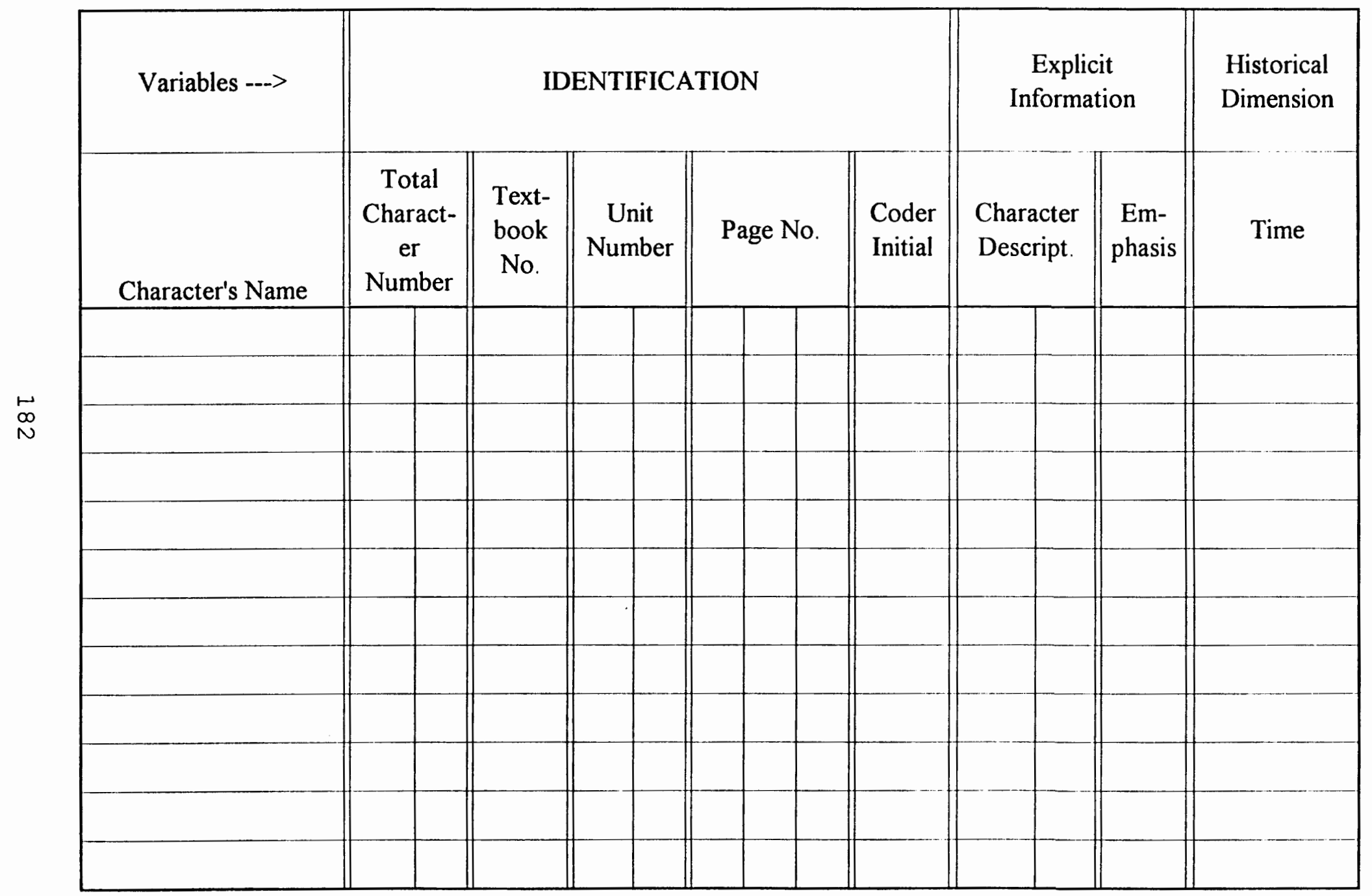


Area V. Manner of Presentation

\begin{tabular}{|c|c|c|c|c|c|c|c|}
\hline \multicolumn{8}{|c|}{ VARIABLES } \\
\hline \multicolumn{6}{|c|}{ IDENTIFICATION } & \multicolumn{2}{|c|}{ Manner } \\
\hline $\begin{array}{c}\text { Total } \\
\text { Question }\end{array}$ & $\begin{array}{l}\text { Unit } \\
\text { Ques- } \\
\text { tion }\end{array}$ & $\begin{array}{l}\text { Text- } \\
\text { book }\end{array}$ & Unit & Page & Coder & & Stance \\
\hline No. & No. & No. & No. & No. & Initial & Question & \\
\hline & ! & & ! & ! & & & \\
\hline 1 & 1 & & 1 & I & & & \\
\hline i & $i$ & & $i$ & 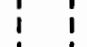 & & & \\
\hline ! & $i$ & & i & i & & & \\
\hline i & $i$ & & i & i & & & \\
\hline 1 & 1 & & 1 & 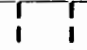 & & & \\
\hline i & 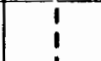 & & 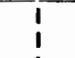 & i & & & \\
\hline 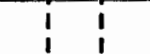 & 1 & & 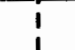 & i & & & \\
\hline 1 & ? & & i & i & & & \\
\hline & $?$ & & $?$ & 4 & & & \\
\hline i & 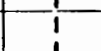 & & 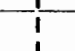 & 1 & & & \\
\hline 11 & $i$ & & 1 & 1 & & & \\
\hline & 1 & & 1 & & & & \\
\hline$i$ & i & & 1 & 1 & & & \\
\hline
\end{tabular}

